\title{
Have we dropped a stitch? \\ Collecting born digital documentary heritage in New Zealand cultural heritage institutions
}

\section{by}

\section{Julia Mary Thompson}

Submitted to the School of Information Management,

Victoria University of Wellington

in partial fulfilment of the requirements for the degree of

Master of Library and Information Studies 


\section{Acknowledgements}

Firstly I would like to thank Dr Sydney Shep for the invaluable guidance and wisdom she provided throughout this project, which made this a fulfilling and enjoyable experience. I would also like to thank all of those who took the time to provide such valuable, insightful contributions in the survey and interviews. Thank you also to those who provided feedback on my pilot survey, and all of those who gave their time to talk to me while I was formulating my research topic. I also could not have done this without the support of my classmates, who were always there to remind me that I was not alone. Finally, I would like to thank Katie, for your support and endless patience. 


\section{Contents}

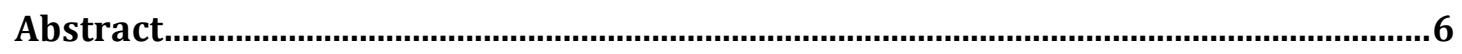

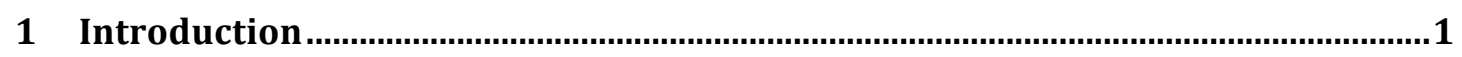

1.1 Problem statement

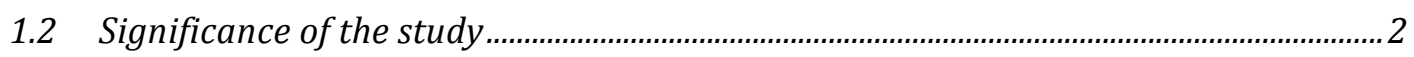

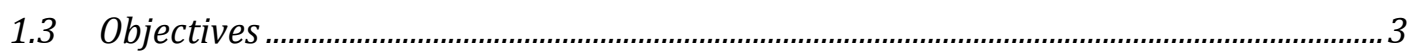

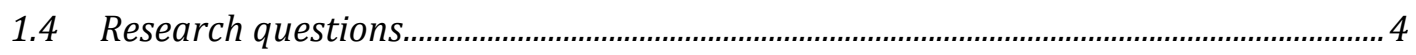

1.5 Definition of terms

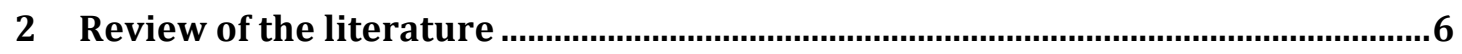

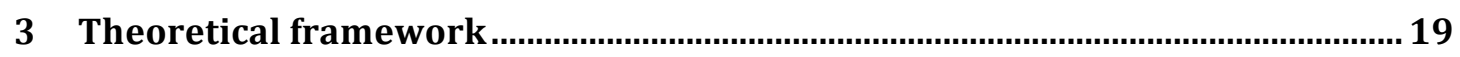

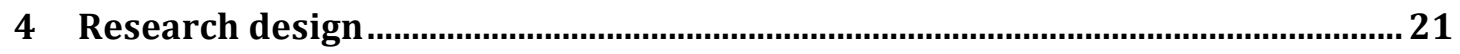

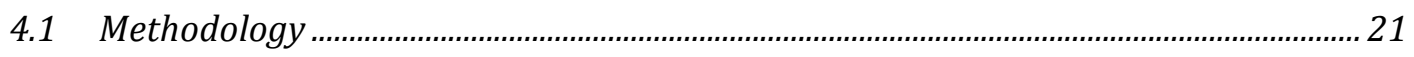

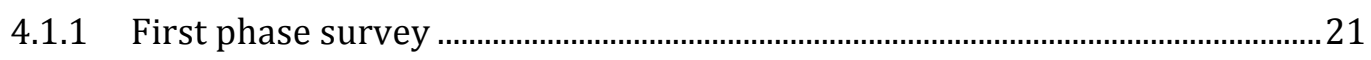

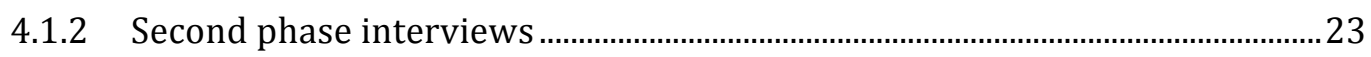

4.1.3 Documentary material.......................................................................................2

4.2 Sample

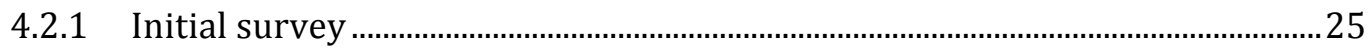

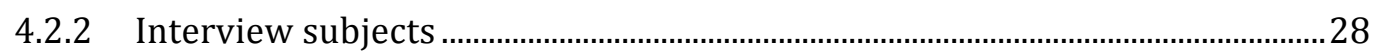

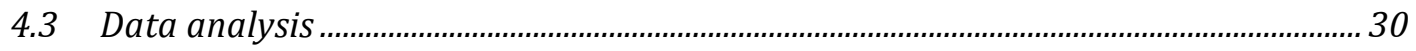

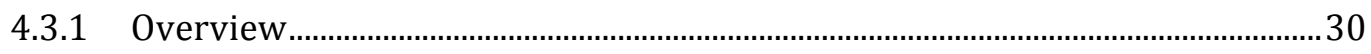

4.3.2 Analysis of quantitative survey data ………..........................................................31

4.3.3 Qualitative analysis of interviews and survey open questions.........................32

4.4 Validation

5 Ethical issues 
$7 \quad$ Limitations

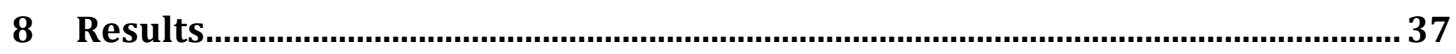

$8.1 \quad$ Nature of current collections............................................................................................ 37

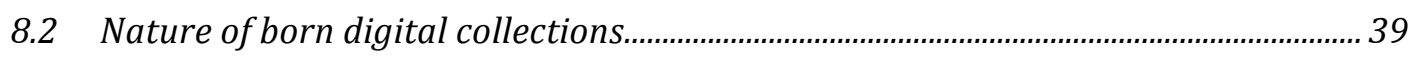

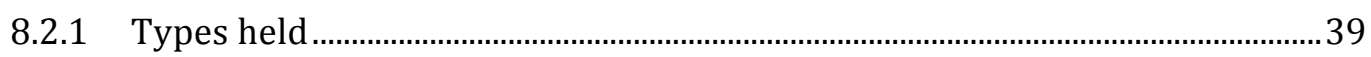

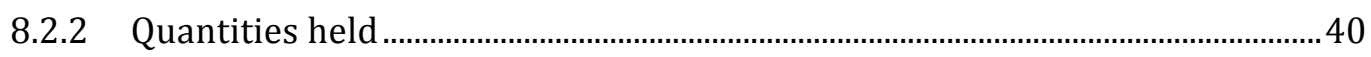

8.2.3 Internally created born digital heritage.............................................................. 41

8.2.4 Externally created born digital materials ..........................................................42

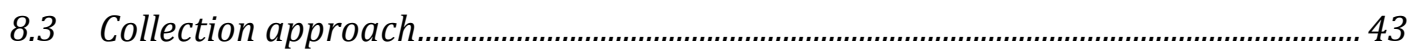

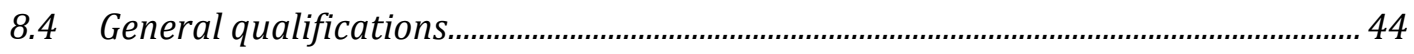

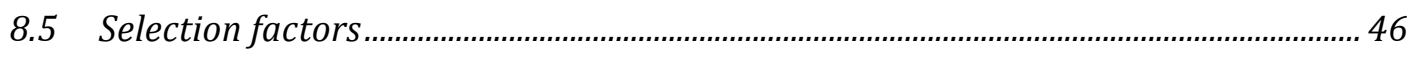

8.5.1 A hierarchy of selection factors ........................................................................... 47

8.5.2 Resourcing and capability limitations affecting selection .................................4

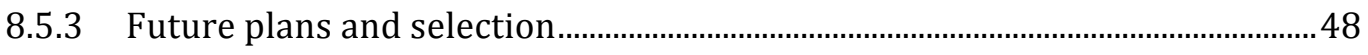

8.6 Factors limiting and enabling born digital collection.................................................. 50

8.6.1 Resourcing and the institutional context ..........................................................50

8.6.2 Factors closer to the materials........................................................................... 61

8.6.3 Clarity around responsibilities ………………….................................................63

8.6.4 Networking and collaboration ..........................................................................6

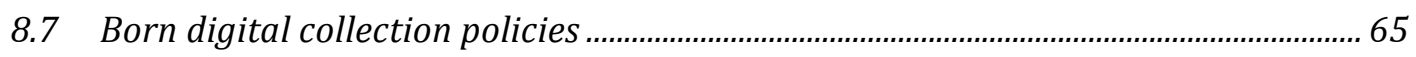

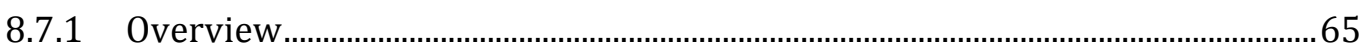

8.7.2 Low levels of collection policy development .......................................................65

8.8 Born digital preservation policies and procedures......................................................... 69

8.8.1 Policies governing the preservation of born digital materials...........................69

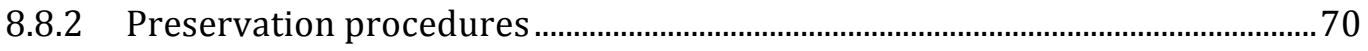

8.8.3 Nature of current preservation practices.............................................................. 


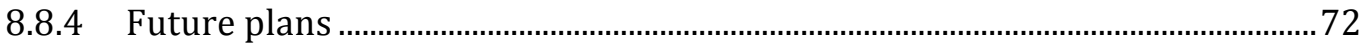

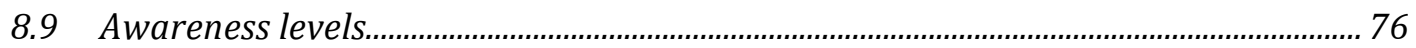

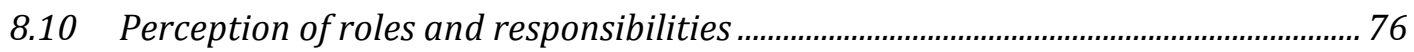

8.10.1 Strongly agree and agree: Continuity of roles and responsibilities ..............78

8.10.2 Disagree and neutral: Discontinuity of roles?

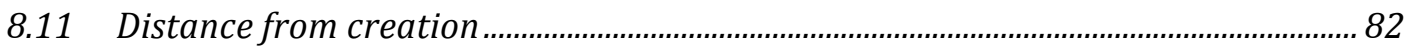

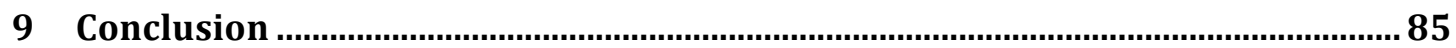

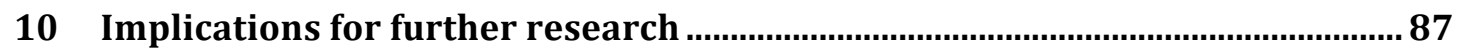

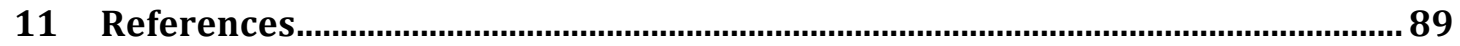

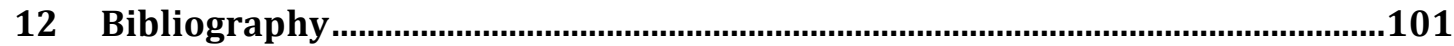

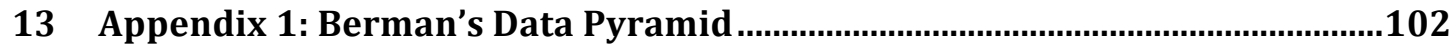

Appendix 2: The Records Continuum ...............................................................103

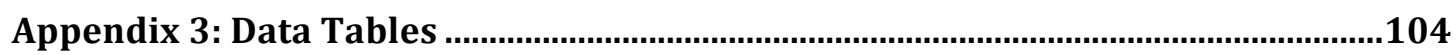

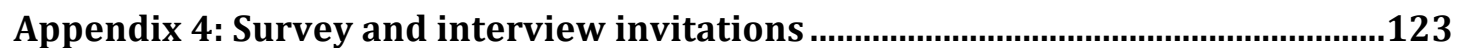

Appendix 5: Survey example, including consent form and letter of introduction

Appendix 6: Sample of qualitative analysis approach ..............................................144 


\section{Abstract}

This study explored the factors affecting the nature and extent of the collection of born digital materials for long-term retention by collecting repositories in New Zealand cultural heritage institutions, below the national level. This included exploration of selection factors, limiting and enabling factors affecting activities, preservation and acquisition policies for born digital materials, preservation procedures, and perceptions of roles and responsibilities. This two phase, mixed methods study consisted of a broad web survey followed by semi-structured interviews. The collecting repositories studied hold a range of born digital materials, but in small quantities. The collection of born digital heritage seems to be a new activity that requires additional resourcing and skills that are lacking in many of these collecting repositories. Levels of policy development are low and there is generally a lack of procedures for preserving born digital materials. However respondents generally perceived that collecting and preserving born digital materials was part of their role. The study concludes that the traditionally passive approach to acquisition of many of the collecting archives studied, combined with a lack of resourcing and expertise, pose a threat to the long term accessibility of local and regional born digital heritage. Some recommendations for action are provided.

Keywords: cultural heritage, digital preservation, archives, museums, special collections 


\section{Introduction}

“...digital artifacts constitute what may be described as the digital fabric of society. It is through this digital fabric that our culture expresses itself, and it is therefore this fabric that constitutes the cultural heritage that needs to be preserved" (Mackenzie Owen, 2007, p. 49)

The title of this study comes from the idea that preserving this "fabric" requires continuity of care. The fabric of digital preservation is made up of many separate stitches: many different people and institutions. To keep the fabric of our digital heritage intact, we cannot afford to "drop" any stitches, even the smaller ones.

\subsection{Problem statement}

Deegan and Tanner (2006, p. 3) see preserving cultural heritage as "essential to support the very foundations of our civilization" and "one of the key responsibilities held by libraries, museums and other memory organizations" . The UNESCO Charter on the Preservation of the Digital Heritage (UNESCO, 2003a) notes that many digital materials "have lasting value and significance" and are part of the cultural heritage, but cautions that "unless the prevailing threats are addressed, the loss of the digital heritage will be rapid and inevitable."

This is particularly pertinent in the case of born digital materials that have no analogue equivalent. Digital materials are inherently fragile, and ensuring their long-term accessibility requires preservation actions from the point of their creation (Deegan \& Tanner, 2006; Digital Preservation Coalition, 2008a; Harvey, 
2005). In addition to technological complexity, the collection and preservation of born digital materials comes with legal and economic and challenges and shifts in responsibilities and roles. In New Zealand, little is known about the activities of smaller cultural heritage institutions in relation to the collection and preservation of born digital heritage. In a context of resource constraints, competing demands, and the lack of a legal deposit mandate, what role are these institutions playing in the collection and preservation of born digital cultural heritage? If the majority of activity in the collection and preservation of digital materials is happening at the national level, then there is a particular risk that digital items of regional significance will be lost forever.

\subsection{Significance of the study}

As an increasing volume and proportion of information is created in digital form, cultural heritage institutions will need to adjust their practices accordingly. This study will fill a significant gap in the research on the activities of smaller New Zealand cultural heritage institutions in relation to the preservation and collection of born digital heritage. An understanding of their activities, experience, and any challenges they may be facing, will help to identify issues that need to be addressed and will help to reveal the types of information that are at risk of being lost. 


\subsection{Objectives}

The objectives of this study are to:

- Explore factors affecting the nature and level of engagement in the collection and preservation of born digital materials in collecting archives in New Zealand cultural heritage institutions below the national level.

- Identify any barriers or challenges that smaller cultural heritage institutions are facing in the collection and preservation of born digital materials.

- Identify how smaller institutions outside the legal deposit mandate are adapting to the collection and preservation of digital materials.

- Provide baseline data and analysis for a future study comparing the experience of smaller cultural heritage institutions in New Zealand with larger New Zealand institutions, and institutions internationally.

- Identify areas for further investigation and issues that may need to be addressed in a wider planning or policy context. 


\subsection{Research questions}

What are the factors affecting the nature and extent of the collection of born digital materials for long term retention by collecting repositories in New Zealand cultural heritage institutions below the national level?

1. What the types of born digital materials are being collected and what factors are affecting selection?

2. What are the barriers to, and enablers of, the collection of born digital materials, and how and why do they affect activities?

3. To what extent are institutions engaged in the preservation or long-term retention of born digital materials?

4. To what extent are institutions adapting their collection and preservation policies to include born digital materials?

5. What are the future plans and aspirations of institutions in terms of the collection and preservation of born digital materials?

6. How do smaller cultural heritage institutions perceive responsibilities and roles in the collection and preservation of born digital materials? 


\subsection{Definition of terms}

\section{Collecting repository}

Also known as a collecting archive or manuscript repository, this is "an organisation or part of an organisation that has as its principal function the collection of the records of a variety of organisations, families and individuals" (Crush, 2008, p. 211).

Born digital materials

"Digital materials which are not intended to have an analogue equivalent, either as the originating source or as a result of conversion to analogue form" (Digital Preservation Coalition, 2008a, p. 24).

\section{Cultural heritage}

"Those sites, objects and intangible things that have cultural, historical, aesthetic, archaeological, scientific, ethnological or anthropological value to groups and individuals." (National Library of Australia, 2003, p. 28).

\section{Documentary heritage}

"The consciously created information-carrying artefact" (Feather, 2006, p. 6).

\section{Digital preservation}

"All those processes aimed at ensuring the continuity of digital heritage materials for as long as they are needed" (National Library of Australia, 2003, p. 34). 


\section{Review of the literature}

\section{Introduction}

This literature review focuses on born digital documentary heritage. It has been noted that born digital materials are more at risk than digital materials that also exist in an analogue format, for instance created through digitisation (Deegan \& Tanner, 2006, p. 155; Reed, 2006) and "should be given priority" (UNESCO, 2003a). This review also focuses particularly on what Deegan and Sutherland (2009, p. 163) refer to as "the more ephemeral kinds of publications" which in analogue form "often survived by accident" but in digital form they are much more likely to be lost. Deegan and Sutherland (Deegan \& Sutherland, 2009, p. 170) note that "the accidental survival of materials not recognized as of 'high' cultural, scholarly, commercial or government value is less likely in the digital world than in the analogue". Therefore, this review will not focus on the preservation of widely published materials, institutional recordkeeping, or scholarly information, though there are related, and important issues associated with the preservation of these types of information. In terms of institutions, the focus is therefore on "manuscript repositories, which collect manuscripts from individuals and organizations outside the respective institutions" rather than "institutional archives, which preserve records of respective parent organizations" (Jimerson, 2003, p. 54). 


\section{The risks to digital materials}

Ensuring long-term access to analogue materials is focused on preservation of the physical object, and it is possible for materials to survive through "benign neglect" (Burrows, 2000, p. 144; Deegan \& Sutherland, 2009, p. 155; Harvey, 2005, p. 2). The same cannot be said of digital materials, which "are bad at selfpreservation" (Deegan \& Tanner, 2006, p. 15). Long term access requires the preservation of the hardware and software required to interpret the material, and preservation of the digital object's authenticity and integrity (Deegan \& Tanner, 2006, p. 6). Compounding this is the relative fragility of digital storage media and the potential for rapid deterioration without appropriate care; and the rapid pace of technological change and the resulting obsolescence of the technologies needed to interpret the bit stream (Deegan \& Tanner, 2006; Digital Preservation Coalition, 2008a). This adds urgency to the challenge.

\section{Technological approaches}

There is no single, best approach to the preservation of digital materials (Deegan \& Sutherland, 2009, p. 164; Reed, 2006). Long term access requires a combination of appropriate strategies for "storage and maintenance", such as media refreshing, selection of appropriate file formats, and appropriate environmental conditions; and strategies for "long-term preservation", such as migration and emulation (Digital Preservation Coalition, 2008a, p. 103). 


\section{A new paradigm and emerging theories}

It is widely acknowledged that the management of digital materials for long term access requires a significantly different approach, which takes into account the additional challenges and complexities (Abid, 2007; Deegan \& Sutherland, 2009; Digital Preservation Coalition, 2008a; Harvey, 2005; Reed, 2006). Digital materials require active, continuous management, beginning as early as possible in their existence (Deegan \& Sutherland, 2009; Digital Preservation Coalition, 2008a; Lynch, 2003; UNESCO, 2003b). Harvey (2005, p. 66) notes the value of archival and recordkeeping approaches to the selection of and management of digital objects, noting the value of the "continuum approach" (for example, the records continuum) in selection for digital preservation because it is "a way of thinking about the life of a record from its creation onwards". Models and theories more specific to digital preservation and curation are starting to emerge. One example is the "Data Pyramid" (Berman, 2008) which expresses digital preservation in terms of different levels. Another is the DCC Digital Curation Lifecycle Model illustrates "the stages required for successful curation and preservation of data" and is oriented towards guiding planning and practice (Higgins, 2008, p. 134).

\section{The shifting role of collection and selection}

Pymm (2006) notes that there has been increased focus on issues around significance and selection because of the scale, complexity and costs of digital preservation. The volume of digital material, varying quality, multiple versions of items, and the resources constraints of institutions all make selection 
necessary, but also more complicated (Digital Preservation Coalition, 2008a, p. 42; Harvey, 2005, pp. 54-55). Harvey (2005, p. 62) argues that new approaches to selection are needed for digital materials, that reflect these additional complexities.

Some have cautioned that selection decisions for digital materials may be based on technological issues and cost rather than value (Burrows, 2000, p. 148; Deegan \& Tanner, 2006, p. 16). The stakes are high because, as digital objects are less likely to survive by accident, a failure to make an active decision to select a digital object for preservation "is tantamount to de-selection" (Burrows, 2000, p. 152). This is changing the relationship between preservation and collection, which are now "inherently intertwined, as what is not collected cannot be preserved" (Meyer, 2009, p. 17). There has always been a link between collection and preservation, but particularly in the digital world, the link between not collecting and not preserving is much stronger. It is therefore important to consider what digital materials are being collected, in addition to how institutions are preserving the digital objects that they happen to have in their possession.

\section{More than a technological challenge}

It is widely acknowledged that the problems with ensuring long-term access to digital materials go far beyond technological challenges, and include a range of economic, legal, social, political and institutional issues (Galloway, 2005; Harvey, 2005; Lavoie \& Dempsey, 2004). 
It has been suggested that preservation is likely to cost more in the digital environment, and at the very least, determining the costs associated with digital preservation is complex and uncertain, and affected by range of factors, including the context, types and range of objects being managed and the chosen preservation strategy (Digital Preservation Coalition, 2008a; Lavoie, 2006).

Many digital preservation strategies require the kind of actions that may breach current copyright laws (Ayre \& Muir, 2004, March; Sierman, 2009, April; The Library of Congress National Digital Information Infrastructure and Preservation Program, The Joint Information Systems Committee, The Open Access to Knowledge (OAK) Law Project, \& The SURFfoundation, 2008, July). There does not seem to have been a similar investigation of the same issues in the New Zealand context, however at the very least, the situation in New Zealand seems complicated and unclear beyond the National Library and its collection under legal deposit.

\section{Roles and responsibilities}

Economic aspects of digital preservation are closely intertwined with roles and responsibilities. This is clear from the report of the Blue Ribbon Task Force on Sustainable Digital Preservation and Access (2010, February), which noted the problem of a "lack of clarity about roles and responsibilities among stakeholders" and a gap between those who have the right or ability to preserve digital materials and those who have an incentive to do so. It has been noted frequently that there is a need for the involvement of a wider range of parties than previously, including creators, because of the need to manage digital 
materials from the time of their creation and the complexity of the challenges involved (Digital Preservation Coalition, 2008a; Galloway, 2005; Harvey, 2005; UNESCO, 2003b).

Despite the shifts in relationships and roles that are necessitated by the nature of managing digital materials, it is widely agreed that cultural heritage institutions still have an important role in ensuring long-term access to heritage in the digital age (Mackenzie Owen, 2007; Smith, 2007; UNESCO, 2003b). The core argument is that it is important that publicly funded cultural heritage institutions are involved because they serve the public interest, and that digital preservation should not be driven by economic forces (Blue Ribbon Task Force on Sustainable Digital Preservation and Access, 2010, February; Rodes, Piejut, \& Plas, 2003; Smith, 2007; UNESCO, 2003b). But as Lavoie and Dempsey (2004) have noted, they are unlikely to be able to manage digital preservation alone. There are different levels and timeframes of responsibility that can be taken, and some is better than none (Rusbridge, 2006, February; UNESCO, 2003b).

\section{The digital artefact}

The ease with which changes can be made to digital materials makes it more difficult to ensure their authenticity and integrity (Deegan \& Sutherland, 2009; Digital Preservation Coalition, 2008a). In addition, Reed (2006, pp. 122-123) notes that "traditional collections are driven by possession of originals". But the ease of duplication of digital materials makes it more difficult to define what a unique original is (Reed, 2006; Tredinnick, 2006). Digital materials are not as closely tied to their carrier, so some traditional indicators of value "are gone or at 
least marginalized" (Smith, 2007, p. 10). It can be expected that these issues may be creating challenges for institutions such as museums, archives, and special collections.

\section{A focus on access}

It has been noted frequently that while there has been a great deal of focus on the creation of, and current access to an increasing volume of digital material, there has not been the same attention given to its long-term management and accessibility (Deegan \& Sutherland, 2009, p. 155; Digital Preservation Coalition, 2008a, p. 18; Forde, 2006; Smith, 2007). In addition, the literature suggests that collecting archives, special collections and museums, even quite recently, have tended to focus on digitisation rather than the collection of digital materials (Duff, et al., 2009; Galloway, 2005; Prochaska, 2009).

\section{Broad studies of digital preservation activities and readiness}

There have been a number of studies in recent years of digital preservation activities, needs and readiness. The majority have focused on institutions in the United Kingdom (Boyle, Eveleigh, \& Needham, 2008; Simpson, 2005; Waller \& Sharpe, 2006) or the United States (Clareson, 2006, February 15; Gregory, 2009, April; Hedstrom \& Montgomery, 1998, December; Kenney, 2005, August 15; OCLC/RLG PREMIS Working Group, 2004, September). Exceptions include the a study by Planets that included mostly European institutions (Sinclair, et al., 2009) and a study by Pymm and Lloyd (2007) of State and National Library staff in Australia. The study by Waller and Sharpe (2006) covered a wide range of 
types of institutions that collect for many different purposes, however most of the studies above have focused specifically on cultural heritage institutions. They have, however, tended to focus on larger institutions, and on libraries or archives in academic institutions (Clareson, 2006, February 15; Gregory, 2009, April; Kenney, 2005, August 15; OCLC/RLG PREMIS Working Group, 2004, September; Simpson, 2005; Sinclair, et al., 2009).

Smaller institutions, museums and public libraries are particularly underrepresented. However, the study by Boyle et al. (2008) of local authority archives does include some smaller institutions. In addition, Davis (2008) focused on smaller collecting repositories as a response to the focus on large institutions and institutional recordkeeping, though despite aiming for a range of institution types, the academic archives dominate. Rhodes and Neacsu (2009) looked specifically at law libraries and digitally born legal information (though again, state and academic law libraries).

Almost all of these studies used some form of survey, frequently including open questions as well as closed, in some cases followed by qualitative interviews. An exception was Pymm \& Lloyd (2007), who conducted qualitative face-to-face interviews. The use of surveys does mean that these studies lack depth, however their use was probably necessitated by the desire to get a broad overview (many of the studies were carried out with the intention of informing broader policy) and because of the newness of the topic area.

In terms of the content of these studies, there has been a greater focus on digital preservation readiness and strategies than issues around what digital materials 
are being collected and why. Several studies have looked at what types of digital materials are held, but a distinction is not always made between the preservation of digitised materials and born digital, or between materials obtained from outside the organisation and created within it (Boyle, et al., 2008; Kenney, 2005, August 15; Sinclair, et al., 2009). Some, however, have explored quantities and types of born digital materials held (Pymm \& Lloyd, 2007; Simpson, 2005). Selection and collection practices have been covered to an extent (Davis, 2008; Pymm \& Lloyd, 2007), but are generally less well-explored than preservation practices.

Despite their differing focuses and populations, a number of common themes are revealed through these studies. A number found that digital preservation policies and practices were in the early stages (Clareson, 2006, February 15; Simpson, 2005; Sinclair, et al., 2009; Waller \& Sharpe, 2006) and that collection of digital materials is ad-hoc and reactive (Boyle, et al., 2008; Davis, 2008). Any findings around levels of activity have to be considered critically, because some studies targeted those institutions more likely to be involved or interested in digital collection or preservation activities (OCLC/RLG PREMIS Working Group, 2004, September; Simpson, 2005; Sinclair, et al., 2009). The possibility of a general bias towards active or interested respondents has also been noted (Davis, 2008; Kenney, 2005, August 15).

In exploring barriers and challenges in relation to digital preservation, a number of studies have noted a lack of funding as a key barrier to digital preservation activities (Boyle, et al., 2008; Pymm \& Lloyd, 2007; Rhodes \& Neacsu, 2009; Simpson, 2005). Other frequently noted challenges were lack of necessary 
expertise and inadequate staffing, with an associated need for training and guidance (Boyle, et al., 2008; Gregory, 2009, April; Pymm \& Lloyd, 2007; Rhodes \& Neacsu, 2009). Another common challenge described is a lack of information technology support (Boyle, et al., 2008; Clareson, 2006, February 15; Davis, 2008; Gregory, 2009, April; Pymm \& Lloyd, 2007). These three aspects seem to arise as the most significant challenges, but others have been noted. The study by Rhodes \& Neacsu (2009) was unique because it explored law libraries' perceptions of what kinds of materials they should be preserving, and both limiting and motivating factors affecting activities. Barriers and enablers in relation to collection, rather than preservation, have not been explored a great deal in previous studies.

\section{Specific projects and activities}

The literature on specific projects and activities in born digital collection and preservation is largely descriptive rather than research-based. Much is focused on web archiving, government or political information, and on the activities of larger institutions, particularly national libraries, and therefore collection within a legal deposit framework (Crook, 2009; Jacobsen, 2008; Lilleniit, 2007; Lin \& Eschenfelder, 2008; Martin \& Eubank, 2007; Taylor, 2004). Providing a contrast to the focus on web archiving, Hilton and Thompson (2007a, 2007b) describe the collection of born digital materials from the point of view of a United Kingdom collecting institution. 


\section{Library special collections and museums}

There has been discussion of born digital materials in relation to special collections, but this still appears be quite young, and is largely coming out of academic or research libraries in the United States. Recent literature related to special collections describes a context of resource constraints, complex legal issues, rapid, significant change and uncertainty, and a need for new skills and relationships (Association of Research Libraries, 2009, p. 6; Dooley, 2009; Prochaska, 2009). Similar issues as above are reflected in the results of a recent qualitative study of technology and museum work in North America, which describes a lack of funding for technology, a lack of necessary expertise, and the requirement of new skills to deal with digital objects (Duff, et al., 2009).

\section{The New Zealand context}

Within New Zealand, research related to digital preservation for cultural heritage purposes has focused on the activities of the National Library of New Zealand, which has a legal mandate for collection and undoubtedly greater resources than smaller institutions. Thompson (2008) carried out a qualitative case study of preservation strategies being used for "natively digital objects held in physical form" in the Alexander Turnbull Library, but the focus on "published digital collections" in physical form does exclude many types of digital materials. King (2009, June 8) studied Web archiving at the Alexander Turnbull Library, focusing on authorship and authority in the Web 2.0 environment, and how this was affecting the collection policy. Beyond the national level, attention has been given to digitisation activities (Dorner, Chawner, \& Searle, 2002; Gow, 2003; 
Reynolds, 2006) and to digital preservation in the public sector, which focused on institutional recordkeeping rather than digital materials created outside of the institution (Dorner, Liew, \& Crookston, 2006, June). Despite its focus on digitization, the study by Dorner, Chawner and Searle (2002) is relevant because it was an exploration of a reasonably new activity, covered a range of institutions, and looked at current and planned activities, motivations, and issues around technology and collaboration.

At least at the national level, there has been work towards the collection and preservation of digital cultural heritage in New Zealand. This includes the inclusion of digital content in the National Library legal deposit mandate and the creation of the National Digital Heritage Archive (Carnaby, 2009, March 4). The 2006 Report on New Zealand's Documentary Heritage: Preservation and Access (National Library of New Zealand, 2006, June) notes that cultural heritage institutions not receiving direct government support struggle with limited resources and expertise, and experience conflicting demands of preservation, access and collection development, and that "few institutions are well placed in terms of staff, equipment, standards, technical knowledge and skills to deal with digital preservation and the digitisation of existing material" (National Library of New Zealand, 2006, June, p. 12). While that report touched on digital preservation, it didn't look in-depth at the collection or preservation of born digital heritage specifically. There is a clear need for further investigation of what effect this context is having on the role of smaller institutions in collecting and preserving born digital cultural heritage. 


\section{Summary}

Ensuring long-term access to born digital cultural heritage is complex and challenging, and requires the involvement of many different players. If so many challenges are being noted in studies and descriptions of the activities of larger institutions, then this suggests that smaller institutions may face even greater challenges. However, there is a gap in the literature on the activities and experiences of New Zealand cultural heritage institutions below the national level, and indeed, globally when it comes to smaller cultural heritage institutions, particularly in terms of collecting, as well as preserving, digital materials. In addition, there is a need to look further at perceptions around roles and responsibilities, which as yet have not been widely explored. 


\section{Theoretical framework}

This study had an overall "inductive theoretical drive" (Morse, 2003, p. 196). That is, while it did not focus on pure theory generation, it had elements of an inductive process. As suggested by Corbin and Strauss (2008, pp. 39-49) the theoretical framework was used to provide some direction in the design of the study, and to guide and support the analysis, but with an element of fluidity and openness.

The newness of the topic meant that there was no single theoretical framework that was ideal for this study. Instead, two theoretical frameworks were used. The Data Pyramid (see Appendix 1) illustrates the role of particular types of institutions in digital preservation, in relation to the type and "value" of data and level of institutional responsibility, stability and infrastructure (Berman, 2008, p. 53). It provides a way to situate institutions and their activities within a broader digital preservation context.

To complement this, the records continuum model was also used (See Appendix 2). While it is not specifically oriented to digital preservation, it was created in part as a response to the challenges of digital recordkeeping (Bettington, Eberhard, \& Loo, 2008, pp. 21-24) and adds another useful theoretical dimension. The records continuum does not separate space and time: it sees records as simultaneously performing multiple functions, for instance acting as evidence of a business transaction but also part of the collective memory (McKemmish, 1997). In this study, the records continuum guides the 
conceptualisation of the place of the institutions being studied in relation to a digital object's creation. 


\section{Research design}

\subsection{Methodology}

A mixed methods approach was used because the nature of this research problem required both quantitative and qualitative data to produce "a more complete picture" (Creswell \& Plano Clark, 2007, p. 33). The overall study design, guided by Creswell (2009), was sequential and had a qualitative weighting, leading on naturally from an interpretevist paradigm.

\subsubsection{First phase survey}

An initial web-based survey was carried out, because the exploratory nature of the research, and the suspected low levels of involvement in the activity under investigation meant that it was necessary to gather quantitative data to provide an initial snapshot of trends and patterns in a large number of institutions. This is similar to the approach used by Cloonan and Sanett (2002) who settled on a survey method rather than a case study because it was too soon to study a smaller number of cases in-depth. Some qualitative data was also gathered through the survey (adding a concurrent element to the design).

The overall questionnaire design (see Appendix 5) was guided by the research questions and particular research context, with reference to the literature generally and several previous surveys (Boyle, et al., 2008; Davis, 2008; Dorner, et al., 2006, June; Rhodes \& Neacsu, 2009; Simpson, 2005; Waller \& Sharpe, 2006). Types of born digital materials were drawn largely from $A$ framework of 
guidance for building good digital collections (National Information Standards Organization, 2007, December) with the addition of some types that have been included in other surveys (Dorner, et al., 2006, June; Kenney, 2005, August 15). The list of types is format rather than genre-based, because the lines between different genres of digital content are unclear, and there are many new types that have appeared (Deegan \& Sutherland, 2009, p. 175; Mackenzie Owen, 2007). Questions on selection were guided by the Digital Preservation Coalition selection decision tree (Digital Preservation Coalition, 2008b) because of its inclusion of various aspects, including technical ones, which Harvey (2005) notes are also important, alongside significance, in selection for digital preservation.

The questionnaire was piloted to ensure its reliability and content validity, and adjusted accordingly. Pilot testers were two students in the Master of Library and Information Studies programme, for domain-specific understanding, and a layperson, for extra clarity. Unfortunately, because of the size of New Zealand, and the closeness of the sample size to the total population of institutions, it was not possible for the researcher to pilot the survey with someone who was directly involved in exactly the kind of work being studied, which may have been beneficial.

Strategies to increase the response rate included:

- Allowing extra time for completion

- Sending two reminders, with an accompanying letter that aimed to address some of the early indications of confusion or reasons for possible non-response, and reiterating the relevance and value to respondents 
- Making the survey anonymous

- Offering a summary of the results of the survey, as recommended by Alreck and Settle (2004, p. 209).

\subsubsection{Second phase interviews}

The first phase survey made it possible to carry out the second phase, by identifying areas for further exploration and appropriate interview subjects. The interviews, and the qualitative survey data, performed an important explanatory role to complement and explain the largely exploratory and descriptive first phase results. The qualitative data elicited a deeper understanding of the context and meaning of processes from the point of view of participants, and allowed the exploration of perceptions and the potential of "unexpected results" (Bryman, 2008, pp. 609, 618, 394; Creswell, 2007, p. 40; Gorman \& Clayton, 2005, pp. 4-6).

"Semi-structured" interviews (Bryman, 2008, p. 438) included exploration of aspects of the research questions that were not so well addressed by a survey, interviewees' individual survey responses and aggregated results, and any areas requiring clarification. All interviews were conducted by phone, and were recorded, allowing the researcher to be responsive and engaged (Bryman, 2008, p. 451).

\subsubsection{Documentary material}

The intention was to use qualitative documents to complement and provide context for the interviews, but few were able to be gathered due to the newness 
of the topic, limiting the ability to triangulate results and add to the validity of the study. Some relevant documentary material, including collection and donation policies, was gathered from institutional websites prior to interviews, and interviewees provided relevant documents if available. The notes kept by the researcher also provided a form of "document" and a source of qualitative data (Creswell, 2007, p. 130). 


\subsection{Sample}

\subsubsection{Initial survey}

This study used a purposive sample, where sampling is strategic and guided by the research questions (Bryman, 2008, p. 415). The sampling frame included collecting repositories within New Zealand cultural heritage institutions, primarily with a regional, rather than a national focus, that were likely to be collecting documentary heritage for cultural heritage purposes rather than accountability or recordkeeping, and for long-term retention. The aim was for geographic variation and a range of institution types to reflect a range of perspectives, which also supports the credibility of the findings (Marshall \& Rossman, 2006, p. 63). Sixty-three collections were targeted, and these included heritage, local history, archival or special collections within public and academic libraries, and manuscript or archive collections within larger regional or metropolitan museums and art galleries.

Public library levels were identified using the Public Library Statistics 2008/09 (Library and Information Association of New Zealand Aotearoa (LIANZA), 2009), and museums and art galleries were purposively selected from institutions that were listed in the National Register of Archives and Manuscripts (NRAM), which indicates that the institution holds archives and manuscripts (Archives New Zealand, 2009).

The final survey sample represented a reasonable range of institution types, including a variety of sizes of public library (Figure 1). It appears that no 
respondents were from institutions that were primarily art galleries, but this cannot be verified. Although some regions are not represented at all, a reasonable amount of geographic variance was achieved (Figure 2). Unfortunately, some of the regions that are not represented are also regions where quite small institutions had been targeted.

Because of the qualitative weighting of the study, respondents were given the opportunity to choose more than one institution type if applicable, so it is not possible to work out response rates by institution type. Just under half chose more than one (see Table 1, Appendix 3), suggesting that the hybrid nature of institutions that was already evident in at least one sample institution is reasonably common. It was particularly common for respondents to choose "archive" in addition to another institution/collection type. No respondent identified as more than one type of public library, so public library results could be combined for the purposes of analysis. Burrows (2000, pp. 151-152) and Pymm (2006, p. 61), have noted that the common demands of managing digital objects is a driver towards cross-sectoral collaboration, and indeed, the identification of an "archive" already clearly crosses domain boundaries.

A large proportion of survey respondents worked closely with heritage collections, and reflected the types that were targeted where possible: librarians involved in special/heritage collections, and those involved in curating manuscripts and archives (Figure 3). The inclusion of respondents at a management level as well means that a higher-level perspective is also provided. 


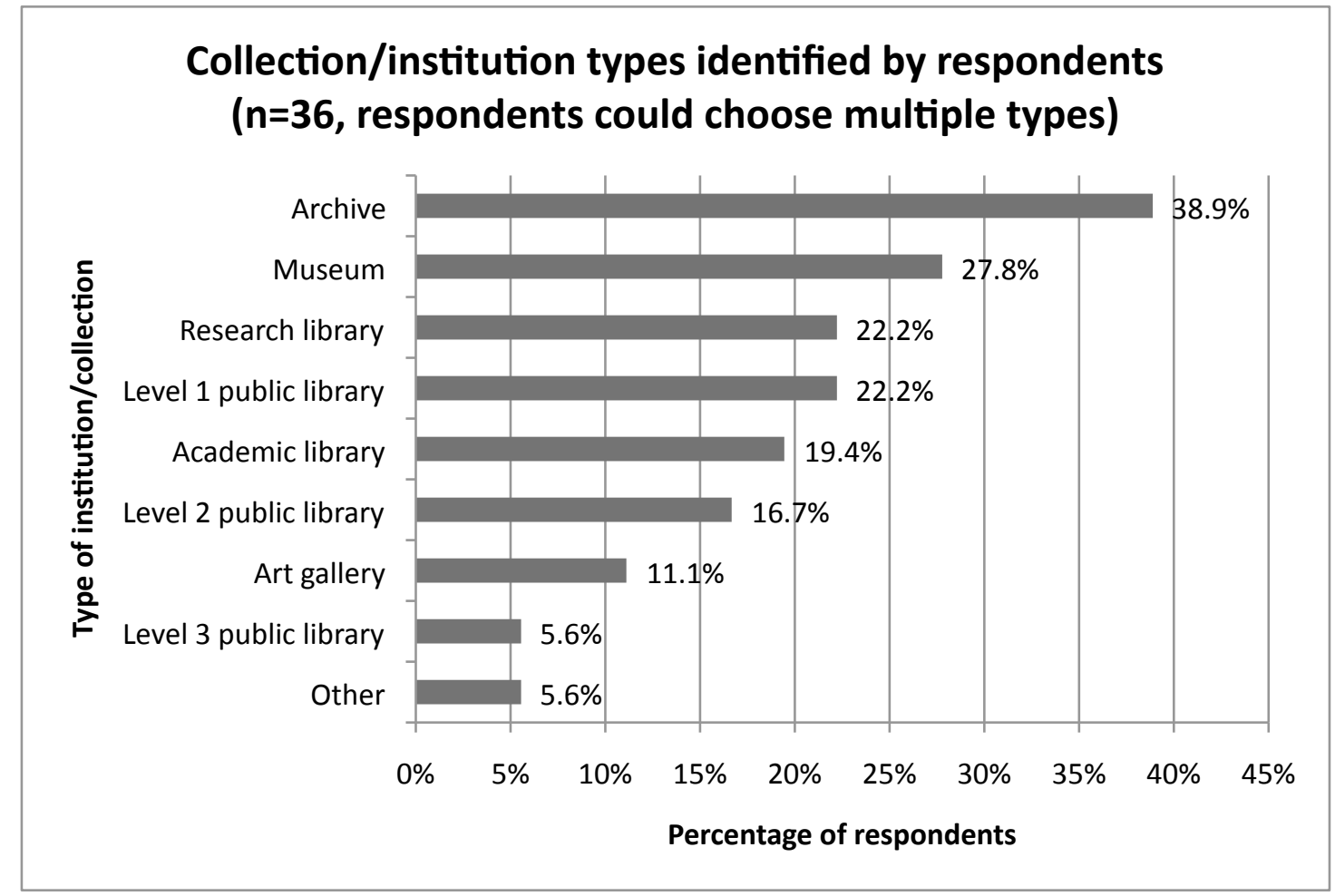

Note: heritage/local history/special collections were specified.

Figure 2

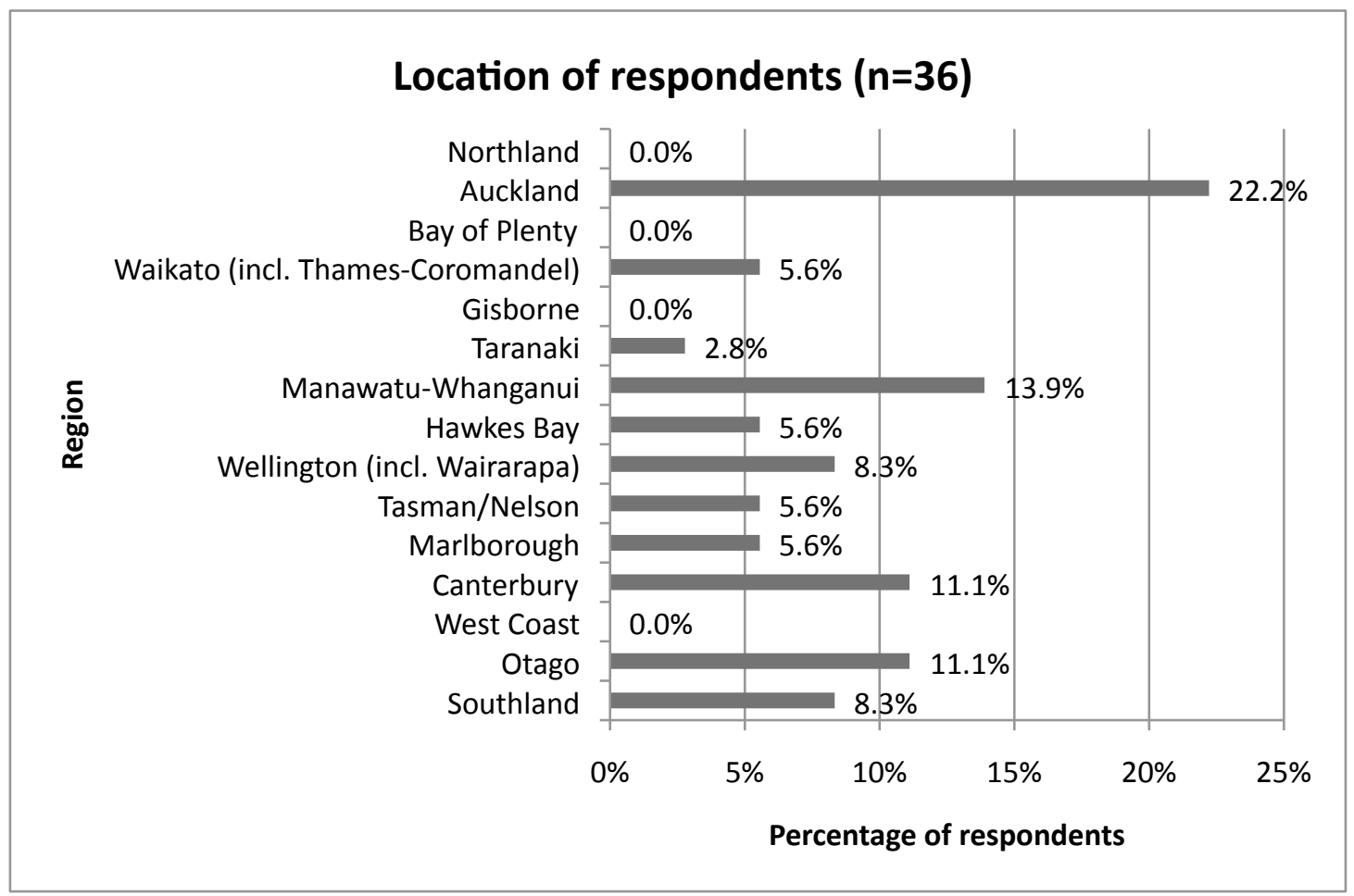




\section{Figure 3}

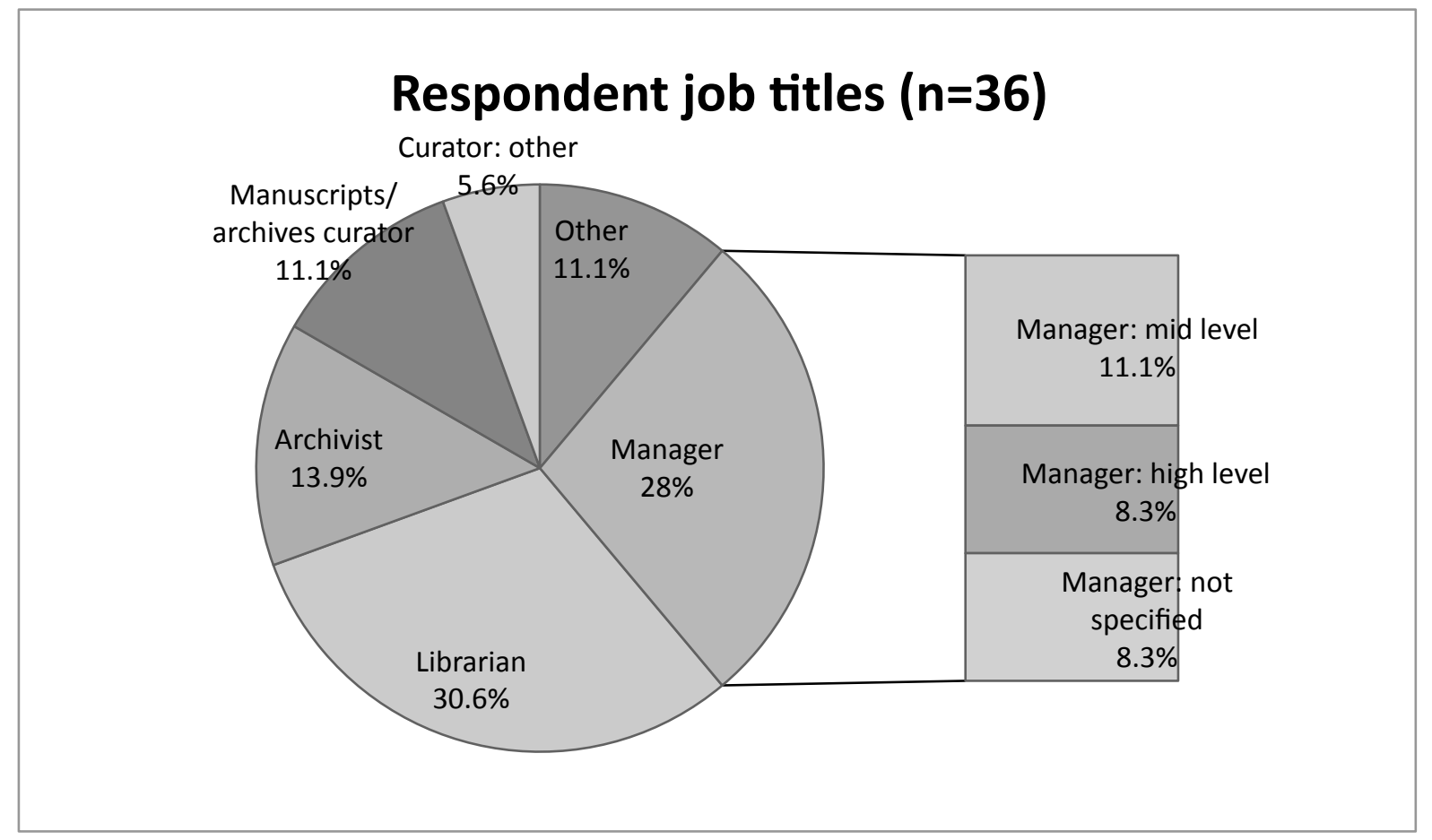

\subsubsection{Interview subjects}

"Sequential sampling" (Creswell, 2009) was used to select interviewees, whereby survey recipients were given the opportunity to elect to participate in follow-up interviews. There is likely to have been a sampling bias towards those who wanted to talk further: 12 respondents. Only institutions currently holding born digital materials were interviewed, as a result of weighing up a number of factors:

- Patterns in the aggregated results (including typical cases and anomalies/outliers: including a respondent with a "neutral" view of roles and responsibilities)

- An aim to reflect range of institution types and geographical locations 
- Particular responses worth exploring further.

The first three interviews did not elicit the depth of understanding required so two additional interviews were carried out. The result was that the interview sample was biased towards public libraries (three interviewees), one in a museum, and one in an academic library. 


\subsection{Data analysis}

\subsubsection{Overview}

\subsubsection{Treatment of missing data}

Before analysis was started, missing data was dealt with. Suspected duplicates in incomplete responses were removed prior to the missing data analysis. Apparent duplicates in completed responses were retained. As suggested by McKnight et al. (2007) , survey data was dummy coded to calculate response totals for each question, then results were investigated visually for any apparent patterns in respondent drop-off.

All final analysis was undertaken using completed responses only because of the importance of being able to use the demographic information at the end of the survey in the analysis.

\subsubsection{Overall approach}

Microsoft Excel was used for all analysis, because of its ability to "handle both structured and unstructured data within one database" and can therefore be used to "to facilitate both integration of different types of data and the conclusions from separate data analyses" (Niglas, 2007, pp. 297-299).

The approach used to mix the two datasets was what Teddlie and Tashakkori (2009, pp. 266-269) refer to as "parallel mixed data analysis", initially analysing the two sets largely separately, and then using a variation called "cross-tracks 
analysis", where the researcher allows "the analysis of the strands to inform one another by mixing those analyses in earlier phases of the study, rather than waiting for the meta-inference stage". The results of the initial analysis of survey data guided the selection of interviewees.

\subsubsection{Analysis of quantitative survey data}

Where it was necessary to compare responses across different selection factors, barriers/challenges, or enablers, the "don't know" responses were excluded (as generally they only made up a small proportion of answers, although the number did vary between factors) and percentages were calculated from the number of responses excluding the don't knows, to allow for comparison across the factors. The "don't know" responses, and their potential meaning, was considered separately, and also taken into account when interpreting the results overall.

Statistical analysis of quantitative survey data was predominantly "descriptive", as the purpose was to provide an overview and identify patterns across the sample (Creswell, 2009, p. 152). This included analysis of the frequency of particular responses and identification of the mode, for categorical variables, and median, for ordinal variables (such as scales) (Vaughan, 2001). It was not possible to use chi-square to identify the strength of relationships between variables, because a random sample was not used, and expected cell frequencies were too low (Vaughan, 2001, p. 88). Instead, contingency tables were created and then percentages were calculated for each cell and compared with the percentages for other categories in the same row, and overall, which can at least "provide a rough idea of the strength of a relationship" (Blaikie, 2003, p. 96). 


\subsubsection{Qualitative analysis of interviews and survey open questions}

Interviews were almost fully transcribed, though any sections that were not completely relevant were paraphrased. The approach used was close to "thematic analysis" (Bryman, 2008, p. 554) and was guided by Bryman (2008, pp. 550-551), Creswell (2009, pp. 186-187) (2009, p.186-7) and particularly the analytical approach of Corbin and Strauss (2008). This involved identifying initial concepts in the data, grouping these into higher-level categories, and also analysing for process and context, and connecting the analysis to the literature and theoretical frameworks. Alongside the analytical process, "memoing" was used (Miles \& Huberman, 1994, p. 72). There were few documents gathered, but

where they were available, they were used to supplement and explain the related survey and interview data, but were not treated to as comprehensive analysis as the other qualitative data.

\subsection{Validation}

As this is study has a qualitative weighting, validation was considered largely in terms of a qualitative study. Strategies for enhancing validity included: triangulation, checking for convergence of themes from the surveys and interviews; member checking, where interview participants were given the opportunity to review transcripts for accuracy (Creswell, 2009, p. 191); and piloting the survey to enhance content validity. 


\section{Ethical issues}

Human Ethics Approval was gained, and procedures were guided by the Victoria University of Wellington Human Ethics Policy (Victoria University of Wellington Research Policy Group, 2007, July 13). This included providing information sheets and gaining written informed consent from participants (see Appendix 5). The survey itself was anonymous unless participants chose to volunteer for an interview. Data has been stored securely, with access restricted to the researcher and supervisor.

\section{Delimitations}

The study excluded commercially produced, widely available e-books and electronic journals, and digital objects produced within the institution, for accountability or recordkeeping purposes. While these are potentially part of the documentary heritage, involve quite specific issues related to collection and preservation that are not the focus of this study.

An unequal weighting in the mixed methods design was chosen to make the study more manageable than if collection and analysis of both types of data were equally rigorous (Creswell \& Plano Clark, 2007, p. 82).

The choice of a reasonably small sample allowed the researcher to explore the topic in more depth within the time and resource constraints. Larger regional institutions were focused on to allow the researcher to cover a broader sectoral and geographical range of institutions within the scope of this study. 


\section{Limitations}

Subjects may have been unwilling to disclose sensitive information because the interviews were recorded (Gorman \& Clayton, 2005, p. 136), though they were self-selected, so this risk is low. Social desirability bias was mitigated through the use of self-completion questionnaires (Schutt, 2006, p. 276), guarantees of confidentiality and provision of opportunities to discuss future plans and aspirations. Though every effort was made to approach interviews in a neutral manner, presence of the interviewer can create bias, and affect the responses of the interviewee.

A purposive sample, limited by the resources of the researcher, meant that there is inherent bias in the sample. Findings will not be generalisable to all collecting repositories in smaller New Zealand cultural heritage institutions, however this study does not aim to generalise to a population but rather to carry out an initial exploration of the situation within a particular context. The aim of purposive sampling is to facilitate "insights and in-depth understanding rather than empirical generalizations" (Patton, 2002, p. 230).

There were a few invalid answers to one question, and digitisation was mentioned by a couple of respondents. There can be no guarantees, despite the definitions that were provided, that all respondents understood all terminology, or were, indeed talking or thinking about born digital materials, or necessarily about heritage materials rather than internal recordkeeping, or were answering on behalf of the appropriate collection (in the case of libraries). 
The anonymous survey meant that it was not possible to ensure only one response per institution or per person. This was not deemed a large concern, because of the qualitative weighting of the study. It does mean, however, that results can only be considered in terms of "respondents" rather than "institutions". Based on the presence of duplicate IP addresses, it appears that there may have been three institutions that made two responses, maybe from different people within the institution, and a further one institution that may have made three responses. This is a small proportion of the total sample, however. The proportion of respondents identifying as more than one type of collection/institution, and the small number of responses received in some category types, mean that analysis by institution type is not really possible. These results were therefore not mentioned unless there were quite significant differences that were apparent, and even then, they may not hold much meaning.

The relationships between variables are only rough estimations, and meaning is limited by small numbers in some categories, particularly the group holding no born digital materials.

\subsubsection{Response rates and non-response bias}

There is evidence that online surveys have lower response rates than postal surveys (Bryman, 2008, p. 648), but strategies were used to minimise the risk of a low response rate. Though there may be duplicates, there were 36 completed responses from the 63 collections approached, a reasonable response rate. 
The proportion of those holding born digital versus those not holding, in the survey results, may possibly mean that the survey is biased towards those who already have some involvement with born digital materials, or possibly more interest in the topic. There is no way of knowing what the characteristics of those who did not respond were, but they cannot be assumed to be the same as those who did respond (McKnight, et al., 2007). Therefore the results cannot be generalised beyond the sample, limiting the ability to identify the real "extent" of activities more broadly. There was some indication in email correspondence to the researcher that some respondents did not think the survey was relevant to them because they did not hold digital materials, and that the use of the word "smaller" may have caused some institutions to decide it was not applicable to them. Other circumstantial reasons for non-response may have included lack of time, lack of access to a computer, or potentially targeting the wrong person at the institution.

A reasonably high proportion of those who answered the consent question (47) subsequently finished the survey (36). Five did not continue beyond the consent form, but the rest who did not complete the survey dropped off later at various points. The survey durations for those who completed it were generally quite long, more than half an hour, so the length of the survey may have been a deterrent. Even for questions where there was no validation, all respondents who completed the survey responded to the questions on collection policies, preservation policies, and procedures for management of materials, and even where questions were conditional on a previous answer to a question, generally the expected number responded. Response rates for text responses were 
generally quite low, and added weight to the need for the second phase interviews to add depth to the study. McKnight et al. (2007, p. 55) note that "as the burden on participants increases, the probability of missing data increases" so the burden placed on respondents by a long survey, combined with the effort taken to answer open questions may have contributed to lower response rates for text-based questions.

\section{Results}

\subsection{Nature of current collections}

Most respondents indicated that they held a wide range of types of cultural heritage materials (Figure 4) when asked about what they held in any media. The "other" category included technology, Taonga Maori and realia. The implication here is that if institutions have such a wide range of materials, one would expect that a similar range might be appearing in digital format.

Indeed, at least for this group of respondents, born digital materials are starting to appear, to some extent, in the majority of their collections: 75\% (See Figure 5). 
Figure 4

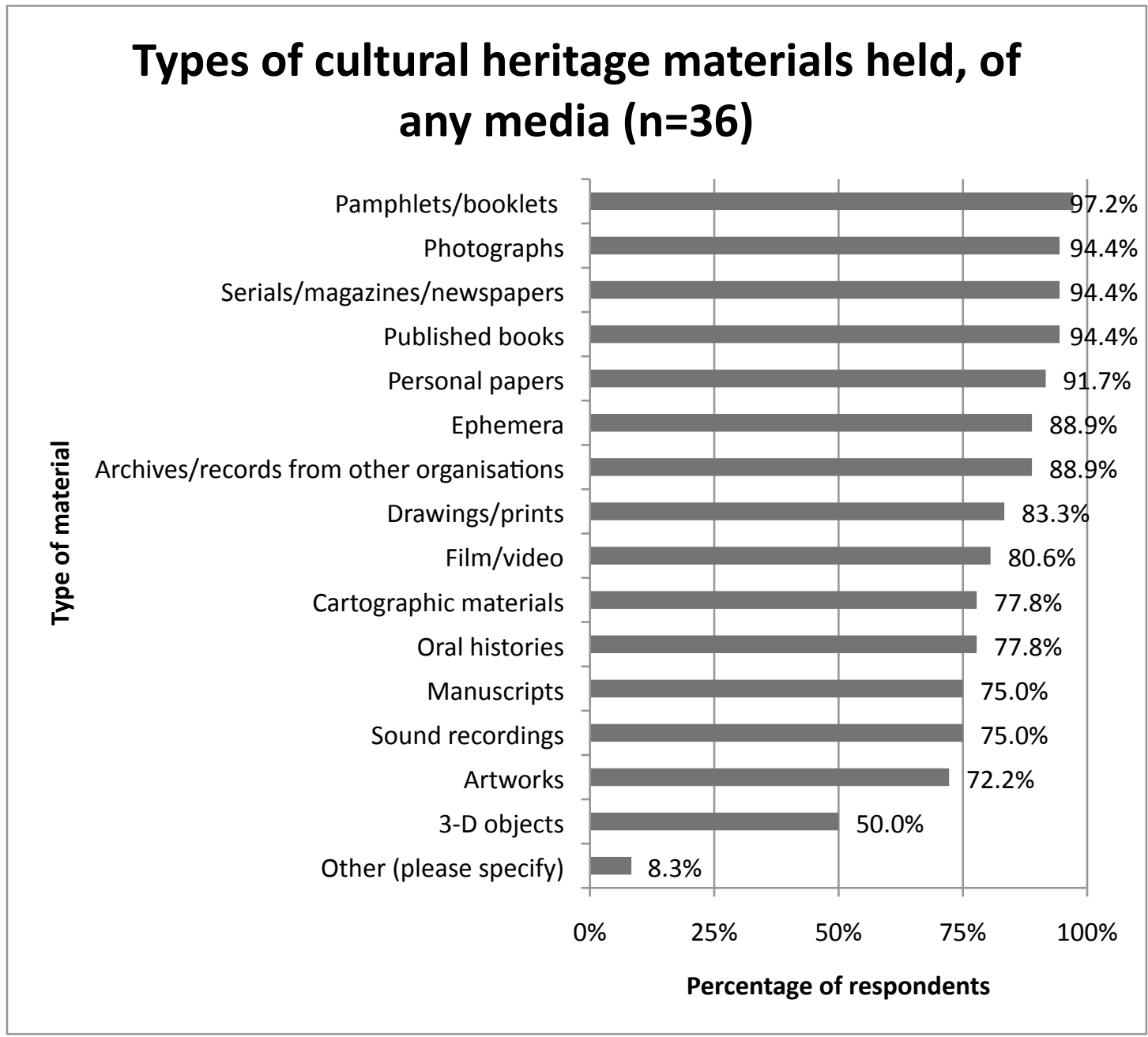

Figure 5

\section{Percentage of respondents with born digital materials in their collection $(n=36)$}

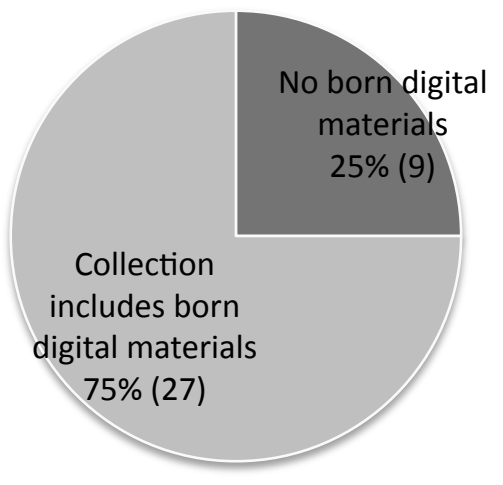




\subsection{Nature of born digital collections}

\subsubsection{Types held}

Of the 27 respondents holding born digital materials in their collection, the most commonly held type was digital photographs or digital raster graphics, followed by documents, digital audio and databases/datasets (Figure 6). A recent study of digital preservation readiness in European cultural heritage institutions also found that the most common types held were documents and images (Sinclair, et al., 2009, pp. Discussion, Para 13). Only one respondent answered "other", specifying software.

Figure 6

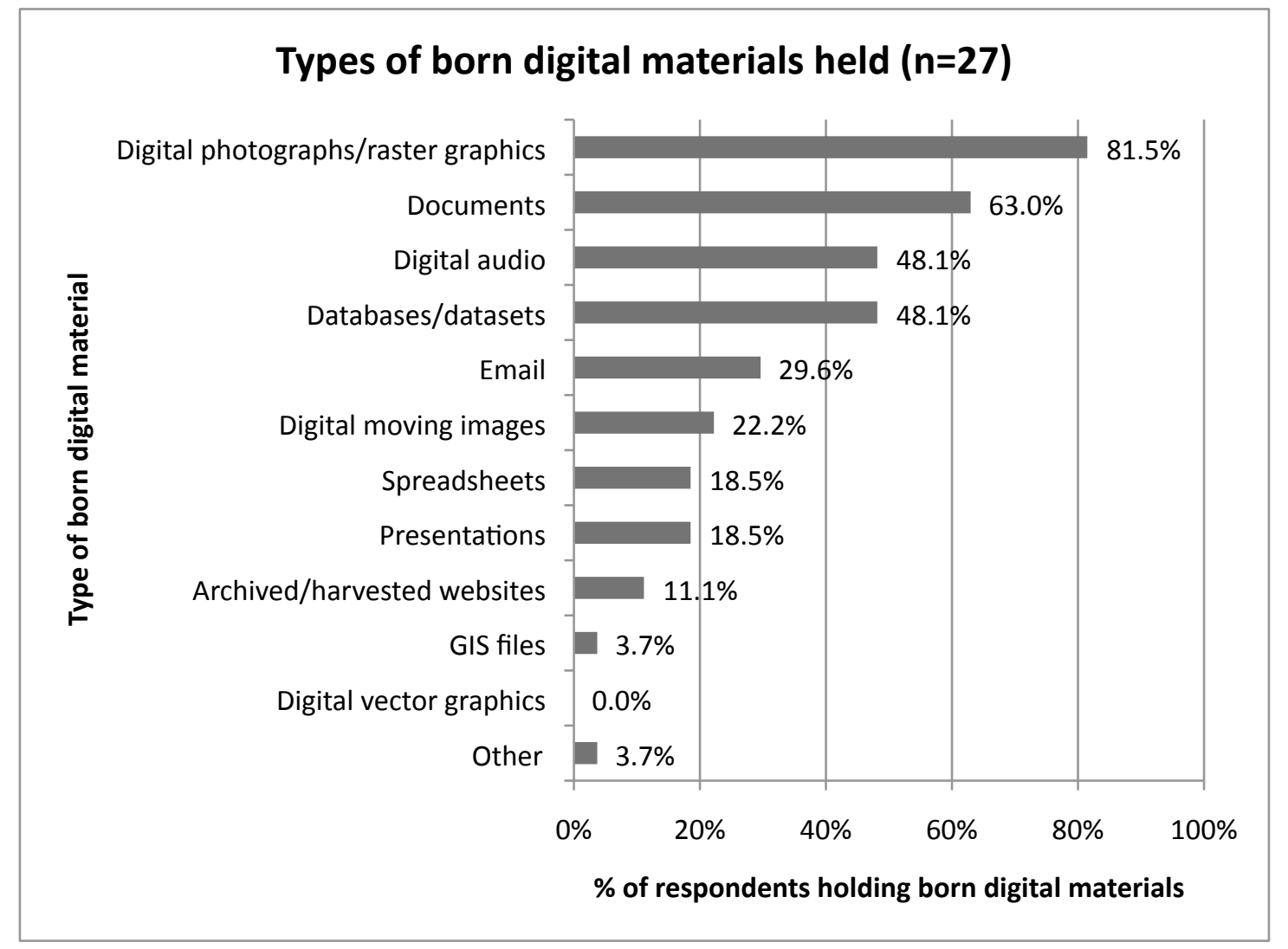




\subsubsection{Quantities held}

Four out of the five interviewees, and six survey respondents, indicated that there is little born digital material in their collections. This is reflected in the quantitative data, where although some types of materials were held by a number of respondents, the same types were not in the "top three greatest quantities" for many (Figure 7). Likewise, the typical respondent did not hold a large number of different types of born digital materials: the median was 3 , and the mode was 1 (Table 3, Appendix 3).

In addition, four interviewees noted that the majority of these materials had actually been created internally. At least for these institutions, digital materials have been slow to come into the collections from external creators. One library respondent noted that:

"We're not getting a lot of stuff flooding in to us in born digital format. It would be mostly material that either Library or Council staff take ourselves".

The apparent confusion of a couple of respondents, who mentioned digitisation, suggests that for some, the concept of "born digital" is not something that they are familiar with (despite the provision of definitions). Similarly, a study of local authority archives noted that respondents were digitisation with digital preservation (Boyle, Eveleigh, \& Needham, 2009). 


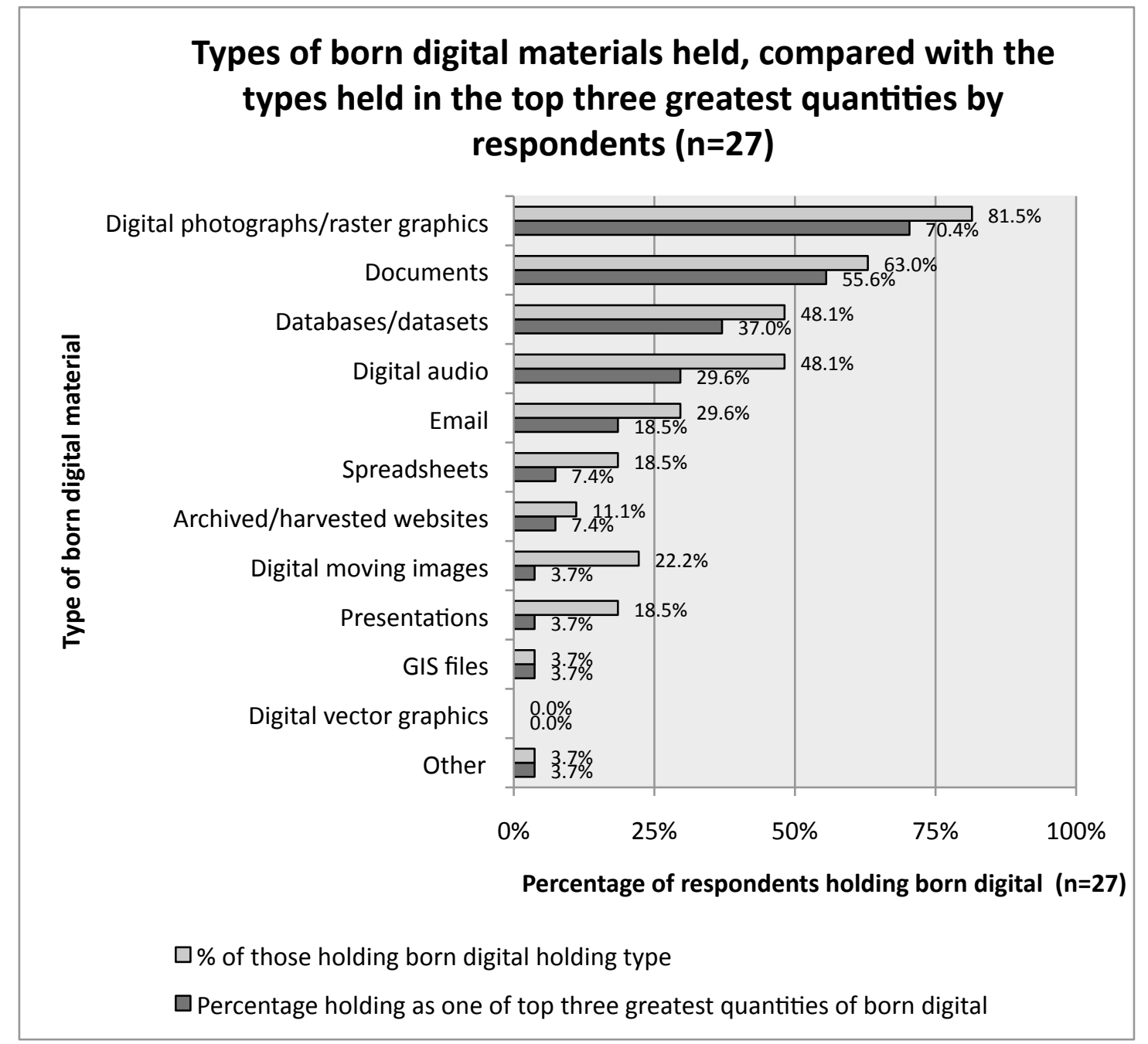

\subsubsection{Internally created born digital heritage}

While the quantitative results indicate that many respondents hold digital photographs/raster graphics, or digital audio, the qualitative responses give a better clue to their nature. It seems quite common for institutions to incorporate internally-created digital materials into their heritage collections. Several respondents indicated that their collection included internally created digital oral histories, digital photographs or digital video, created to document community events or local places. In the case of two museums, digital photographs and audiovisual materials had been retained in the collection after 
an exhibition was dismantled. That these are part of the born digital collections of museum respondents is not surprising, as Rodes et al (Rodes, et al., 2003, pp. 60-61) suggest that because of the traditional focus of museums on unique, original 3D objects, digital technology will be more of an influence for museums when it comes to dissemination rather than collecting.

\subsubsection{Externally created born digital materials}

It was not possible to get an in-depth sense of what types of born digital materials were held beyond those that were created internally, even from interviewees, as they were held in such small quantities. One library respondent indicated that the majority of their externally donated materials were digital photographs. One interviewee held a database created by an external organisation, and an academic library respondent indicated that they were preserving external emails received, as examples of "e-ephemera".

While one respondent noted that their institution had been involved in actively making snapshots of websites to add to the collection, only three respondents indicated that they hold archived/harvested websites. The idea of actively collecting web content largely seems to be not on the radar yet, reflecting a finding by King (2009, June 8), who found that it was not feasible to do a comparative study because of a lack of institutions that were engaging in Web archiving in New Zealand. 


\subsection{Collection approach}

Beyond the active internal creation of born digital materials, external items seem to be acquired in a largely passive way, reacting to what donors or depositors are offering rather than actively soliciting materials. This approach is apparently not unique to digital materials: "as we are primarily a donation based archive we accept relevant offered material". Nor is it confined to a particular institution type or perception of roles with regards to digital materials. The reason for small quantities of born digital materials held seems to be that they are just not being donated in great quantities yet. One respondent indicated:

"Our collection is largely shaped by what is donated to us. To date, born digital material has not been donated. Until it is, we will probably not address it."

This may be part of the reason for such a high proportion of "don't know" answers to the question about future plans of those with no born digital materials: that it is something that collecting repositories may not tend to think about until it happens (Figure 8).

There is an indication of continuity of channels of receipt of materials, with one respondent indicating that they "would collect material that relates to physical collections already held" and another indicating that they held "born digital material acquired as part of hard copy archive collections". New channels and methods of collecting are not necessarily being considered. For instance, one library that had been taking snapshots of some websites due to demand, had not 
yet decided whether it would collect the websites of community groups that they had previously collected paper newsletters from.

Figure 8

\section{If your collection does not currently include born digital materials, do you plan to include them? $(n=9)$}

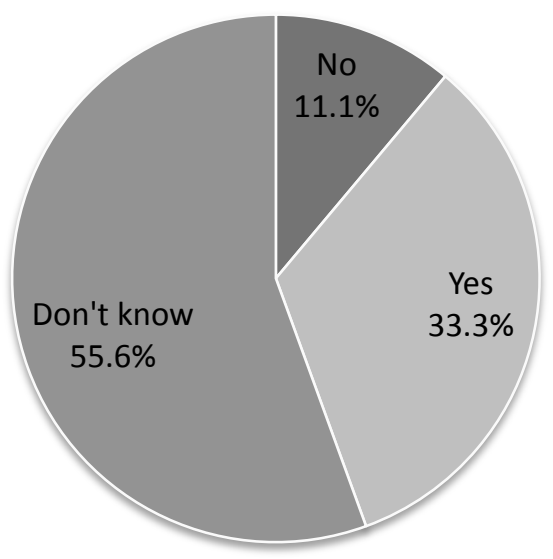

\subsection{General qualifications}

The following results need to be considered in light of the indication that collecting born digital material is still a very new activity. Volumes and diversity of types are often limited. One respondent stated: "our institution is very much in its infancy in terms of born digital so it is very difficult for me to answer any of these questions in any depth". Interviewees had difficulty elaborating on some selection factors and enabling or limiting factors, particularly those that were related to managing digital materials themselves rather than issues of resourcing, or content and significance. It was difficult to gain a great deal of insight into how these factors were affecting activities. One respondent noted in the survey responses that the future preservation requirements of the materials 
were barriers/challenges to a great extent, couldn't actually elaborate in the interview, noting instead that "well we're probably not far enough down the track to know...some of those things are probably yet to come." One interviewee was asked about technological factors and selection, because that had been noted as a "very important" selection factor in the survey, but noted in the interview "it hasn't been a huge issue yet", suggesting that some respondents may have been answering some questions in a hypothetical way. In addition, a significant proportion of born digital collections may be internally created. Some respondents seemed to have been thinking about selection in terms of what they would select to photograph or record for their own born digital creation activities. 


\subsection{Selection factors}

One survey respondent indicated that they were preserving all of a particular type of born digital material, because they didn't have a selection process yet. This reflects the findings of another study of collecting repositories, which found that acquisition was quite ad-hoc (Davis, 2008). This is reflected in the findings on the presence of collection policies (Section 8.7).

It appears that born digital selection factors related to the content of the material, its significance and value, and relevance to the collection policy, have been of the highest importance to most respondents (Figure 9). Despite the medium, institutions appear to be focusing on value and content in selection, and taking a similar approach to selection of born digital materials as other types: one noting that the "same acquisition priorities and principles apply regardless of medium". This is similar to what was found in study of the collection of born digital materials in Australian libraries, that institutions were largely using the same criteria for born digital as for other types of materials (Pymm \& Lloyd, 2007, p. 173). There were few don't know responses for factors around significance and value, which may be because these concepts are well established.

Technological aspects seem to also be playing a part, though maybe a less important one, in selection decisions. Indeed, the small numbers of responses in the "not important" category for all factors, except "ease of gaining/negotiating legal rights to acquire/preserve" suggests that for many respondents, all have been selection factors for born digital materials to some extent. There were a 
higher number of "don't knows" for factors related to other operational and technological issues, possibly because of the newness of working with born digital materials.

\subsubsection{A hierarchy of selection factors}

In some cases there is a hierarchy of selection factors for born digital materials. Although several respondents had indicated that a wide range of factors were affecting selection, text responses showed that content and fit with the collection policy was most important. One museum respondent noted that "if born digital material has good provenance but is not in a suitable format... or copyright is not clearly established, those factors certainly become a consideration in whether or not we would collect the material." While they are not of primary importance, technological factors are potentially affecting what born digital materials are selected, something that has been noted in other studies (Lin \& Eschenfelder, 2008; Phillips, 2005). Davis (Davis, 2008) found that there were limits on formats being accepted by collecting repositories, something that is anticipated by one respondent in this study, who noted that "it is likely that we would limit our collection of born digital materials to oral history and electronic documents (such as PDF)".

\subsubsection{Resourcing and capability limitations affecting selection}

Several respondents indicated that resource constraints and limited capability to deal with digital materials have, or could, affect selection decisions when it comes to born digital materials. An academic library respondent who indicated 
that technological aspects were very important in selection, noting that "size of files when server space at a premium" was a factor. Three respondents indicated that material only offered in born digital format was a factor in "selecting" born digital materials, suggesting that there may be a preference for a medium that they could more easily manage given a choice.

\subsubsection{Future plans and selection}

The overall greater importance of selection factors regarding intellectual content and long term value of materials is reflected in the future plans of a number of respondents. Specific plans to collect digital materials are not necessarily being made. Some respondents are simply planning to collect as per their collection policy, which most indicated would naturally include born digital materials. One stated: "our collection policy implicitly includes born-digital material, but does not specify future plans for collecting such materials".

A few respondents reflected an active approach in their future plans. For instance, a library respondent talked about "capturing" materials, such as websites, and another described an intention to collect e-books and digital articles by local authors or about the city. However most indicated a reactive, passive approach to their future plans, indicating a commitment to collect born digital, but as it is donated. 


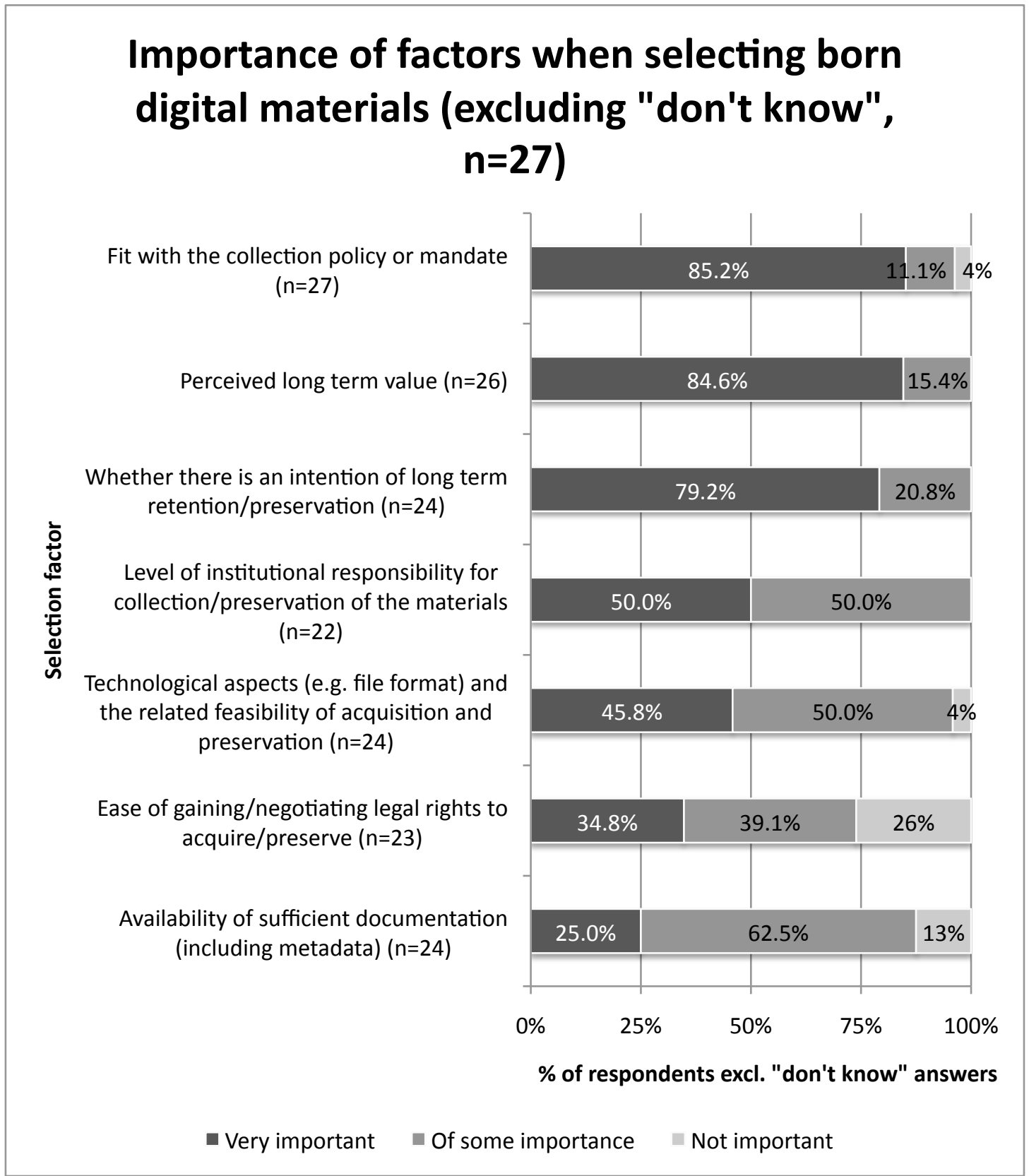




\subsection{Factors limiting and enabling born digital collection}

Respondents were asked to indicate to what extent a list of factors had been a barrier or challenge to the nature or level of collecting born digital heritage in their collection/institution. A similar question was asked about factors that would enable or encourage born digital collection activities. The questions were framed in this way to make it applicable to both respondents who held a range of born digital materials, and those who held few or none. The results from the two questions will be integrated here, because to an extent, these are two sides of the same coin.

\subsubsection{Resourcing and the institutional context}

Almost all the top factors acting as challenges or barriers are related to resourcing and the institutional context. Lack of necessary expertise and inadequate technological support or infrastructure were the strongest challenges/barriers, followed by inadequate staffing levels, the future preservation requirements of the materials, lack of adequate funding, competing institutional demands and priorities and lack of access to guidance and training (Figure 10).

These reflect the aspects that seem to arise as the most significant factors in other studies. A 2006 National Library of New Zealand report on documentary heritage described many of the same challenges: "a lack of technical knowledge and training", "inadequate technological infrastructure", staffing shortages and a 
lack of support and advice (National Library of New Zealand, 2006, June, pp. 1112).

Not surprisingly, the factors that respondents perceived as being the strongest enablers/encouragers were closely related to the most significant challenges or barriers, the top three being recruitment/cultivation of staff with necessary expertise, improved technological support or infrastructure, and increased staffing (Figure 11). Most respondents saw these as factors that would enable or encourage their born digital collection activities to some extent, with at most, seven responses in "to little or no extent". A study of collecting and preserving born digital materials by law libraries (Rhodes \& Neacsu, 2009, p. 54) identified similar enabling factors, particularly "additional funding, expertise, and the recruitment of staff with necessary expertise".

In addition, each enabling/encouraging factor was perceived overall as a stronger enabler/encourager than the corresponding factor was perceived as a challenge or barrier. Perhaps it is easier for respondents, particularly those with few born digital materials, to think in terms of enablers rather than barriers or challenges. The smaller number of "don't know" responses for the enabling/encouraging factors suggests that this may be the case. Even respondents who do not perceive a particular factor, such as funding, as a strong challenge/barrier, may still see increased funding as an enabling factor. This was noted a study of born digital collection and preservation in law libraries, where a lack of collaborative opportunities was not seen as a strong limiting factor, but it was seen as a strong encouraging factor (Rhodes \& Neacsu, 2009). 
Several factors were identified as stronger challenges/barriers for those with no born digital materials, particularly lack of necessary expertise and inadequate technological support or infrastructure (Appendix 3, Table 6) and again for enabling/encouraging factors, particularly increased funding, improved technological support and infrastructure, and increased access to guidance or training. Similarly, a study of digitisation activities in New Zealand found that some factors were more of an issue for institutions that were not yet digitising, including lack of funding (Dorner, et al., 2002, p. 21). If there is indeed a relationship between the presence of born digital materials in the collection, and the extent to which factors such as funding or expertise are felt as barriers or challenges, the direction of that relationship is not clear. 


\section{Extent to which factors have been a barrier or challenge to the nature or level of collecting born digital materials in respondents' collections/institutions (excl. "don't know")}

Lack of necessary expertise within the institution $(n=35)$

Inadequate technological support or infrastructure $(n=34)$

Inadequate staffing levels $(n=35)$

The future preservation requirements of the materials $(n=31)$

Lack of adequate funding $(n=34)$

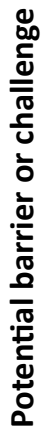

Competing institutional demands/priorities, e.g. of digitisation $(n=34)$

Lack of access to guidance or training $(n=34)$ Lack of clarity about collection and preservation responsibilities $(n=35)$

Challenges gaining or identifying rights to acquire or preserve $(n=30)$

Lack of opportunities to collaborate with other institutions $(n=30)$

Difficulty obtaining materials in required/ preferred media/formats $(n=28)$

Difficulty obtaining necessary documentation (including metadata) $(n=29)$

Difficulty determining authenticity, context or origin $(n=30)$

Difficulty determining uniqueness $(n=30)$

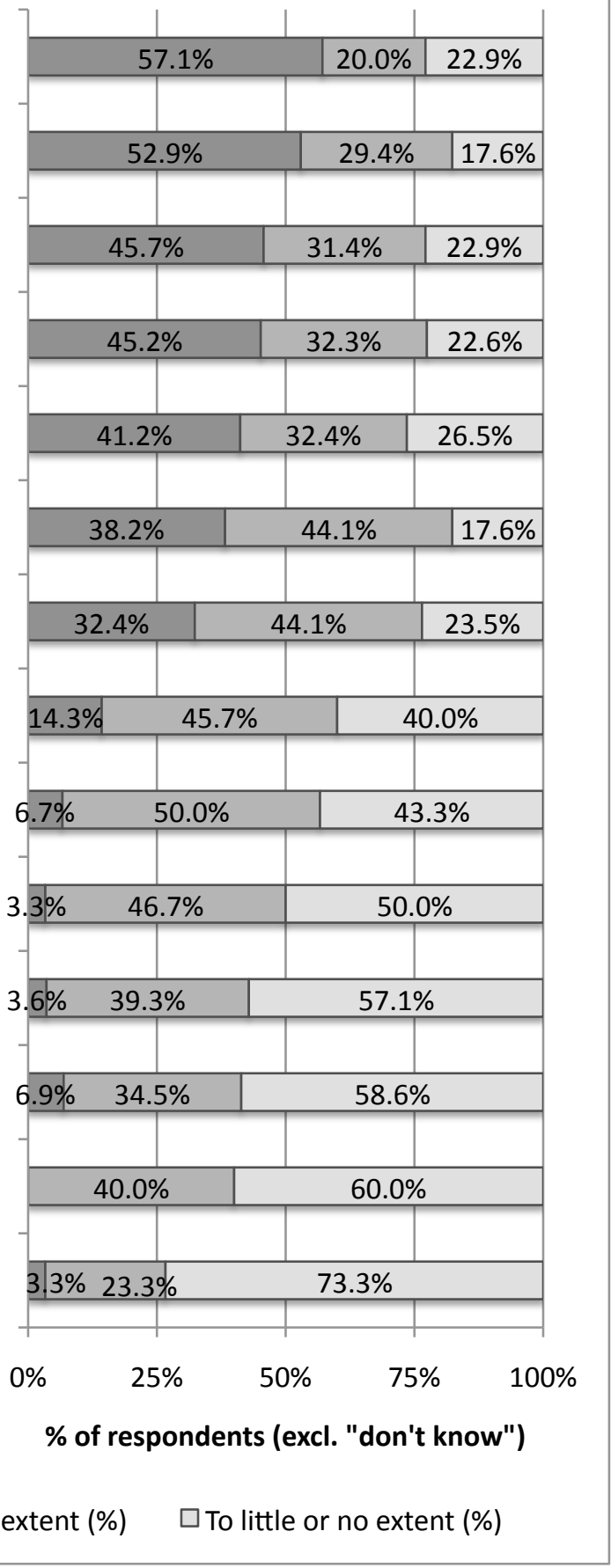

$\square$ To a great extent (\%) $\quad \square$ To a moderate extent (\%) $\quad \square$ To little or no extent (\%) 


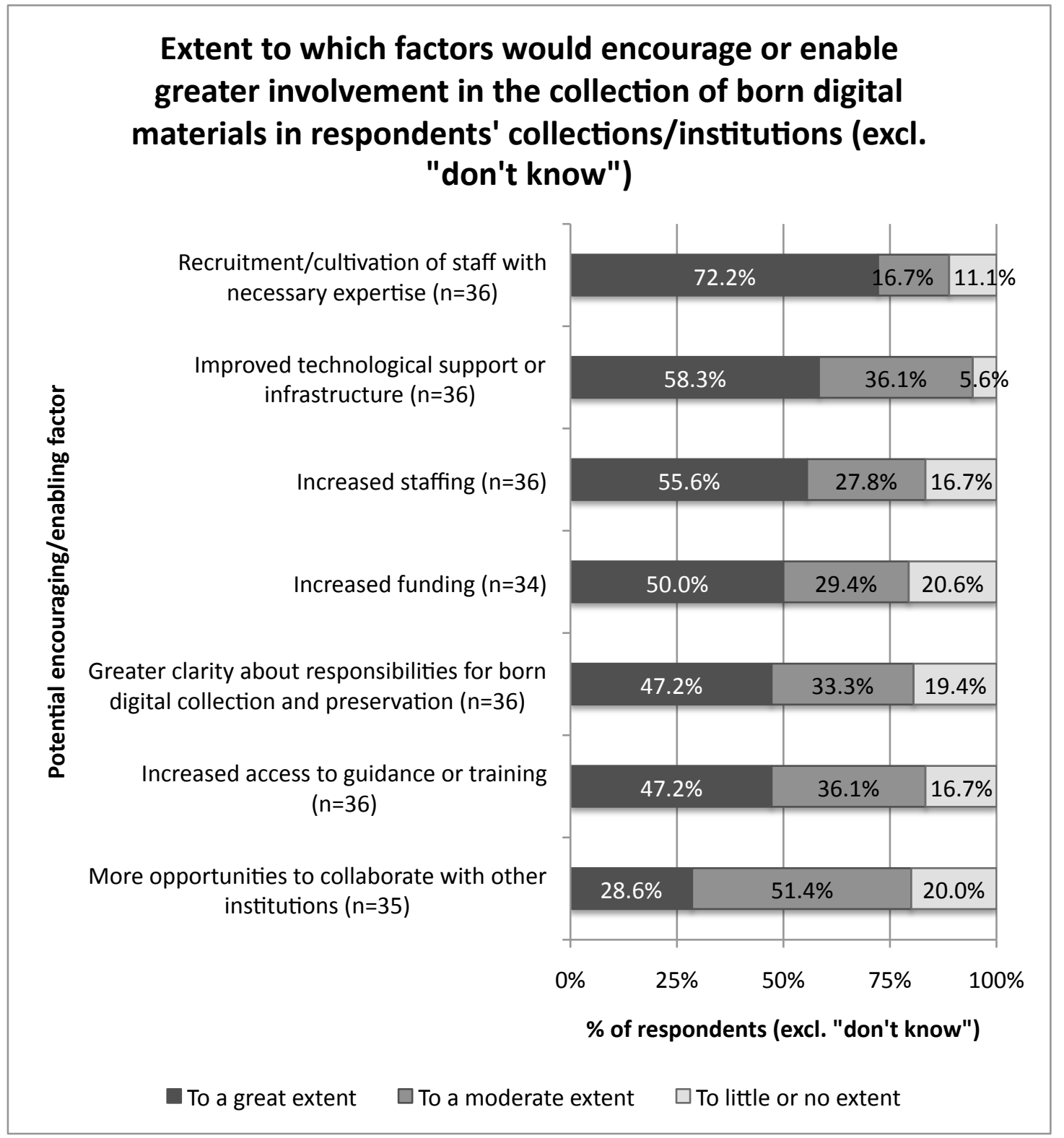




\subsubsection{Relationships between factors}

It is clear from the qualitative data that the factors related to resourcing and the institutional context are closely interrelated. For instance, two respondents noted that lack of funding was limiting their ability to attend courses or conferences to develop expertise. Likewise, several respondents noted that funding limitations were affecting staffing levels, the development of technological infrastructure and the level of technological support. This reflects the findings of the study of local authority archives, which noted that funding seemed to be "the key barrier which will cascade down and impact on other challenges" (Boyle, et al., 2008, pp. Section E, Para 2). Respondents also noted that there was no point having technological infrastructure, or additional staff, without expertise. This may be part of the reason for lack of expertise being a stronger barrier/challenge than staffing levels.

\subsubsection{Competing demands and priorities}

For a number of respondents there were various institutional priorities competing for limited resources, sometimes leaving little room for collecting and managing born digital materials. Indeed, lack of time was mentioned twice as an additional challenge/barrier. The activities competing for resources included digitisation and managing the current collection. This reflects the findings of a report on New Zealand documentary heritage collections, which described cataloguing backlogs, and the need to balance newer born digital demands "with the institutions' existing commitment to preserve and provide access to traditional materials" (National Library of New Zealand, 2006, June, pp. 11-12). 
One respondent noted that "most of it is digitised as opposed to born digital", similar to what has been noted in other studies (Pymm \& Lloyd, 2007; Rhodes \& Neacsu, 2009; Simpson, 2005). A 2002 study of digitisation activities in New Zealand found that museums, archives, public libraries and tertiary libraries were planning to increase their involvement in digitisation (Dorner, et al., 2002, p. 11), so it is not surprising to see digitisation activities still dominating the focus of some institutions.

Several respondents noted that caring for physical materials was taking all available resources: "our first priority is to preserve, catalogue and make available the collection that we currently care for and this takes all of our staff time and budget". Pymm and Lloyd (2007) noted a similar tension between traditional and newer activities in Australian Libraries with regards to collecting born digital materials.

\subsubsection{Resource constraints affecting activities}

Some respondents indicated that their born digital collection activities had been limited by resourcing constraints. One noted that "lack of time and organisational expertise have been barriers in extending the scope of our collection policy with regards to heritage collections." This reflects what the National Library of New Zealand reported with regards to documentary heritage collections: that there were constraints on the growth of collections "due to operational demands on funding" (National Library of New Zealand, 2006, June, p. 12). 
Several respondents indicated that their future collection plans were contingent on adequate resourcing. One noted that "the plan is to expand the digital collection when more funds and staffing become available" and another said that "development of the current infrastructure is necessary before we can look at actively collecting in this area." Here, both agreed that although collecting born digital materials is part of their role, their activities are affected by resourcing constraints.

For some, resourcing limitations seemed to be driving a more passive approach to collecting born digital materials than may otherwise be taken. An academic library respondent noted that: "we have difficulty keeping up with our existing activities so collection of born digital material is done very passively." Future preservation activities, and the development of expertise in digital preservation, were also noted as being possibly affected by resource constraints.

One public library respondent, when discussing future plans for a collection policy with born digital materials, described a possible situation where, if they had an old floppy disc, they may need to make a "judgment based on budget and you have to balance that off against the difficulty of extracting the information technically and whether it's worth it in terms of its content". Despite the intention of a format-neutral collection policy, decisions about keeping digital material accessible may need to be made partly based on resourcing available. 


\subsubsection{Expertise, training and guidance}

A number of respondents saw working with born digital materials as a new and significantly different activity, and therefore the expertise required is not already available in the institution. In some cases there was a perception the necessary expertise was confined to the Information Technology (IT) department and the "digital librarian", but one public library respondent felt that IT staff "don't really know much more than you do... they don't have any experience necessarily with audio formats, and digital recording and that kind of thing." There seems to be a new kind of expertise needed, not something that the IT department can necessarily provide. Not long ago, New Zealand cultural heritage institutions had a wide range of training needs for digitisation (Dorner, et al., 2002, p. vi). While one respondent mentioned that they had developed some expertise and capabilities as part of their digitisation activities, it is clear that there is a further need for expertise when it comes to collecting and preserving born digital materials.

The expertise required seems to be very broad, described by one respondent as "the whole gamut of digital preservation", including policy development. Specific needs also included information on formats likely to be received, and technical metadata. Hilton and Thompson (2007a, pp. Conclusion, Para 5) described the "steep learning curve" they have faced in "acquiring and managing born digital collections" in a large United Kingdom collecting institution, so it is not surprising that respondents in this survey are describing lack of expertise as a challenge. 
Either the current guidance that is available is not enough to support the needs of some cultural heritage institutions, or they lack the time and resourcing to make the most of this guidance. Lack of access to guidance or training was less of a challenge or barrier than lack of expertise, suggesting that the latter may be the case. However, there is a risk that asking this question in terms of "access" rather than "availability" may have resulted in confusion around the meaning of the question.

\subsubsection{The extra pressures of digital materials}

Amongst several respondents there was a perception that digital materials present significant extra pressures and demands, with one noting that:

“It's a biggy! It requires significant investment in developing knowledge and skills in the staff, and in the infrastructure to support collecting born digital materials."

One respondent noted that challenges with digital materials in terms of issues such as rights and authenticity are similar to those of other kinds of materials, however this respondent also expressed a sense that possibly not all the challenges had been revealed yet, and wouldn't be until the materials are actually received.

\subsubsection{Technological infrastructure and support}

Specific problems to do with technological infrastructure and support included "piecemeal" access to the necessary technology, and the challenge posed by a 
lack of consistency of born digital materials compared to the products of digitisation. The difficulty in collecting and preserving materials created externally has been identified in several other studies as a challenge, increasing the complexity and cost of collection and preservation (Boyle, et al., 2008; Davis, 2008; Sinclair, et al., 2009; Waller \& Sharpe, 2006).

The distance between the point of collection of heritage materials, for instance the local history collection in libraries, and the provision of the necessary technological support or infrastructure needed for managing the digital materials (in the IT department) seems to be a challenge in some cases. This is partly related to what was noted earlier, that the necessary expertise often lies with the IT department or digital librarian. However respondents also expressed frustration that they had to rely on either their internal IT department, or that of the council, for provision of the infrastructure and support needed, resulting in a lack of control over the management of materials, or access to technology needed. It seems that because digital materials require specific kinds of technology for their management, there is an extra dimension added to the management of heritage materials that shifts the management, or control, away from those who would traditionally have managed heritage materials entirely themselves.

\subsubsection{Funding constraints}

For some institutions/collections, it seems that the collection of born digital materials is not being treated as a continuation of previous activities, with one noting the need to "get funding for a specific project" and another noting a need 
for "institutional buy-in". This reflects Lavoie and Dempsey (2004) who noted that funding for digital preservation has tended to be in short supply, and shortterm. It seems that this is the case here, despite the need for an "ongoing resource commitment" (Lavoie, 2006, p. 114).

\subsubsection{Factors closer to the materials}

Less acute challenges or barriers seem to be largely those that are more to do with the digital materials themselves, rather than the broader institutional/resourcing context (Figure 10). Clarity about responsibilities, challenges gaining or negotiating rights to acquire or preserve, and lack of opportunities to collaborate all had a significant proportion in "to a moderate extent", but with a similar proportion in "to little or no extent". Difficulty obtaining necessary documentation, and difficulty obtaining materials in the required/preferred media/formats seem to be less of a barrier or challenge, but the two factors that were generally the least significant barriers/challenges to respondents were difficulty determining authenticity, context or origin and difficulty determining uniqueness.

This may be because it is too soon for respondents to be identifying strong issues to do with these factors. Indeed, the higher number of "don't know" responses for many of these factors suggests that this might be the case. One respondent, explaining why issues around gaining or negotiating rights, or difficulties obtaining materials in required or preferred media or formats had not been much of a problem, noted that: 
“It's probably yet to come, actually. Because I guess it's like we just acquired the stuff, and we haven't necessarily negotiated all that yet."

There was some difficulty noted, however. Two respondents indicated that rights issues to do with some of their born digital archival materials had not been fully tackled. In one case where there was difficulty noted in determining the provenance of born digital materials, these were the same issues that were faced with other materials as well; serving as a reminder that it can not be assumed that these factors are necessarily more of a challenge for born digital materials. 


\subsubsection{Clarity around responsibilities}

Overall, lack of clarity around responsibilities is not a strong barrier or challenge, and is potentially more of an issue with newer types of materials, with two library respondents expressing a need for clarity around what the National Library is doing regarding web harvesting, and what their role was in relation to this. For both it seemed like there was a perception that the National Library may be harvesting the kinds of materials that would be relevant to these collections, so some clarity is clearly needed so that institutions don't assume that it is taken care of.

\subsubsection{Networking and collaboration}

When asked about collaboration in the interviews, all respondents talked more about the potential value of contact with other institutions to see what they are doing and share expertise, rather than working in collaborate ventures. This result is similar to the findings from the study of digitisation by Dorner, Chawner and Searle (2002, p. 19) where "contact with other organisations with similar projects" and "information about digitisation activities in NZ" were seen as more useful than "partnerships with other organisations". One respondent particularly saw the potential value of being able to see what larger institutions, such as the National Library, are doing. This reliance of smaller institutions on larger ones for support and preservation advice generally was also noted by the National Library of New Zealand (2006, June, p. 7). 
Some respondents did, however, mention the potential value of or need for collaborative relationships in terms of the preservation of born digital material; driven by the perception that these institutions do not have the resources or capability needed to adequately manage digital materials themselves. For instance, two public library respondents indicated that they would like to collaborate with the National Library in terms of preservation. Two respondents, an academic library and public library, suggested that working with other institutions on policy development and planning would be useful, partly because it could clarify responsibilities. A number of other studies also identified needs for opportunities to collaborate with or learn from other institutions involved in digital preservation (Kenney, 2005, August 15; Meyer, 2009; Simpson, 2005; Waller \& Sharpe, 2006).

It seems that a many of the collections surveyed are sitting at the lower end of the "Data Pyramid" (Appendix 1), with less capability to care for digital materials than national institutions further up the Pyramid. The UNESCO Guidelines for the Preservation of Digital Heritage (UNESCO, 2003b) recommend a pragmatic approach to digital preservation, and see roles for a wide range of institutions, with a place for smaller contributions. It seems that this will need to be the case in New Zealand, as some smaller institutions are indicating that they may not be able to manage digital materials alone. 


\subsection{Born digital collection policies}

\subsubsection{Overview}

Respondents were asked whether their collection/institution currently had a written policy governing the acquisition of born digital materials. Written policies were asked about because it indicates a certain level of formalisation. The majority of respondents (78\%) indicated that their collection/institution did not currently have a written policy governing the acquisition of born digital materials (Figure 12). This is similar, but slightly lower proportion than in a study of collecting repositories in the United States, where $29 \%$ had an acquisition policy for digital records (Davis, 2008, p. 178) Some respondents did, however, have an intention to create a policy, five of those within a year (Figure 14).

\subsubsection{Low levels of collection policy development}

Two respondents indicated that while there was the intention to create a policy, this was contingent on sufficient resourcing, mentioning "time and current commitments". This could be the reason why some other respondents do not have a policy and do not know whether they will create one.

Another reason why policy development levels are low may be because there is some evidence of a reactive approach to developing policies and procedures for dealing with born digital materials, with respondents noting the difficulty of creating a policy before actually receiving the materials, and some respondents indicating a need for guidance. Similarly, a recent study of local authority 
archives noted that digital preservation planning was largely reactive (Boyle, et al., 2008). In addition, born digital collection may not yet have been incorporated formally into policies because it is a new activity. A high proportion of "don't know" answers to the question on future plans for policy creation suggests that perhaps formal policies for acquisition of born digital materials have not yet been considered.

Another contributing factor may be that institutions may not see the need for a policy explicitly covering born digital materials: one stated that: "our policy covers any type of format of information that is donated, all material donated falls under the same policy of collection, access, promotion". Indeed, two respondents who said that they did have a policy governing the acquisition of born digital materials also indicated that their collection policy was format neutral, and implicitly, rather than explicitly, included born digital materials. That may also be the case with respondents who said that they did not have a policy.

Because at this stage, factors related to issues such as format of materials are not a strong feature in selection practices, it is not surprising that policies specific to acquiring born digital materials are not being created. However, Harvey (2005, p. 62) argues that new approaches to selection are needed for digital materials, that take into account the additional complexities, so maybe this is something that should be considered more by those collecting born digital heritage. The Digital Preservation Coalition Interactive Assessment: Selection of Digital Materials for Long Term Retention is one example, which divides selection into "selection of version and content", "rights and responsibilities", "technical/costs" 
and "documentation and metadata/costs", in addition to content (Digital Preservation Coalition, 2008b).

Figure 12

Percentage of respondents with a written policy governing the acquisition of born digital materials? $(n=36)$

Don't know

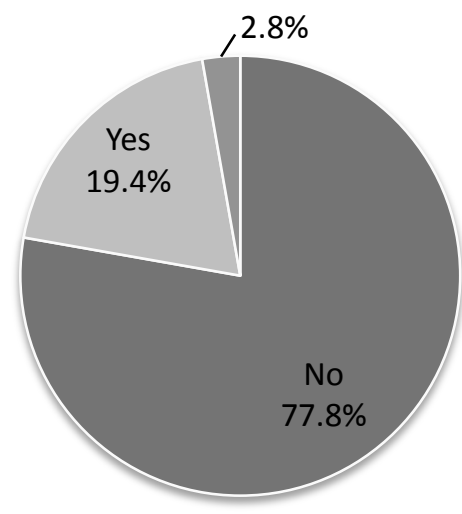




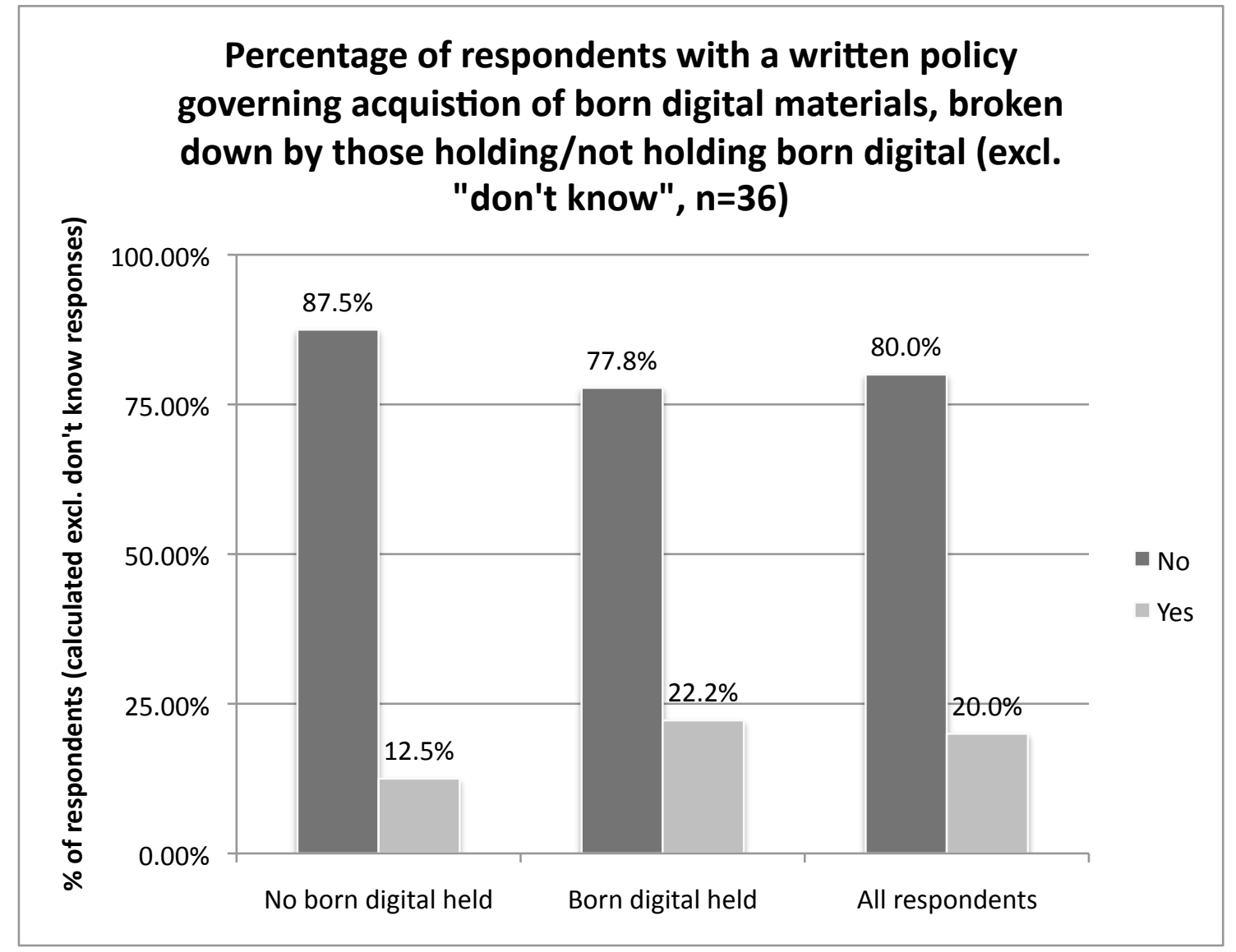

Figure 14

Respondents with no written policy governing the acquisition of born digital materials: plans to create one? $\left(n=27^{*}\right)$

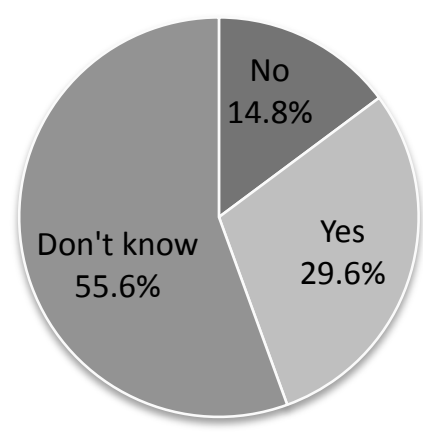

Note: there were only 27 valid responses, because one person with no policy answered "not applicable" to this question. In addition, one respondent that did currently have a policy answered "yes" and was also excluded from the analysis. 


\subsection{Born digital preservation policies and procedures}

\subsubsection{Policies governing the preservation of born digital materials}

\subsubsection{Overview}

For the question on whether respondents' collections/institutions currently had a policy governing the preservation of born digital materials, proportions were similar to those for an acquisition policy. The majority, 78\% (28) did not have a policy governing the long-term management or preservation of born digital materials (Figure 15). Half of the respondents with no preservation policy did not know if there were plans to create one. Of the 11 (39\%) that said yes, only six provided a timeframe: most within the next year (Figure 17).

\subsubsection{Low levels of preservation policy creation}

The low level of preservation policy creation, and number of "don't know" answers regarding plans to create one, suggests that generally there may not be much in the way of thinking about digital preservation by those involved in these particular collections, let alone formalisation of practices. Five of "don't know" answers came from respondents in management positions, who could be expected to be aware of activity and intentions.

Studies by Sinclair et al. (2009) and Gregory (2009, April) also reported a low level of digital preservation planning and activity. A particularly interesting finding was that of Sinclair et al (2009, pp. Discussion, Para 13) that "the existence of a [digital preservation] policy is a critical early step" and that those 
institutions were more likely to have a budget and a current or planned digital preservation solution. So it would be encouraging to see more of these collections with a policy governing the preservation of their born digital materials.

\subsubsection{Preservation procedures}

As with a preservation policy, a significant proportion of respondents, $51.43 \%$ (18) said that they did not have any procedures for the long term management or preservation of their born digital materials, including a significant proportion of those holding born digital materials (see Figure 19 and 20).

It is worth noting that two respondents who said that their collection/institution did not have any preservation procedures indicated that management of digital materials was provided by the wider council, so for others that answered "no", there may still have been some procedures provided in a broader sense.

Because the questions about policies and procedures for digital preservation asked specifically about born digital materials, it is possible that institutions/collections do have procedures in place for preservation of the products of digitisation, or internally created items. Indeed, one interviewee had a preservation policy for the management of digitised materials. Regardless of this possibility, it is concerning that a significant proportion of respondents said that they did not have any procedures in place for born digital materials. 


\subsubsection{Nature of current preservation practices}

All of the nine respondents who said that they did have procedures for the longterm management/preservation of their born digital materials described their procedures. It appears that those with some sort of access to external digital management, on a larger scale, had better procedures in place. For instance, in one case the management of digital materials was carried out on a wider scale by the Council IT department, and those procedures included digital preservation strategies such as migration.

However in the case of some respondents who perceive that they do have procedures for the long-term management or preservation of their born digital materials, those procedures are often inadequate. For two, the extent of their management was saving materials to a secure server. Another referred simply to backing up. Two respondents did mention migration as a procedure, although for both this was rather ad-hoc. Indeed, four of the respondents who did have procedures said that they did not have a policy, suggesting that in some cases, procedures are not formalised in written policies.

There were respondents who said that they did not have procedures for longterm management/preservation but actually noted some of the same kinds of activities as those who did perceive that they had procedures. There are clearly differing levels of understanding when it comes to what long-term maintenance or preservation of digital materials means. Awareness seems to be generally low, similar to the results of a survey of New Zealand public sector readiness for digital preservation a few years ago, which found that "the level of organisational 
awareness of digital preservation is generally low, and the degree of digital preservation activity is modest overall" (Dorner, et al., 2006, June, p. ix).

\subsubsection{Future plans}

Respondents were asked to "describe any plans or aspirations for the preservation of born digital materials in your collection/institution". It seems that resource constraints are affecting current and future preservation strategies, as discussed in Section 8.6.1.3. Not a great deal of detail was provided, concerning if silence when it comes to any future plans or aspirations regarding the preservation of born digital materials means that that it is not on the radar, no thought has been given, and no preparations are being made.

It is encouraging, however, that two of the respondents whose current procedures involved saving materials to a server indicated plans to improve their procedures, in one case plans for a digital asset management system and a more comprehensive preservation management policy. Other respondents indicated awareness of the need to migrate materials and retain them in accessible formats. 


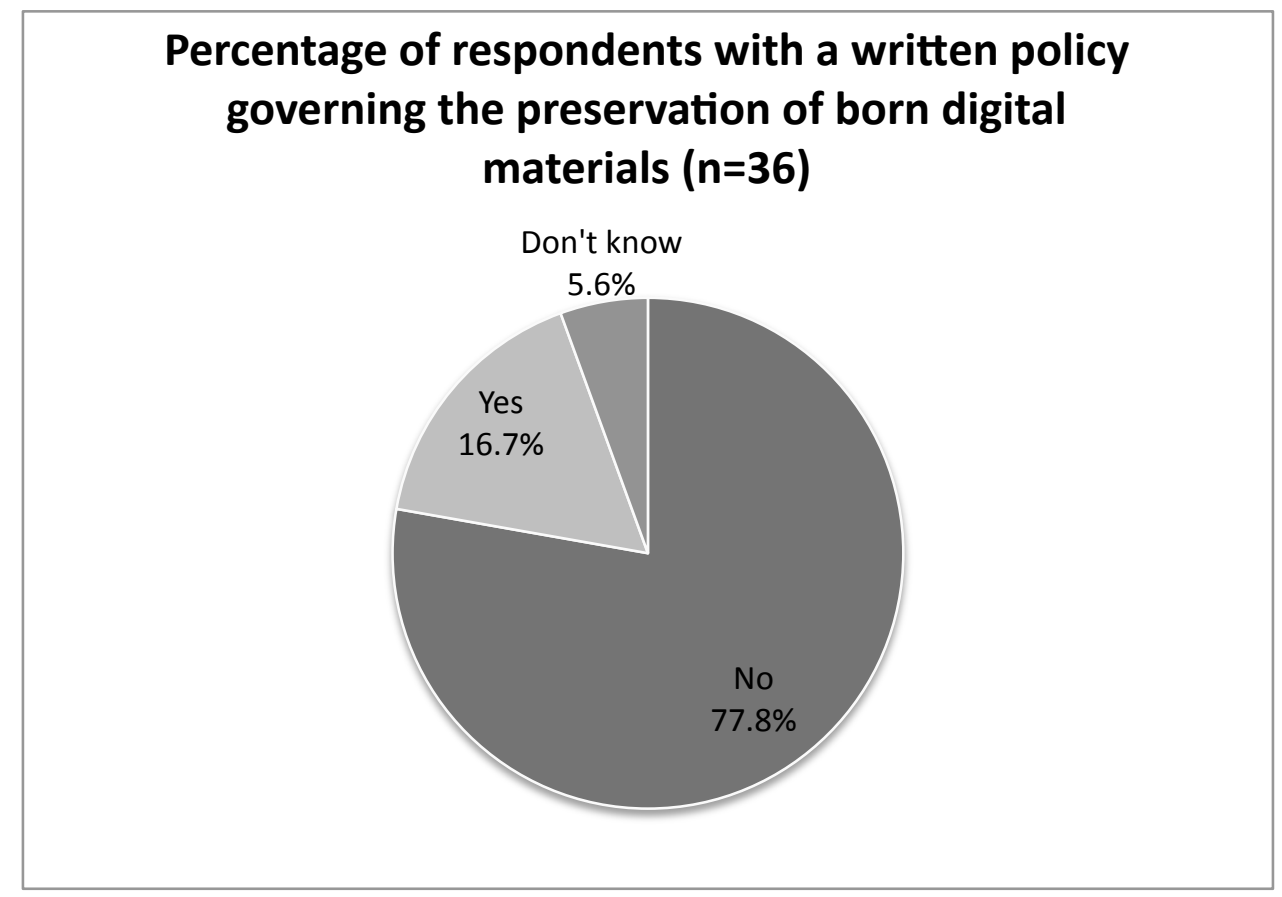

Figure 16

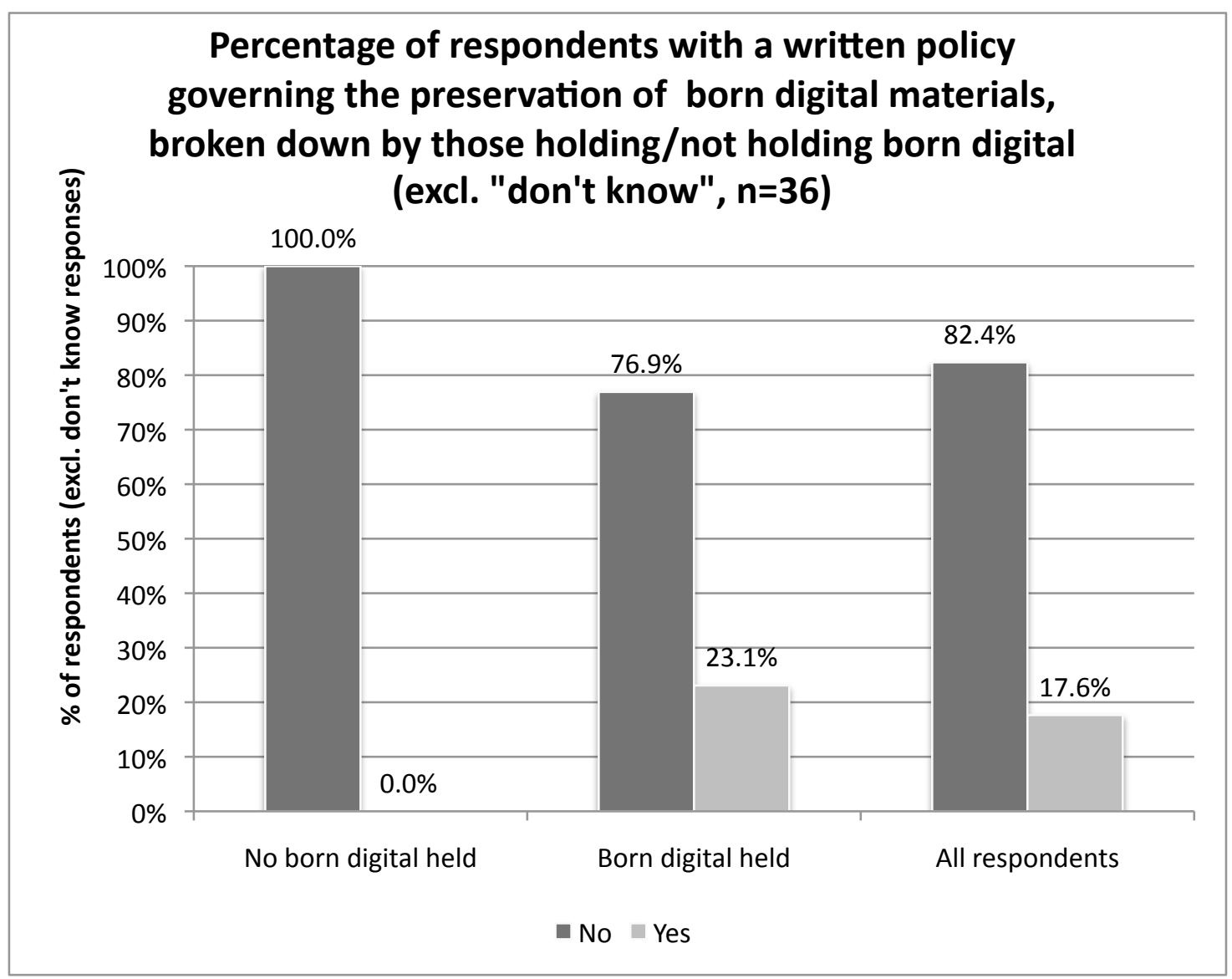


Respondents with no digital preservation policy: plans to create one? $(n=28)$

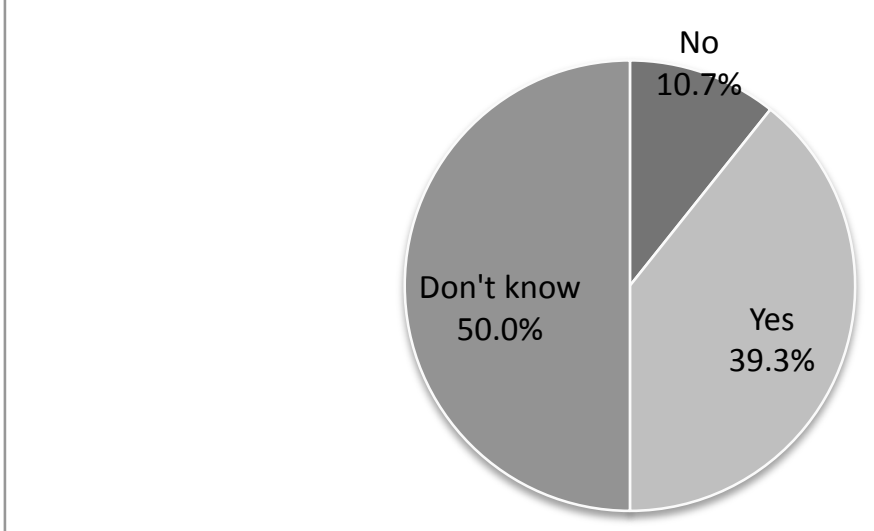

Figure 18

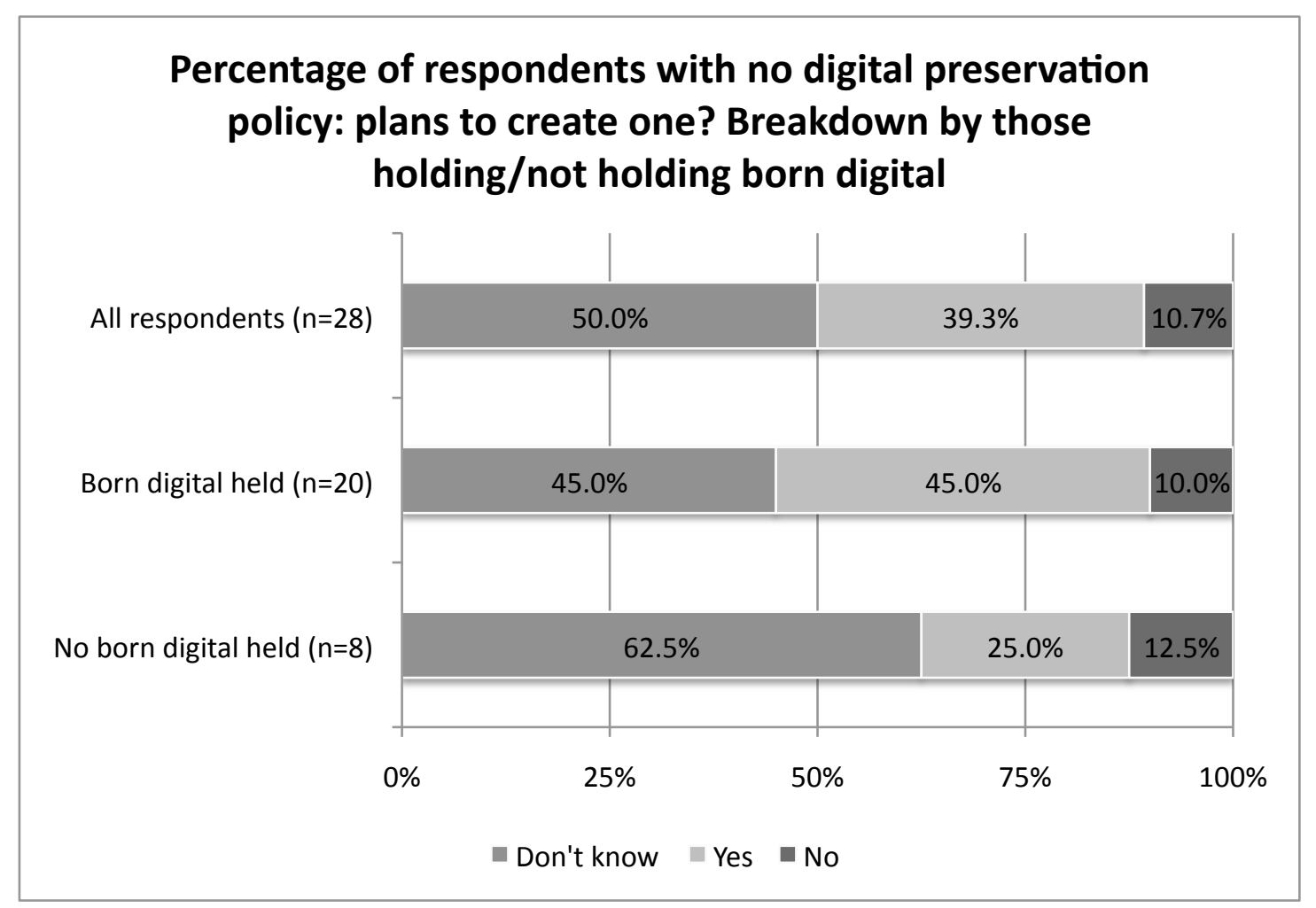




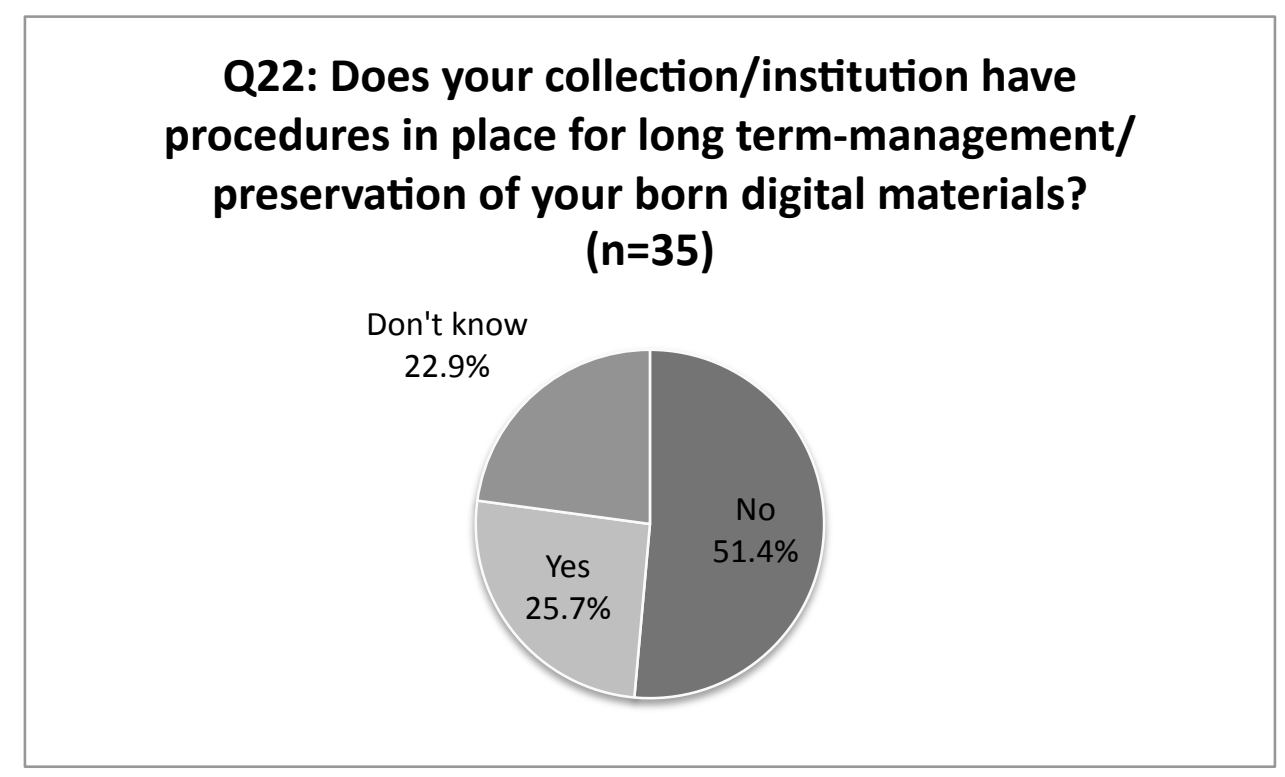

Figure 20

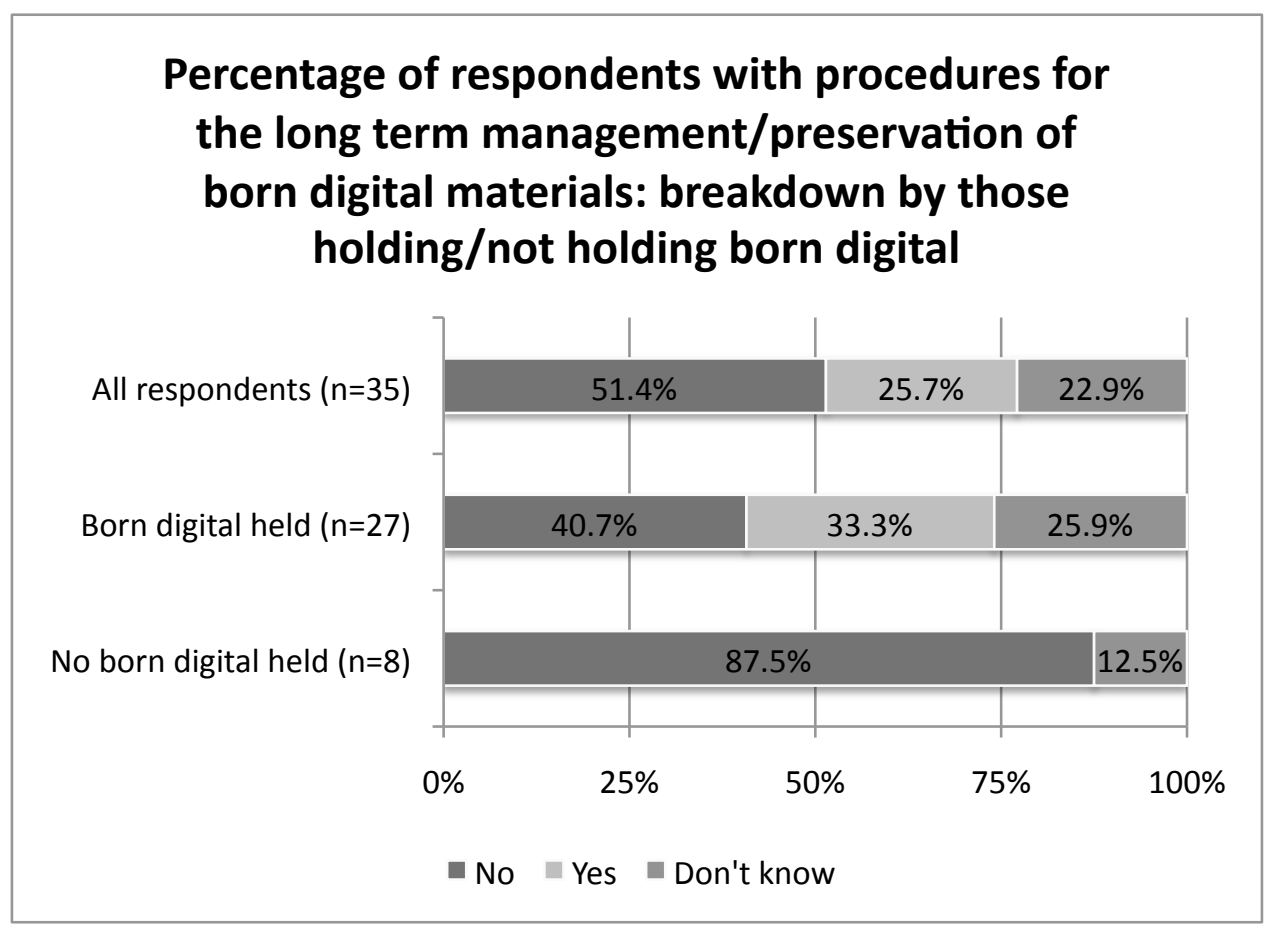




\subsection{Awareness levels}

While there are generally low levels of expertise, planning, and practice in terms of maintaining digital materials, there is at least some evidence of awareness of the collection and preservation of digital materials as an important, impending problem. Two respondents noted the particular vulnerability of digital materials, and one noted the need for an active approach to capture digital materials while they are available. Another demonstrated good awareness of potential issues with materials created in older operating systems, and the need to potentially migrate materials.

\subsection{Perception of roles and responsibilities}

It is encouraging that the majority of respondents agreed that the collection, and preservation of born digital materials is part of their collection/institution's role (Figure 21). While no respondents answered strongly disagree, a minority of respondents don't necessarily see the work of their collection/institution extending into the realm of digital materials. 


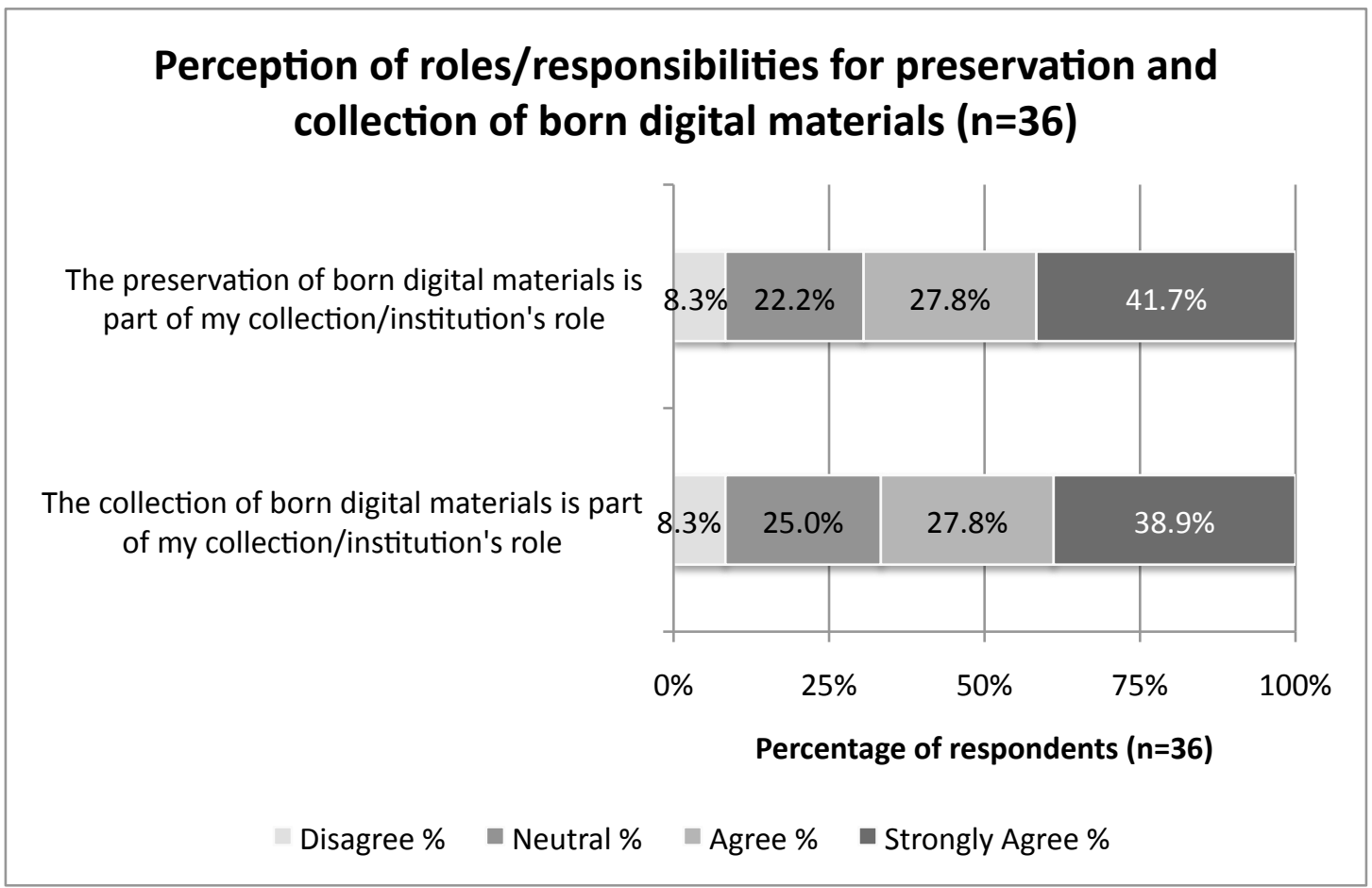

Figure 22

\section{Perceptions of collection of born digital materials as} a role: breakdown by born digital held/not held

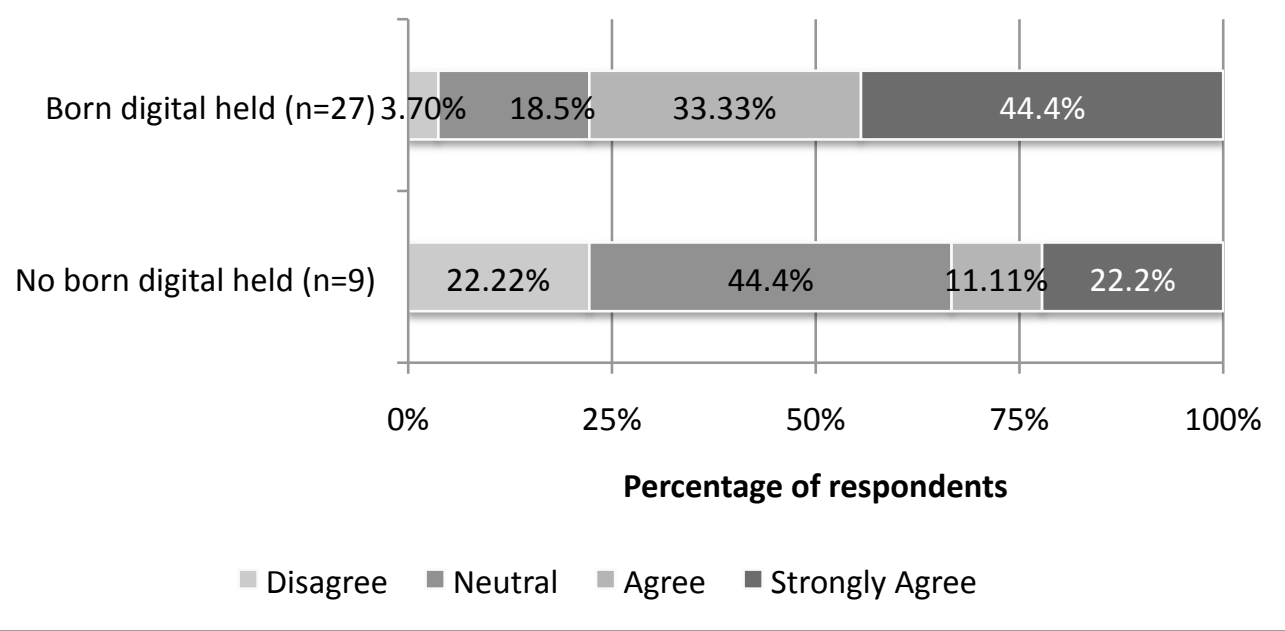




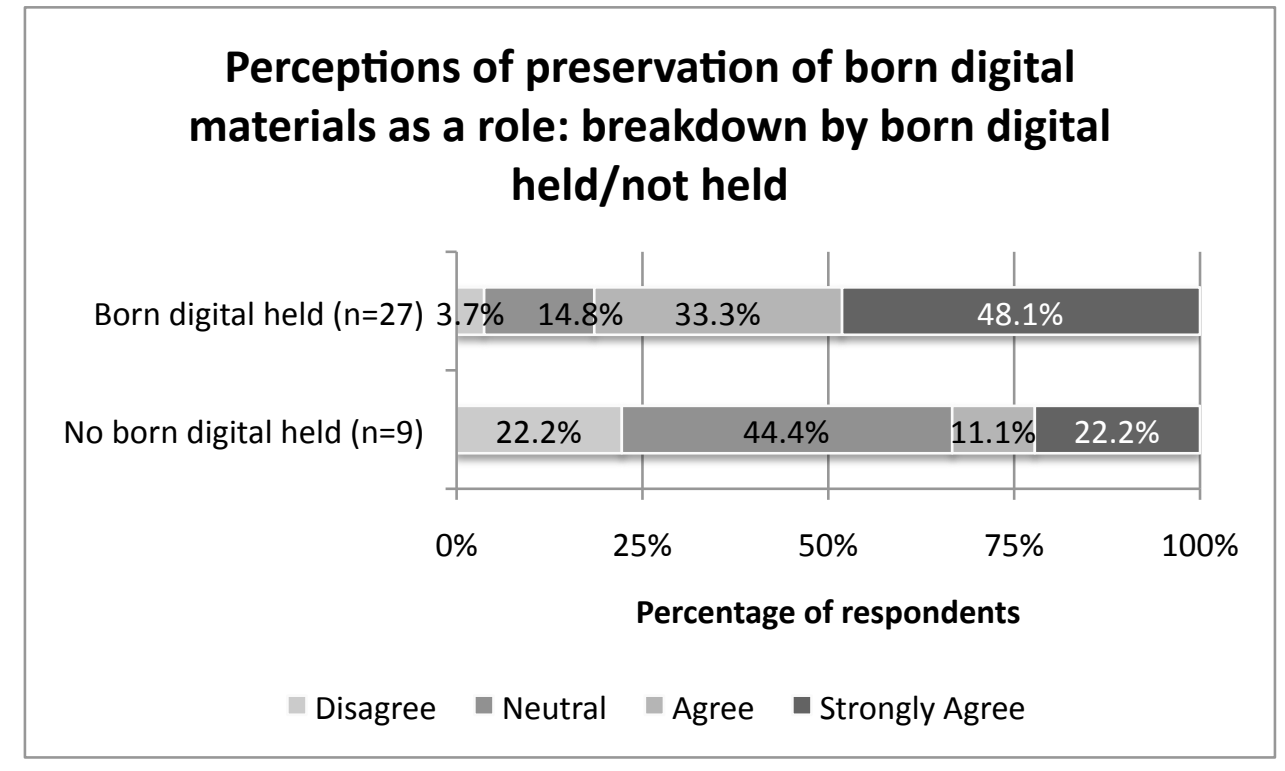

\subsubsection{Strongly agree and agree: Continuity of roles and responsibilities}

Most respondents who answered strongly agree or agree perceived there would be continuity of their role; that their collection policies were format neutral, and would therefore naturally include born digital materials. For instance: "I see this as a carrying on of what we have been doing all along with hard copy resources".

Several reflected a view of inevitability as a driver to the inclusion of digital material in their collections. For instance, one respondent indicated that: "it is a sign of the times that digital material is being created, we obviously need to take this into account as we move archival institutions into the future".

Two respondents reflected the idea that regional or local institutions have an important, continuing role in collecting local digital heritage. One public library noted that " 'born digital' is part of the community heritage, which should be collected by archives in the district". Indeed, Spence (2005, pp. 366, 370), suggests that digital materials present an opportunity to preserve a wider view 
of history, and argues for the participation of smaller institutions in digital preservation, to increase "the volume and diversity" of material preserved.

\subsubsection{Disagree and neutral: Discontinuity of roles?}

Neutral and disagree responses are discussed together here, because, while the two do not mean the same thing, even neutral indicates at least some ambivalence.

Although there were significantly fewer respondents in the "no born digital materials held" compared to the "born digital materials held" category, there does seem to be a difference between the two groups in the results (Figure 22 and 23). A higher proportion of respondents with no born digital materials selected disagree or neutral, for both collection and preservation. There is a possibility that asking the question about roles in the present tense may have been part of the reason for a higher proportion of respondents with no born digital materials saying neutral or disagree. It is therefore not possible to determine for sure whether there is a meaningful difference.

In contrast to those who answered agree, none of those who said neutral or disagree suggested that their collection policies would naturally include born digital materials. There is potentially discontinuity in the way they perceive roles and responsibilities.

There is some evidence of current resistance or reluctance amongst some of those who answered neutral or disagree. However, a number of those who seemed ambivalent about their role with regards to born digital materials 
indicated factors that could potentially enable their activities. It seems that in some cases, a neutral attitude is driven by resourcing and expertise limitations. For instance, one museum respondent, who answered neutral for collection and preservation, indicated that: "we also have a lack of understanding and support of digital media so as a result this is not a priority for us". Indeed, some of those who had a neutral view of collection and preservation roles still indicated a commitment to attempt to manage what was donated, or at least did not say outright that they did not plan to collect born digital materials. There were plenty of respondents who answered agree or strongly agree who also noted challenges to their activities, however, so there is likely to be more to a neutral or disagree response than just resource limitations. More investigation would be needed to explore this.

For several, the answers of disagree, or neutral, seemed to be driven by the fact that born digital collection has not yet been considered. One respondent, in explanation of why they said disagree, responded: "to date, born digital material has not been donated. Until it is, we will probably not directly address it."

\subsubsection{Difficulty conceptualising the digital artefact}

In terms of institution types, all three of the respondents who said disagree, for both questions, also identified as museums. There was not a significant difference to proportions for museums for the neutral category compared to the proportion overall, however, so this may not be significant. Nonetheless, this might be related to what was noted by one "neutral" museum respondent, who noted that one of the most significant barriers was actually "the mindset of the 
institution"; that the "museum focus" of some meant that "they can't envisage how an object can just exist in a digital format". Another two museum respondents seemed to reflect this, both indicating a preference for converting materials and archiving them in hard copy. It is not surprising to see this, as a recent qualitative study of technology and museum work in North America noted the challenges that digital materials pose to "basic concepts of traditional museology" such as determining an authentic object (Duff, et al., 2009, p. 5). This serendipitous finding requires further investigation, however, as not all museums expressed this view. 


\subsection{Distance from creation}

The design of this survey was influenced by an assumption that the level or nature of activities around collecting born digital materials in these collections was something that may be influenced by particular limiting or enabling factors. It seems, however, that one of the biggest limiting factors so far may be simply that little is being donated, and one of the biggest threats to local digital heritage may be the distance of the institutions charged with the care of heritage from the creation of digital materials, particularly in terms of time.

Not surprisingly, the collections in this sample largely seem to be operating in the fourth dimension of the records continuum; "pluralise", which is concerned with "collective memory" (McKemmish, 1997, pp. A dimensional reading of the continuum, Para 1). One of the core ideas behind the recordkeeping continuum is that "records are both current and historical from the time of their creation" (McKemmish, 1997, pp. A dimensional reading of the continuum, Para 2). Digital materials will not survive through "benign neglect" and instead require active management from the time of their creation (Deegan \& Sutherland, 2009, p. 155). There is evidence, however, that digital materials of local and regional significance may not be appropriately cared for from the point of their creation, that is, while they are operating in the other three dimensions of the records continuum, and by the time they reach cultural heritage institutions, if they do, it may be too late.

Contributing to the apparent distance from the point of creation seems to be both the perception of creators and potential depositors of materials, and the 
collecting approach and perceptions of institutions themselves. On the side of collecting repositories, the primarily reactive, passive collecting approach noted earlier may not be suitable for digital materials. Adding to this, some respondents seemed to perceive collecting and managing born digital materials as an activity for the future rather than the present. In addition, some respondents also indicated a reactive approach to planning and preparation for dealing with digital materials. This could result in institutions being ill-prepared to deal with digital materials when they receive them.

On the side of creators, some respondents noted the tendency of donors to deposit "old" material in an archive or museum: "as a history museum, we are still tending to receive only pre-digital material from donors, other than digital images of original photos". A library respondent, made a similar observation: "it's actually quite hard to get people to think of contemporary photographs or even photos taken ten, fifteen, twenty years ago as historic or heritage, they don't really start to see the value of them until they really get quite old". There may be a tendency to treat digital materials the same as physical, potentially storing a pile of CDs in a drawer, as with a pile of photographs, and donating them all twenty years down the track as part of an estate. By then, they may be inaccessible.

Indeed, several examples of inaccessible digital materials surfaced in the interviews, particularly floppy discs. One respondent described a situation where there was a donation from someone's estate, and "there were these black floppy discs... there's work on them, that, well, we can't read." There may well be similar stories in other collections. 
Adding to this is apparent discontinuity of the channels of transfer of materials into heritage collections, rather than simply delay. Several respondents described the possibility that people may not even consider donating their digital materials at all. In addition, two interviewees perceived the ease of deletion of digital materials as a problem, particularly in terms of correspondence, because emails are often less formal than letters in hard copy, and are more easily deleted. One museum respondent indicated that they would have expected to be receiving more digital materials from the community, and as noted earlier, other respondents are receiving only small amounts of born digital materials from external creators. Either digital materials are slow to come, or maybe they will not come at all, because surely, at least to an extent, they are being created.

This indicates a need for cultural heritage institutions to work more closely with creators of digital materials to encourage donations, and ensure digital materials are cared for appropriately before donation, as noted frequently in the literature (Blue Ribbon Task Force on Sustainable Digital Preservation and Access, 2010, February; Digital Preservation Coalition, 2008a). However, this cannot happen without addressing the limited expertise and resourcing noted by many respondents. 


\section{Conclusion}

The collection, and preservation, of born digital cultural heritage in this group of collecting repositories seems to be in its early stages. Born digital materials are not held in great quantities, and the level of policy creation around collecting and preserving born digital materials was reasonably low. Even though the majority of respondents hold born digital materials, for the most part, they do not have procedures in place for the preservation of those materials.

The small quantities of born digital materials held does not generally seem to be driven by refusal or reluctance to collect, but rather, that many of these collections acquire their materials in a passive way, through deposit or donation. There is generally a perception that as collection policies are format neutral, selection of digital materials is, and will be, similar to other types, driven by significance and value.

Limited expertise, technological support and infrastructure, staffing and funding are some of the biggest barriers and challenges affecting the born digital collection activities of respondents. While the majority of respondents perceived that the collection, and preservation of born digital materials is part of their collection or institution's role, it is not clear that they will have the resourcing and expertise to do so. There is a clear need for additional resourcing and expertise to support these institutions, including through contact, and possibly cooperation, with better-equipped institutions that are situated further up the Data Pyramid. 
One of the biggest threats to local digital heritage appears to be the distance of these collecting archives from the point of creation of digital materials, combined with a traditionally reactive approach to collection. There is a need for earlier intervention on the part of institutions, or community awareness-raising on digital preservation, to ensure that digital materials do, in fact, make it into the cultural heritage institutions that can care for them in the long term. This more proactive approach, however, also requires resources that are in short supply.

As one respondent put it:

"As we move into a more digital environment we will have to begin collection of born digital material relating to our local people and our local heritage. Even though at the moment we don't have the time or resources, we still need to include this within our long term plans."

Resolving this dilemma will be the key to ensuring the long-term access to New Zealand's local digital heritage. 


\section{Implications for further research}

Because interviews were only conducted with a small number of respondents, and answers to open survey questions were limited, there is a need to further explore the nature of born digital collections, particularly in terms of volume, media types received, and the presence of inaccessible digital materials or materials at risk. Further qualitative research on the genres rather than formats of born digital materials is also needed, particularly for those materials created externally.

It was not possible to explore differences between institution types in this study because of the small sample size, and the ability of respondents to choose more than one institution type. Other studies have observed differences between institution types, so it would be useful to conduct a study with a larger sample size to determine whether there are similar differences in New Zealand. For instance, Gregory (2009, April) observed that archives were more likely to be archiving born digital materials than libraries. A larger sample would also be useful to explore whether the apparent correlations between variables are significant, for instance further exploring comparisons between those holding and not holding born digital materials.

It would also be worth further exploring perceptions around the meaning of "digital heritage", particularly in the case of museums, as it seems that these perceptions may be a barrier to working with digital materials in some cases. 
Because of the high proportion of respondents who did not currently have any procedures for the preservation of their born digital materials, it would be worth exploring the broader organizational context of these institutions, to explore the extent of this apparent lack of digital preservation readiness. 


\section{References}

Abid, A. (2007). Safeguarding our digital heritage: A new preservation paradigm. In Y. de Lusenet \& V. Wintermans (Eds.), Preserving the digital heritage: Principles and policies (pp. 7-14). Retrieved from http://www.knaw.nl/ecpa/publ/pdf/2735.pdf.

Alreck, P. L., \& Settle, R. B. (2004). The survey research handbook (3rd ed.). New York, NY: McGraw-Hill.

Archives New Zealand. (2009). The community archive: Contributors. Retrieved February 2, 2010, from http://thecommunityarchive.org.nz/explore_collections/contributor Association of Research Libraries. (2009). Special collections in ARL libraries: A discussion report from the ARL working group on special collections. Retrieved 30 December, 2009, from http://www.arl.org/bm doc/scwgreport.pdf

Ayre, C., \& Muir, A. (2004, March). The right to preserve: Rights issues of digital preservation. D-Lib Magazine, 10(3). Retrieved March 19, 2010, from http://www.dlib.org/dlib/march04/ayre/03ayre.html

Berman, F. (2008). Got data? A guide to data preservation in the information age. Communications of the ACM, 51(12), 50-56. doi:

$10.1145 / 1409360.1409376$

Bettington, J., Eberhard, K., \& Loo, R. (2008). What are archives \& archival programs? In J. Bettington, K. Eberhard, R. Loo \& C. Smith (Eds.), Keeping archives (3rd ed., pp. 11-28). Canberra: Austrailan Society of Archivists.

Blaikie, N. (2003). Analyzing quantitative data. London: Sage Publications. 
Blue Ribbon Task Force on Sustainable Digital Preservation and Access. (2010, February). Sustainable economics for a digital planet: Ensuring long-term access to digital information. Retrieved March 10, 2010, from http://brtf.sdsc.edu/biblio/BRTF_Final_Report.pdf

Boyle, F., Eveleigh, A., \& Needham, H. (2008). Report on the survey regarding digital preservation in local authority archive services. Retrieved December 2, 2009, from http://www.dpconline.org/docs/reports/digpressurvey08.pdf

Boyle, F., Eveleigh, A., \& Needham, H. (2009). Preserving local archival heritage for ongoing accessibility. Ariadne, 58(January). Retrieved January 22, 2010, from http://www.ariadne.ac.uk/issue58/boyle-et-al

Bryman, A. (2008). Social research methods (3rd ed.). New York, NY: Oxford University Press.

Burrows, T. (2000). Preserving the past, conceptualising the future: Research libraries and digital preservation. Australian Academic and Research Libraries, 31(4), 142-153. Retrieved from Academic OneFile database.

Carnaby, P. (2009, March 4). The delete generation: Citizen-created content, digital equity and the preservation of community memory. Retrieved March 10, 2010, from http://www.natlib.govt.nz/downloads/DeleteGeneration-Penny-Carnaby.DOC

Clareson, T. (2006, February 15). NEDCC survey and colloquium explore digitization and digital preservation policies and practices. RLG DigiNews, 10(1). Retrieved January 22, 2010, from http://www.worldcat.org/arcviewer/1/OCC/2007/08/08/0000070511/ viewer/file1629.html 
Cloonan, M. V., \& Sanett, S. (2002). Preservation strategies for electronic records: Where we are now - obliquity and squint? American Archivist, 65(Spring/Summer), 70-106.

Corbin, J., \& Strauss, A. (2008). Basics of qualitative research: Techniques and procedures for developing grounded theory (3rd ed.). Thousand Oaks: Sage Publications.

Creswell, J. W. (2007). Qualitative inquiry and research design: Choosing among five approaches. Thousand Oaks: Sage Publications.

Creswell, J. W. (2009). Research design: Qualitative, quantitative, and mixed methods approaches (3rd ed.). Thousand Oaks: Sage Publications.

Creswell, J. W., \& Plano Clark, V. L. (2007). Designing and conducting mixed methods research. Thousand Oaks: Sage Publications.

Crook, E. (2009). Web archiving in a Web 2.0 world. The Electronic Library, 27(5), 831-836. doi: 10.1108/02640470910998542

Crush, P. J. (2008). Acquisition. In J. Bettington, K. Eberhard, R. Loo \& C. Smith (Eds.), Keeping archives (3rd ed., pp. 205-224). Canberra: Austrailan Society of Archivists.

Davis, S. E. (2008). Electronic records planning in "collecting" repositories. American Archivist, 71(Spring/Summer), 167-189.

Deegan, M., \& Sutherland, K. (2009). Durable futures. In M. Deegan \& K. Sutherland (Eds.), Transferred illusions: Digital technology and the forms of print (pp. 155-181). Farnham, Surrey: Ashgate Publishing Lmited.

Deegan, M., \& Tanner, S. (2006). Key issues in digital preservation Digital Preservation and the future of culture (pp. 1-31). London: Facet. 
Digital Preservation Coalition. (2008a). Preservation management of digital materials: The handbook. Retrieved January 2, 2010, from http://www.dpconline.org/advice/digital-preservation-handbook.html Digital Preservation Coalition. (2008b). Interactive assessment: Selection of digital materials for long-term retention.

Dooley, J. (2009). Ten commandments for special collections librarians in the digital age. RBM: A journal of rare books, manuscripts, and cultural heritage, 10(1), 51-59. Retrieved from

Dorner, D. G., Chawner, B., \& Searle, S. (2002). Creating a digital babylon?: Results of a survey of digitisation activities in New Zealand. Wellington, N.Z.: National Library of New Zealand.

Dorner, D. G., Liew, C. L., \& Crookston, M. (2006, June). Public sector readiness for digital preservation. Retrieved December 31, 2009, from http://www.natlib.govt.nz/downloads/Public-sector-readiness-fordigital-preservation_.pdf

Duff, W., Carter, J., Dallas, C., Howarth, L., Ross, S., Sheffield, R., et al. (2009). The changing museum environment in North America and the impact of technology on museum work. Paper presented at the Cultural Heritage on line: Empowering users: an active role for user communities. from http://www.rinascimentodigitale.it/eventi/conference2009/proceedings-2009/duff.pdf

Feather, J. (2006). Managing the documentary heritage: Issues for the present and future. In G. E. Gorman \& S. J. Shep (Eds.), Preservation management for libraries, archives and museums (pp. 1-18). London: Facet Publishing. 
Forde, H. (2006). Access and the social contract in memory institutions. In G. E. Gorman \& S. J. Shep (Eds.), Preservation management for libraries, archives and museums (pp. 166-181). London: Facet Publishing.

Galloway, P. (2005). Preservation of digital objects. Annual Review of Information Science and Technology, 38(1), 549-590. Retrieved from Wiley Interscience Journals database.

Gorman, G. E., \& Clayton, P. (2005). Qualitative research for the information professional (2nd ed.). London: Facet Publishing.

Gow, V. F. (2003). Re-collecting cultural heritage: Selection for digitisation from special collections in New Zealand libraries. Unpublished MLIS research project, Victoria University of Wellington, Wellington, New Zealand.

Gregory, L. A. (2009, April). The practice and perception of web archiving in academic libraries and archives. Master of Science in Library Science, University of North Carolina at Chapel Hill. Retrieved from http://ils.unc.edu/MSpapers/3480.pdf

Harvey, D. R. (2005). Preserving digital materials. München: K.G. Saur.

Hedstrom, M., \& Montgomery, S. (1998, December). Digital preservation needs and requirements in RLG member institutions. Retrieved March 10, 2010, from http://www.oclc.org/research/activities/past/rlg/digpresneeds/digpres. pdf

Higgins, S. (2008). The DCC curation lifecycle model. The International Journal of Digital Curation, 3(1), 134-140. Retrieved February 26, 2010, from http://www.ijdc.net/index.php/ijdc/article/view/69/48 
Hilton, C., \& Thompson, D. (2007a). Collecting born digital archives at the Wellcome Library. Ariadne, 50. Retrieved February 16, 2010, from http://www.ariadne.ac.uk/issue50/hilton-thompson/

Hilton, C., \& Thompson, D. (2007b). Further experiences in collecting born digital archives at the Wellcome Library. Ariadne, 53(October). Retrieved February 16, 2010, from http://www.ariadne.ac.uk/issue53/hiltonthompson/

Jacobsen, G. (2008). Web archiving: Issues and problems in collection building and access. Liber Quarterly, 18(3/4), 366-376. Retrieved August 14, 2009, from http://liber.library.uu.nl/

Jimerson, R. C. (2003). Deciding what to collect. OCLC Systems \& Services, 19(2), 54-57. doi: 10.1108/10650750310481766

Kenney, A. R. (2005, August 15). Developing digital preservation programs: The Cornell survey of institutional readiness, 2003-2005. RLG DigiNews, 9(4). Retrieved March 3, 2010, from http://www.worldcat.org/arcviewer/1/OCC/2007/08/08/0000070511/ viewer/file2165.html

King, S. M. (2009, June 8). What impact does Web 2.0 have on definitions of authoritative sources in web archive collection policy? A case study of archiving of web election material at the National Library of New Zealand. Unpublished MLIS research project, Victoria University of Wellington, Wellington, New Zealand.

Lavoie, B., \& Dempsey, L. (2004). Thirteen ways of looking at...digital preservation. D-Lib Magazine, 10(7/8). doi: 10.1045/july2004-lavoie 
Lavoie, B. F. (2006). The costs of digital preservation. In M. Deegan \& S. Tanner (Eds.), Digital Preservation and the future of culture (pp. 107-132). London: Facet.

Library and Information Association of New Zealand Aotearoa (LIANZA). (2009). Public Library Statistics 2008/09. Retrieved February 2, 2010, from http://www.lianza.org.nz/community/pub-sig/files/20082009_Public_Library_Statistics.xls

Lilleniit, R. (2007). Archiving the canadian web: Experiences at Library and Archives Canada. The Serials Librarian, 53(1), 139-149. doi: 10.1300/J123v53n01_11

Lin, C.-S., \& Eschenfelder, K. R. (2008). Selection practices for Web-based government publications in state depository library programs: Comparing active and passive approaches. Government Information Quarterly, 25(1), 5-24. doi: 10.1016/j.giq.2007.01.005

Lynch, C. A. (2003). The coming crisis in preserving our digital cultural heritage. Journal of Library Administration, 38(3), 149-? doi: 10.1300/J111v38n03_04

Mackenzie Owen, J. (2007). Preserving the digital heritage: Roles and responsibilities for heritage repositories. In Y. de Lusenet \& V. Wintermans (Eds.), Preserving the digital heritage: Principles and policies (pp. 45-49). Retrieved from http://www.knaw.nl/ecpa/publ/pdf/2735.pdf.

Marshall, C., \& Rossman, G. B. (2006). Designing qualitative research. Thousand Oaks: Sage Publications. 
Martin, K. E., \& Eubank, K. (2007). The North Carolina State Government Website Archives: A case study of an American government Web archiving project. New Review of Hypermedia and Multimedia, 13(1), 7-26. doi:

$10.1080 / 13614560701423638$

McKemmish, S. (1997). Yesterday, today \& tomorrow: A continuum of responsibility. Retrieved 27 March, 2009, from http://www.infotech.monash.edu.au/research/groups/rcrg/publications /recordscontinuum-smckp2.html

McKnight, P. E., McKnight, K. M., Sidani, S., \& Figueredo, A. J. (2007). Missing data: A gentle introduction. New York, NY: The Guilford Press.

Meyer, L. (2009). Safeguarding collections at the dawn of the 21st century: Describing roles and measuring contemporary preservation activities in ARL libraries. Retrieved 2 December, 2009, from http://www.arl.org/bm doc/safeguarding-collections.pdf

Miles, M. B., \& Huberman, A. M. (1994). Qualitative data analysis: An expanded sourcebook (2nd ed.). Thousand Oaks: Sage Publications.

Morse, J. M. (2003). Principles of mixed methods and multimethod research design. In A. Tashakkori \& C. Teddlie (Eds.), Handbook of mixed methods in social and behavioral research (pp. 189-207). Thousand Oaks: Sage Publications.

National Information Standards Organization. (2007, December). A framework of guidance for building good digital collections. 3rd. Retrieved March 11, 2010, from http://www.niso.org/publications/rp/framework3.pdf 
National Library of Australia. (2003). Guidelines for the preservation of digital heritage. Retrieved from http://unesdoc.unesco.org/images/0013/001300/130071e.pdf

National Library of New Zealand. (2006, June). A report on New Zealand's documentary heritage: Preservation and access. Unpublished report. National Library of New Zealand.

Niglas, K. (2007). Media review: Microsoft office excel spreadsheet software. Journal of Mixed Methods Research, 1, 297-299. doi: $10.1177 / 1558689807301250$

OCLC/RLG PREMIS Working Group. (2004, September). Implementing preservation repositories for digital materials: Current practice and emerging trends in the cultural heritage community. Retrieved December 2, 2009, from http://www.oclc.org/research/projects/pmwg/surveyreport.pdf

Patton, M. Q. (2002). Qualitative research and evaluation methods. Thousand Oaks: Sage Publications.

Phillips, M. E. (2005). What should we preserve? The question for heritage libraries in a digital world. Library Trends, 54(1), 57-71. Retrieved from ProQuest database.

Prochaska, A. (2009). Digital special collections: The big picture. RBM: A journal of rare books, manuscripts, and cultural heritage, 10(1), 13-24. Retrieved from

Pymm, B. (2006). Building collections for all time: The issue of significance. $A A R L, 37(1), 61-73$. Retrieved from Academic OneFile database. 
Pymm, B., \& Lloyd, A. (2007). Dealing with digital collections: Interviews with the national library and selected state libraries of Australia. Australian Academic and Research Libraries, 38(3), 167-179. Retrieved March 12, 2010, from Academic OneFile database.

Reed, B. (2006). Challenges of managing the digitally born artefact. In G. E. Gorman \& S. J. Shep (Eds.), Preservation management for libraries, archives and museums (pp. 117-132). London: Facet Publishing.

Reynolds, K. L. M. (2006). The digital initiative in archives: A study on the selection of archives for digitisation in New Zealand. Unpublished MLIS research project, Victoria University of Wellington, Wellington, New Zealand.

Rhodes, S., \& Neacsu, D. (2009). Preserving and ensuring long-term access to digitally born legal information. Information \& Communications Technology Law, 18(1), 39-74. doi: 10.1080/13600830902727905

Rodes, J.-M., Piejut, G., \& Plas, E. (2003). Memory of the information society. I. Vinson \& A. Abid (Eds.), Retrieved from http://portal.unesco.org/ci/en/files/12531/10942043935memory_en.p df/memory_en.pdf

Rusbridge, C. (2006, February). Excuse me.... Some digital preservation fallacies? Ariadne, 46. Retrieved March 19, 2010, from http://www.ariadne.ac.uk/issue46/rusbridge

Schutt, R. K. (2006). Investigating the social world: The process and practice of research (5th ed.). Thousand Oaks: Sage Publications.

Sierman, B. (2009, April). The jigsaw puzzle of digital preservation - an overview. Liber Quarterly, 19(1), 13-21. Retrieved December 2, 2009, from http://liber.library.uu.nl/publish/articles/000262/article.pdf 
Simpson, D. (2005). Digital preservation in the regions. Retrieved December 31, 2009 , from http://www.mla.gov.uk/what/publications/ /media/Files/pdf/2005/di gital_preservation_in_regions.ashx

Sinclair, P., Billenness, C., Duckworth, J., Farquahar, A., Humphreys, J., Jardine, L., et al. (2009). Are you ready? Assessing whether organisations are prepared for digital preservation. Paper presented at the iPres 2009, 5-6 October 2009, San Francisco, California. Retrieved March 12, 2010, from http://planetsproject.eu/docs/papers/Sharpe_AreYouReady_iPres2009.pdf

Smith, A. (2007). Valuing preservation. Library Trends, 56(1), 4-25. Retrieved from ProQuest database.

Spence, J. (2005). Small organisations and cultural institutions - a digital future? Program: electronic library and information systems, 39(4), 366-380. doi: $10.1108 / 00330330510627980$

Taylor, R. (2004). MINERVA: Archiving born-digital material at the Library of Congress. Slavic \& East European Information Resources, 5(1), 157-162. doi: $10.1300 / J 167 v 05 n 01 \_16$

Teddlie, C., \& Tashakkori, A. (2009). Foundations of mixed methods research. Thousand Oaks: Sage Publications.

The Library of Congress National Digital Information Infrastructure and Preservation Program, The Joint Information Systems Committee, The Open Access to Knowledge (OAK) Law Project, \& The SURFfoundation. (2008, July). International study on the impact of copyright law on digital preservation. Retrieved December 2, 2009, from 
http://www.digitalpreservation.gov/partners/resources/pubs/digital_pr eservation_final_report2008.pdf

Thompson, S. M. (2008). An evaluation of the preservation strategies used by New Zealand libraries for natively digital objects of heritage value. Unpublished MLIS research project, Victoria University of Wellington, Wellington, New Zealand.

Tredinnick, L. (2006). Digital information contexts: Theoretical approaches to understanding digital information. Oxford: Chandos Publishing.

UNESCO. (2003a). Charter on the preservation of the digital heritage. Retrieved March 10, 2010, from http://portal.unesco.org/ci/en/files/13367/10700115911Charter_en.pd f/Charter_en.pdf

UNESCO. (2003b). Guidelines for the preservation of digital heritage. Retrieved from http://unesdoc.unesco.org/images/0013/001300/130071e.pdf

Upward, F. (2000). Modelling the continuum as paradigm shift in recordkeeping and archiving process, and beyond - a personal reflection. Records Management Journal, 10(3), 115-139.

Vaughan, L. (2001). Statistical methods for the information professional: A practical, painless approach to understanding, using, and interpreting statistics. Medford: Information Today.

Victoria University of Wellington Research Policy Group. (2007, July 13). Human ethics policy. Retrieved February 20, 2010, from http://www.sim.vuw.ac.nz/research/hec/documents/VUW-HEPolicy.pdf 
Waller, M., \& Sharpe, R. (2006). Mind the gap: Assessing digital preservation needs in the UK. Retrieved December 2, 2009, from http://www.dpconline.org/docs/reports/uknamindthegap.pdf

\section{Bibliography}

Caplan, P. (2008). Digital defense: A primer for the preservation of digital materials. American Libraries, 39(5), 38-38. Retrieved from Academic Search Premier database.

Fink, A. (2006). How to conduct surveys: A step-by-step guide (3rd ed.). Thousand Oaks: Sage Publications.

Greene, J. C. (2007). Mixed methods in social enquiry. San Francisco: Jossey-Bass. Laise. (2007). The heritage health index findings on digital collections. First Monday, 12(7). Retrieved January 22, 2010, from http://firstmonday.org/htbin/cgiwrap/bin/ojs/index.php/fm/article/vie $\mathrm{w} / 1920 / 1802$

National library of New Zealand. (2004, June 30). National Library of New Zealand Collections Policy. Retrieved March 11, 2010, from http://www.natlib.govt.nz/downloads/Collections_Policy.doc

Word count: 16,035 
13 Appendix 1: Berman's Data Pyramid

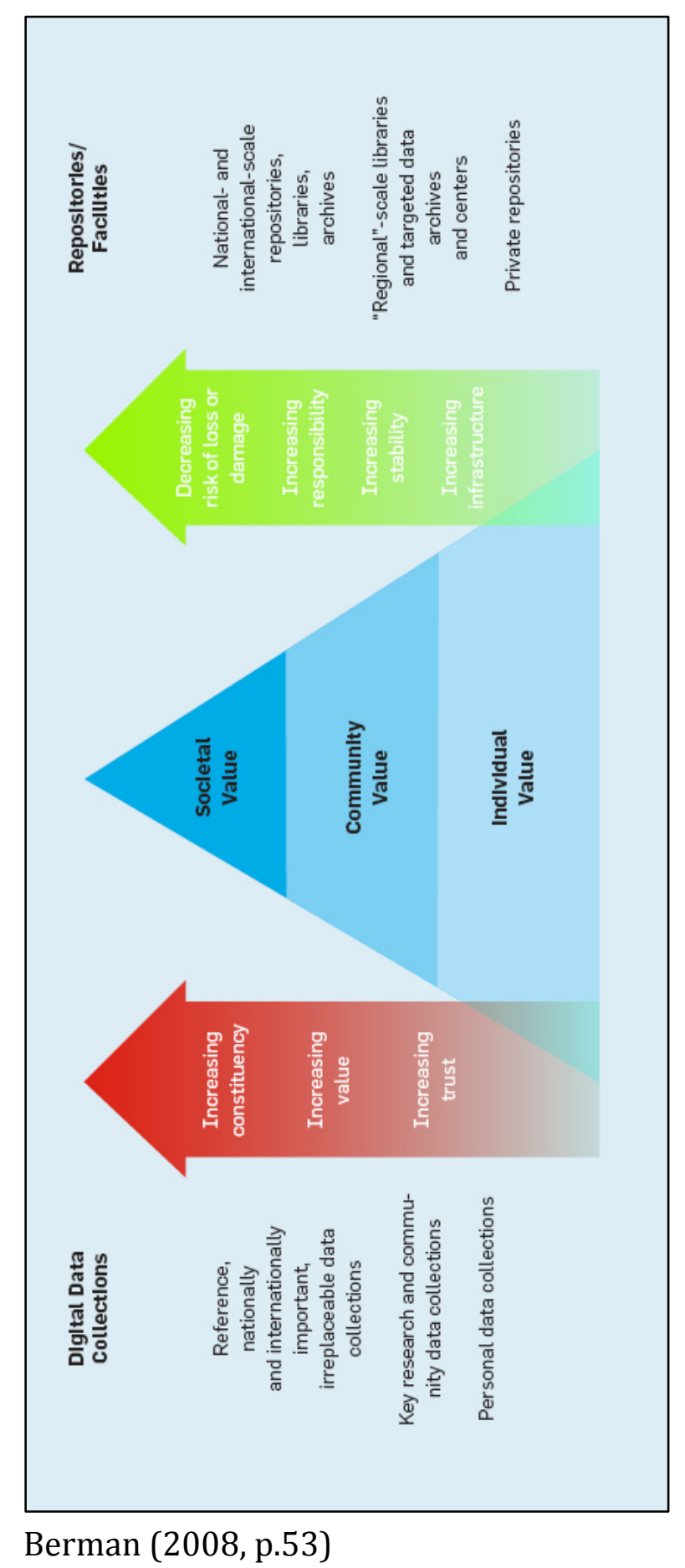


Appendix 2: The Records Continuum

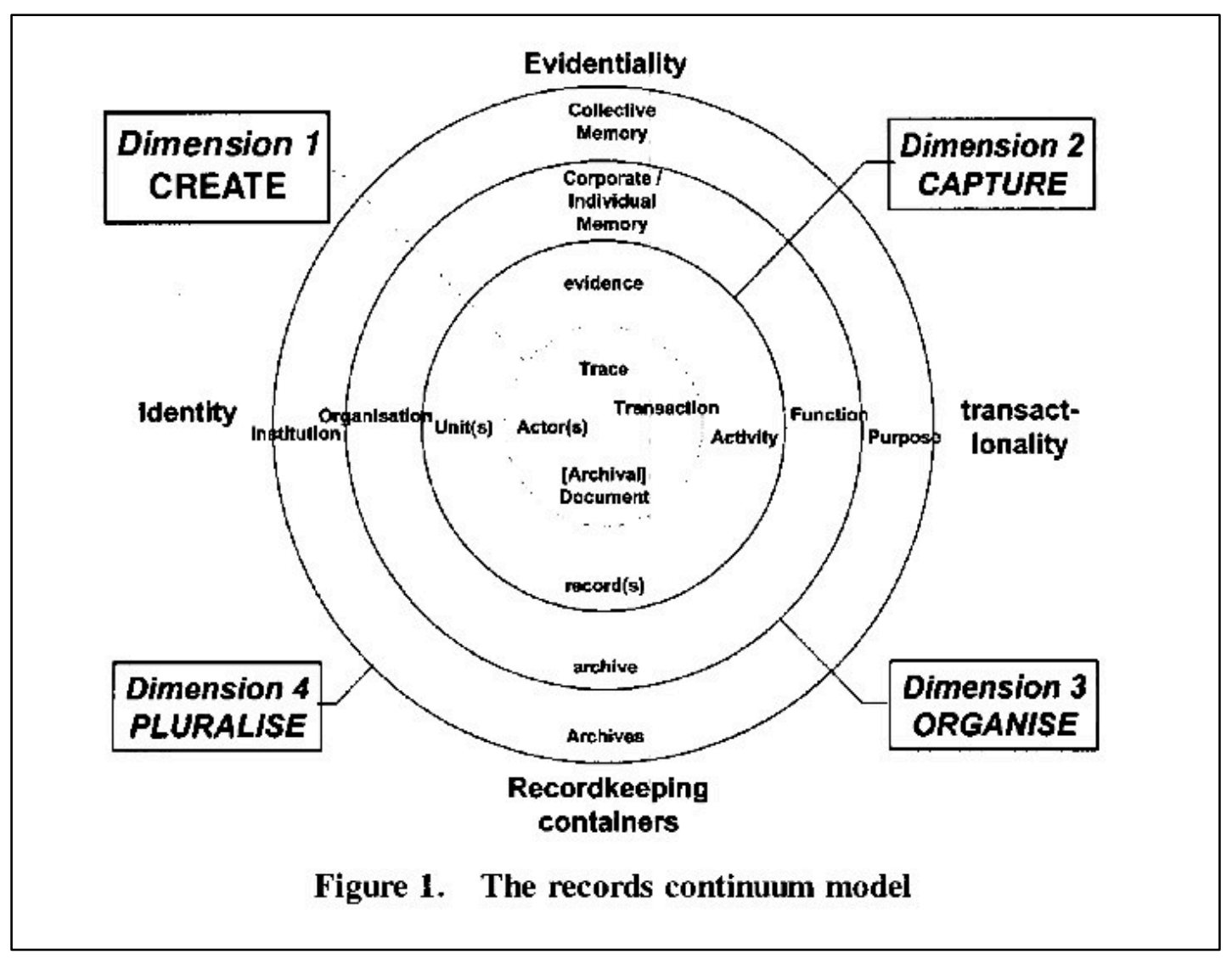

Upward (2000, p.123) 


\section{Appendix 3: Data Tables}

Table 1: Respondents selecting only one institution/collection type

\begin{tabular}{|c|c|c|c|}
\hline $\begin{array}{r}\text { Institution/Collection } \\
\text { Category }\end{array}$ & $\begin{array}{l}\text { Selected category } \\
\text { as only choice (n) }\end{array}$ & $\begin{array}{r}\text { Category } \\
\text { total (n) }\end{array}$ & $\begin{array}{r}\text { \% Selecting that } \\
\text { category as only } \\
\text { choice }\end{array}$ \\
\hline Archive & 2 & 14 & $14.29 \%$ \\
\hline Level 1 public library & $3 *$ & 8 & $37.50 \%$ \\
\hline Level 2 public library & 6 & 6 & $100.00 \%$ \\
\hline Level 3 public library & 1 & 2 & $50.00 \%$ \\
\hline Academic library & 4 & 7 & $57.14 \%$ \\
\hline Research library & 0 & 8 & $0.00 \%$ \\
\hline Museum & 3 & 10 & $30.00 \%$ \\
\hline Art gallery & 0 & 4 & $0.00 \%$ \\
\hline Other & 0 & 2 & $0.00 \%$ \\
\hline Total & 19 & 36 & $52.78 \%$ \\
\hline
\end{tabular}

*Made it 3, because, one of the multiple choices includes "other" and is just a note to say unsure whether level 1 or 3 , so treated as a single choice 
Table 2: Types of born digital materials held $(n=27)$

\begin{tabular}{|c|c|c|c|c|}
\hline Type of born digital material & $\begin{array}{l}\text { Total } \\
\text { holding } \\
\text { type }(n)\end{array}$ & $\begin{array}{r}\% \text { of } \\
\text { those } \\
\text { holding } \\
\text { born } \\
\text { digital } \\
\text { holding } \\
\text { type }\end{array}$ & $\begin{array}{r}\text { Holding } \\
\text { that type } \\
\text { as one of } \\
\text { top three } \\
\text { greatest } \\
\text { quantities } \\
\text { of born } \\
\text { digital (n) }\end{array}$ & $\begin{array}{r}\% \text { holding } \\
\text { as one of } \\
\text { top three } \\
\text { greatest } \\
\text { quantities } \\
\text { of born } \\
\text { digital }\end{array}$ \\
\hline $\begin{array}{r}\text { Digital photographs/raster } \\
\text { graphics }\end{array}$ & 22 & $81 \%$ & 19 & $70 \%$ \\
\hline Documents & 17 & $63 \%$ & 15 & $56 \%$ \\
\hline Digital audio & 13 & $48 \%$ & 8 & $30 \%$ \\
\hline Databases/datasets & 13 & $48 \%$ & 10 & $37 \%$ \\
\hline Email & 8 & $30 \%$ & 5 & $19 \%$ \\
\hline Digital moving images & 5 & $22 \%$ & 1 & $4 \%$ \\
\hline Presentations & 3 & $19 \%$ & 1 & $4 \%$ \\
\hline Spreadsheets & 6 & $19 \%$ & 2 & $7 \%$ \\
\hline Archived/harvested websites & 5 & $11 \%$ & 2 & $7 \%$ \\
\hline Other & 1 & $4 \%$ & 1 & $4 \%$ \\
\hline GIS files & 1 & $4 \%$ & 1 & $4 \%$ \\
\hline Digital vector graphics & 0 & $0 \%$ & 0 & $0 \%$ \\
\hline
\end{tabular}


Table 3: Number of types of born digital materials held

\begin{tabular}{|r|r|r|r|r|r|}
\cline { 2 - 6 } \multicolumn{1}{l|}{} & Median & Mode & Max & Min & Mean \\
\hline $\begin{array}{r}\text { All respondents holding born } \\
\text { digital }(n=27)\end{array}$ & 3 & 1 & 8 & 1 & 3.48 \\
\hline
\end{tabular}

Table 4: Importance of selection factors (excluding “don't know" responses)

\section{Selection factors: Key}

A. Fit with the collection policy or mandate

B. Perceived long term value

C. Whether there is an intention of long term retention/preservation

D. Level of institutional responsibility for collection/preservation of the materials

E. Technological aspects (e.g. file format) and the related feasibility of acquisition and preservation

F. Ease of gaining/negotiating legal rights to acquire/preserve

G. Availability of sufficient documentation (including metadata)

\begin{tabular}{|c|c|c|c|c|c|c|c|}
\hline 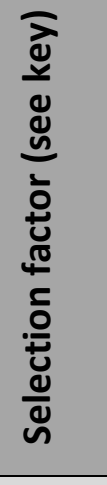 & 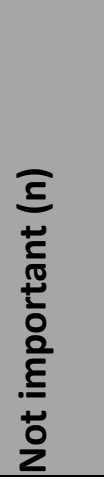 & 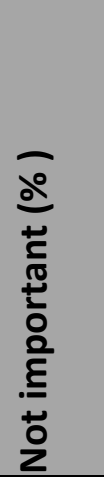 & 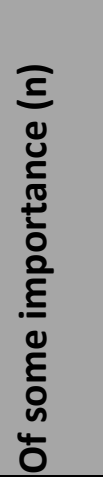 & 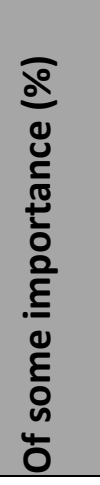 & 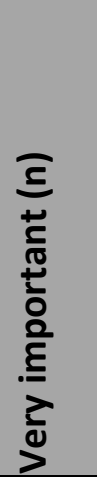 & 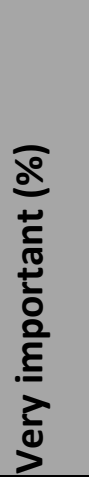 & 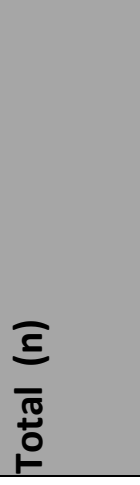 \\
\hline A & 1 & $4 \%$ & 3 & $11 \%$ & 23 & $85 \%$ & 27 \\
\hline B & 0 & $0 \%$ & 4 & $15 \%$ & 22 & $85 \%$ & 26 \\
\hline C & 0 & $0 \%$ & 5 & $21 \%$ & 19 & $79 \%$ & 24 \\
\hline D & 0 & $0 \%$ & 11 & $50 \%$ & 11 & $50 \%$ & 22 \\
\hline
\end{tabular}




\begin{tabular}{|r|r|r|r|r|r|r|r|}
\hline E & 1 & $4 \%$ & 12 & $50 \%$ & 11 & $46 \%$ & $\mathbf{2 4}$ \\
\hline F & 6 & $26 \%$ & 9 & $39 \%$ & 8 & $35 \%$ & $\mathbf{2 3}$ \\
\hline G & 3 & $13 \%$ & 15 & $63 \%$ & 6 & $25 \%$ & $\mathbf{2 4}$ \\
\hline
\end{tabular}

Table 5: Selection factors: "don't know" responses

\begin{tabular}{|c|c|c|c|}
\hline Selection factor & 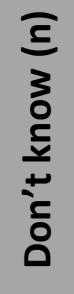 & 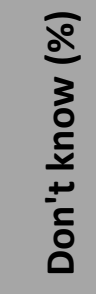 & 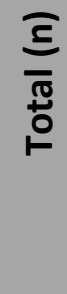 \\
\hline $\begin{array}{l}\text { Level of institutional responsibility for } \\
\text { collection/preservation of the materials }\end{array}$ & 4 & $15 \%$ & 26 \\
\hline $\begin{array}{r}\text { Ease of gaining/negotiating legal rights to } \\
\text { acquire/preserve }\end{array}$ & 4 & $15 \%$ & 27 \\
\hline $\begin{array}{r}\text { Whether there is an intention of long term } \\
\text { retention/preservation }\end{array}$ & 3 & $11 \%$ & 27 \\
\hline $\begin{array}{r}\text { Technological aspects (e.g. file format) and the related } \\
\text { feasibility of acquisition and preservation }\end{array}$ & 3 & $11 \%$ & 27 \\
\hline $\begin{array}{r}\text { Availability of sufficient documentation (including } \\
\text { metadata) }\end{array}$ & 3 & $11 \%$ & 27 \\
\hline Perceived long term value & 1 & $4 \%$ & 27 \\
\hline Fit with the collection policy or mandate & 0 & $0 \%$ & 27 \\
\hline
\end{tabular}


Table 6: Factors acting as barriers or challenges to the nature or level of collecting born digital materials: breakdown by those holding/not holding born digital materials

\begin{tabular}{|c|c|c|c|c|c|}
\hline & & $\begin{array}{c}\text { To little or no } \\
\text { extent }\end{array}$ & $\begin{array}{c}\text { To a } \\
\text { moderate } \\
\text { extent }\end{array}$ & $\begin{array}{c}\text { To a } \\
\text { great } \\
\text { extent }\end{array}$ & $\begin{array}{l}\text { Total excl. } \\
\text { don't knows }\end{array}$ \\
\hline \multirow{5}{*}{ 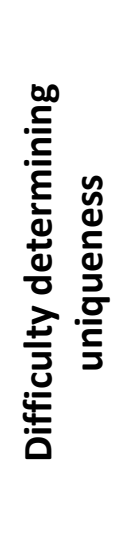 } & None & 4 & 1 & 0 & 5 \\
\hline & None: \% & $80.00 \%$ & $20.00 \%$ & $0.00 \%$ & $100.00 \%$ \\
\hline & BD Held & 18 & 6 & 1 & 25 \\
\hline & BD Held: \% & $72.00 \%$ & $24.00 \%$ & $4.00 \%$ & $100.00 \%$ \\
\hline & All & 22 & 7 & 1 & 30 \\
\hline \multirow{5}{*}{ 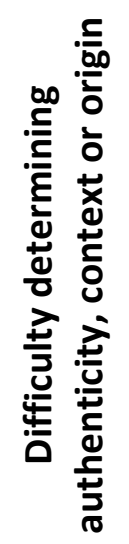 } & None & 2 & 3 & 0 & 5 \\
\hline & None: \% & $40.00 \%$ & $60.00 \%$ & $0.00 \%$ & $100.00 \%$ \\
\hline & BD Held & 16 & 9 & 0 & 25 \\
\hline & BD Held: \% & $64.00 \%$ & $36.00 \%$ & $0.00 \%$ & $100.00 \%$ \\
\hline & All & 18 & 12 & 0 & 30 \\
\hline \multirow{5}{*}{ 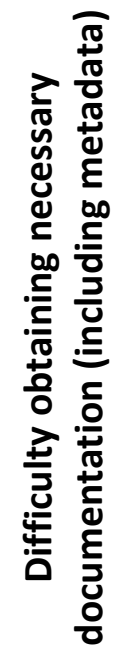 } & None & 3 & 3 & 0 & 6 \\
\hline & None: \% & $50.00 \%$ & $50.00 \%$ & $0.00 \%$ & $100.00 \%$ \\
\hline & BD Held & 14 & 7 & 2 & 23 \\
\hline & BD Held: \% & $60.87 \%$ & $30.43 \%$ & $8.70 \%$ & $100.00 \%$ \\
\hline & All & 17 & 10 & 2 & 29 \\
\hline
\end{tabular}




\begin{tabular}{|c|c|c|c|c|c|}
\hline & & $\begin{array}{c}\text { To little or no } \\
\text { extent }\end{array}$ & $\begin{array}{c}\text { To a } \\
\text { moderate } \\
\text { extent }\end{array}$ & $\begin{array}{c}\text { To a } \\
\text { great } \\
\text { extent }\end{array}$ & $\begin{array}{c}\text { Total excl. } \\
\text { don't knows }\end{array}$ \\
\hline \multirow{6}{*}{ 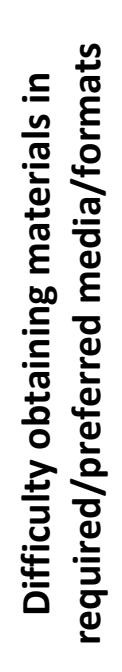 } & None & 4 & 1 & 0 & 5 \\
\hline & None: \% & $80.00 \%$ & $20.00 \%$ & $0.00 \%$ & $100.00 \%$ \\
\hline & BD Held & 12 & 10 & 1 & 23 \\
\hline & BD Held: \% & $52.17 \%$ & $43.48 \%$ & $4.35 \%$ & $100.00 \%$ \\
\hline & All & 16 & 11 & 1 & 28 \\
\hline & All \% & $57.14 \%$ & $39.29 \%$ & $3.57 \%$ & $100.00 \%$ \\
\hline \multirow{6}{*}{ 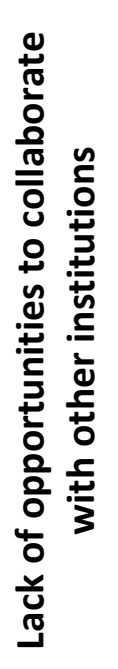 } & None & 4 & 1 & 1 & 6 \\
\hline & None: \% & $66.67 \%$ & $16.67 \%$ & $16.67 \%$ & $100.00 \%$ \\
\hline & BD Held & 11 & 13 & 0 & 24 \\
\hline & BD Held: \% & $45.83 \%$ & $54.17 \%$ & $0.00 \%$ & $100.00 \%$ \\
\hline & All & 15 & 14 & 1 & 30 \\
\hline & All \% & $50.00 \%$ & $46.67 \%$ & $3.33 \%$ & $100.00 \%$ \\
\hline \multirow{6}{*}{ 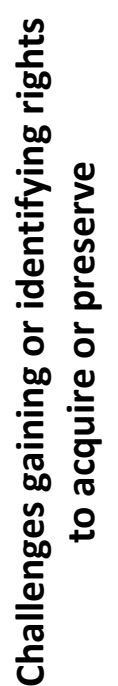 } & None & 2 & 2 & 1 & 5 \\
\hline & None: \% & $40.00 \%$ & $40.00 \%$ & $20.00 \%$ & $100.00 \%$ \\
\hline & BD Held & 11 & 13 & 1 & 25 \\
\hline & BD Held: \% & $44.00 \%$ & $52.00 \%$ & $4.00 \%$ & $100.00 \%$ \\
\hline & All & 13 & 15 & 2 & 30 \\
\hline & All \% & $43.33 \%$ & $50.00 \%$ & $6.67 \%$ & $100.00 \%$ \\
\hline
\end{tabular}




\begin{tabular}{|c|c|c|c|c|c|}
\hline & & $\begin{array}{c}\text { To little or no } \\
\text { extent }\end{array}$ & $\begin{array}{c}\text { To a } \\
\text { moderate } \\
\text { extent }\end{array}$ & $\begin{array}{c}\text { To a } \\
\text { great } \\
\text { extent }\end{array}$ & $\begin{array}{l}\text { Total excl. } \\
\text { don't knows }\end{array}$ \\
\hline \multirow{6}{*}{ 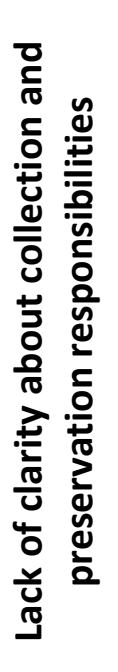 } & None & 2 & 4 & 2 & 8 \\
\hline & None: \% & $25.00 \%$ & $50.00 \%$ & $25.00 \%$ & $100.00 \%$ \\
\hline & BD Held & 12 & 12 & 3 & 27 \\
\hline & BD Held: \% & $44.44 \%$ & $44.44 \%$ & $11.11 \%$ & $100.00 \%$ \\
\hline & All & 14 & 16 & 5 & 35 \\
\hline & All \% & $40.00 \%$ & $45.71 \%$ & $14.29 \%$ & $100.00 \%$ \\
\hline \multirow{6}{*}{ 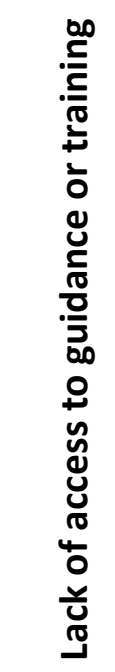 } & None & 1 & 4 & 3 & 8 \\
\hline & None: \% & $12.50 \%$ & $50.00 \%$ & $37.50 \%$ & $100.00 \%$ \\
\hline & BD Held & 7 & 11 & 8 & 26 \\
\hline & BD Held: \% & $26.92 \%$ & $42.31 \%$ & $30.77 \%$ & $100.00 \%$ \\
\hline & All & 8 & 15 & 11 & 34 \\
\hline & All \% & $23.53 \%$ & $44.12 \%$ & $32.35 \%$ & $100.00 \%$ \\
\hline \multirow{6}{*}{ 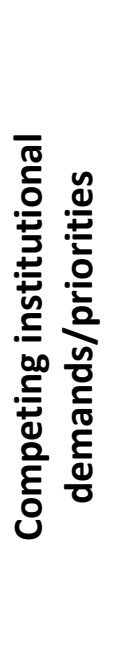 } & None & 1 & 3 & 4 & 8 \\
\hline & None: \% & $12.50 \%$ & $37.50 \%$ & $50.00 \%$ & $100.00 \%$ \\
\hline & BD Held & 5 & 12 & 9 & 26 \\
\hline & BD Held: \% & $19.23 \%$ & $46.15 \%$ & $34.62 \%$ & $100.00 \%$ \\
\hline & All & 6 & 15 & 13 & 34 \\
\hline & All \% & $17.65 \%$ & $44.12 \%$ & $38.24 \%$ & $100.00 \%$ \\
\hline
\end{tabular}




\begin{tabular}{|c|c|c|c|c|c|}
\hline & & $\begin{array}{c}\text { To little or no } \\
\text { extent }\end{array}$ & $\begin{array}{c}\text { To a } \\
\text { moderate } \\
\text { extent }\end{array}$ & $\begin{array}{c}\text { To a } \\
\text { great } \\
\text { extent }\end{array}$ & $\begin{array}{l}\text { Total excl. } \\
\text { don't knows }\end{array}$ \\
\hline \multirow{6}{*}{ 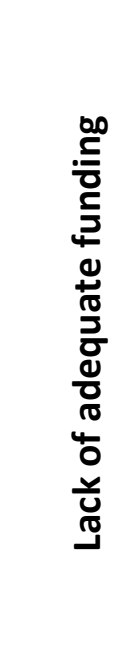 } & None & 1 & 4 & 2 & 7 \\
\hline & None: \% & $14.29 \%$ & $57.14 \%$ & $28.57 \%$ & $100.00 \%$ \\
\hline & BD Held & 8 & 7 & 12 & 27 \\
\hline & BD Held: \% & $29.63 \%$ & $25.93 \%$ & $44.44 \%$ & $100.00 \%$ \\
\hline & All & 9 & 11 & 14 & 34 \\
\hline & All \% & $26.47 \%$ & $32.35 \%$ & $41.18 \%$ & $100.00 \%$ \\
\hline \multirow{6}{*}{ 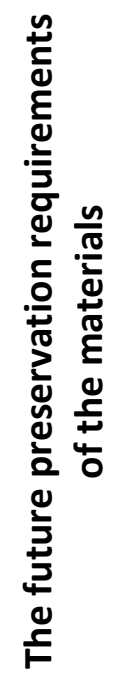 } & None & 0 & 1 & 5 & 6 \\
\hline & None: \% & $0.00 \%$ & $16.67 \%$ & $83.33 \%$ & $100.00 \%$ \\
\hline & BD Held & 7 & 9 & 9 & 25 \\
\hline & BD Held: \% & $28.00 \%$ & $36.00 \%$ & $36.00 \%$ & $100.00 \%$ \\
\hline & All & 7 & 10 & 14 & 31 \\
\hline & All \% & $22.58 \%$ & $32.26 \%$ & $45.16 \%$ & $100.00 \%$ \\
\hline \multirow{6}{*}{ 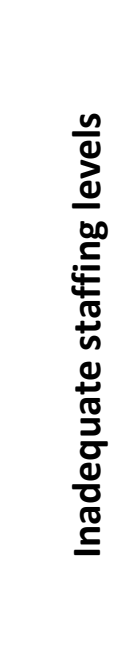 } & None & 1 & 3 & 4 & 8 \\
\hline & None: \% & $12.50 \%$ & $37.50 \%$ & $50.00 \%$ & $100.00 \%$ \\
\hline & BD Held & 7 & 8 & 12 & 27 \\
\hline & BD Held: \% & $25.93 \%$ & $29.63 \%$ & $44.44 \%$ & $100.00 \%$ \\
\hline & All & 8 & 11 & 16 & 35 \\
\hline & All \% & $22.86 \%$ & $31.43 \%$ & $45.71 \%$ & $100.00 \%$ \\
\hline
\end{tabular}




\begin{tabular}{|c|c|c|c|c|c|}
\hline & & $\begin{array}{c}\text { To little or no } \\
\text { extent }\end{array}$ & $\begin{array}{c}\text { To a } \\
\text { moderate } \\
\text { extent }\end{array}$ & $\begin{array}{c}\text { To a } \\
\text { great } \\
\text { extent }\end{array}$ & $\begin{array}{c}\text { Total excl. } \\
\text { don't knows }\end{array}$ \\
\hline \multirow{6}{*}{ 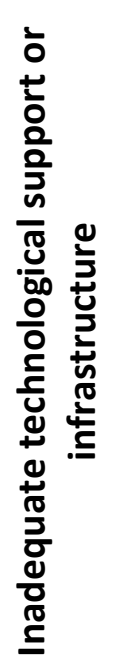 } & None & 0 & 1 & 7 & 8 \\
\hline & None: \% & $0.00 \%$ & $12.50 \%$ & $87.50 \%$ & $100.00 \%$ \\
\hline & BD Held & 6 & 9 & 11 & 26 \\
\hline & BD Held: \% & $23.08 \%$ & $34.62 \%$ & $42.31 \%$ & $100.00 \%$ \\
\hline & All & 6 & 10 & 18 & 34 \\
\hline & All \% & $17.65 \%$ & $29.41 \%$ & $52.94 \%$ & $100.00 \%$ \\
\hline \multirow{6}{*}{ 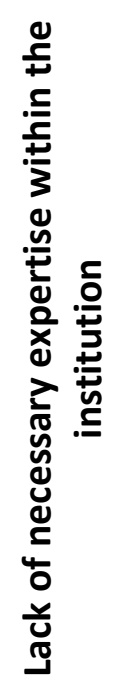 } & None & 1 & 1 & 6 & 8 \\
\hline & None: \% & $12.50 \%$ & $12.50 \%$ & $75.00 \%$ & $100.00 \%$ \\
\hline & BD Held & 7 & 6 & 14 & 27 \\
\hline & BD Held: \% & $25.93 \%$ & $22.22 \%$ & $51.85 \%$ & $100.00 \%$ \\
\hline & All & 8 & 7 & 20 & 35 \\
\hline & All \% & $22.86 \%$ & $20.00 \%$ & $57.14 \%$ & $100.00 \%$ \\
\hline
\end{tabular}


Table 7: Challenges/barriers: don't know answers

\begin{tabular}{|c|c|c|}
\hline & $\begin{array}{r}\text { Don't Know } \\
\text { (n) }\end{array}$ & $\begin{array}{r}\text { Don't Know } \\
(\%)\end{array}$ \\
\hline $\begin{array}{r}\text { Difficulty obtaining materials in required/preferred } \\
\text { media/formats }\end{array}$ & 8 & $22.22 \%$ \\
\hline $\begin{array}{r}\text { Difficulty obtaining necessary documentation } \\
\text { (including metadata) }\end{array}$ & 7 & $19.44 \%$ \\
\hline $\begin{array}{r}\text { Challenges gaining or identifying rights to acquire } \\
\text { or preserve }\end{array}$ & 6 & $16.67 \%$ \\
\hline Difficulty determining uniqueness & 6 & $16.67 \%$ \\
\hline $\begin{array}{r}\text { Lack of opportunities to collaborate with other } \\
\text { institutions }\end{array}$ & 6 & $16.67 \%$ \\
\hline $\begin{array}{r}\text { Difficulty determining authenticity, context or } \\
\text { origin }\end{array}$ & 6 & $16.67 \%$ \\
\hline $\begin{array}{r}\text { The future preservation requirements of the } \\
\text { materials }\end{array}$ & 5 & $13.89 \%$ \\
\hline Inadequate technological support or infrastructure & 2 & $5.56 \%$ \\
\hline Lack of adequate funding & 2 & $5.56 \%$ \\
\hline $\begin{array}{r}\text { Competing institutional demands/priorities, e.g. of } \\
\text { digitisation }\end{array}$ & 2 & $5.56 \%$ \\
\hline Lack of access to guidance or training & 2 & $5.56 \%$ \\
\hline Lack of necessary expertise within the institution & 1 & $2.78 \%$ \\
\hline Inadequate staffing levels & 1 & $2.78 \%$ \\
\hline $\begin{array}{r}\text { Lack of clarity about collection and preservation } \\
\text { responsibilities }\end{array}$ & 1 & $2.78 \%$ \\
\hline
\end{tabular}


Table 8: Enabling/encouraging factors, broken down by those holding/not holding born digital materials (excluding don't know responses)

\begin{tabular}{|c|c|c|c|c|c|}
\hline & & $\begin{array}{l}\text { To little or } \\
\text { no extent }\end{array}$ & $\begin{array}{r}\text { To a } \\
\text { moderate } \\
\text { extent }\end{array}$ & $\begin{array}{r}\text { To a great } \\
\text { extent }\end{array}$ & $\begin{array}{r}\text { Total excl. } \\
\text { don't } \\
\text { knows }\end{array}$ \\
\hline \multirow{6}{*}{$\begin{array}{r}\text { Increased } \\
\text { funding }\end{array}$} & None & 1 & 1 & 6 & 8 \\
\hline & None \% & $12.50 \%$ & $12.50 \%$ & $75.00 \%$ & $100.00 \%$ \\
\hline & BD Held & 6 & 9 & 11 & 26 \\
\hline & BD Held \% & $23.08 \%$ & $34.62 \%$ & $42.31 \%$ & $100.00 \%$ \\
\hline & All & 7 & 10 & 17 & 34 \\
\hline & All \% & $20.59 \%$ & $29.41 \%$ & $50.00 \%$ & $100.00 \%$ \\
\hline \multirow{6}{*}{$\begin{array}{r}\text { Increased } \\
\text { staffing }\end{array}$} & None & 1 & 1 & 7 & \\
\hline & None \% & $11.11 \%$ & $11.11 \%$ & $77.78 \%$ & $100.00 \%$ \\
\hline & BD Held & 5 & 9 & 13 & \\
\hline & BD Held \% & $18.52 \%$ & $33.33 \%$ & $48.15 \%$ & $100.00 \%$ \\
\hline & All & 6 & 10 & 20 & 36 \\
\hline & All \% & $16.67 \%$ & $27.78 \%$ & $55.56 \%$ & $100.00 \%$ \\
\hline \multirow{6}{*}{$\begin{array}{r}\text { Recruitment/culti } \\
\text { vation of staff } \\
\text { with necessary } \\
\text { expertise }\end{array}$} & None & 0 & 2 & 7 & \\
\hline & None \% & $0.00 \%$ & $22.22 \%$ & $77.78 \%$ & $100.00 \%$ \\
\hline & BD Held & 4 & 4 & 19 & \\
\hline & BD Held \% & $14.81 \%$ & $14.81 \%$ & $70.37 \%$ & $100.00 \%$ \\
\hline & All & 4 & 6 & 26 & 36 \\
\hline & All \% & $11.11 \%$ & $16.67 \%$ & $72.22 \%$ & $100.00 \%$ \\
\hline
\end{tabular}




\begin{tabular}{|c|c|c|c|c|c|}
\hline & & $\begin{array}{l}\text { To little or } \\
\text { no extent }\end{array}$ & $\begin{array}{r}\text { To a } \\
\text { moderate } \\
\text { extent }\end{array}$ & $\begin{array}{r}\text { To a great } \\
\text { extent }\end{array}$ & $\begin{array}{r}\text { Total excl. } \\
\text { don't } \\
\text { knows }\end{array}$ \\
\hline \multirow{6}{*}{$\begin{array}{r}\text { Increased access } \\
\text { to guidance or } \\
\text { training }\end{array}$} & None & 1 & 1 & 7 & \\
\hline & None \% & $11.11 \%$ & $11.11 \%$ & $77.78 \%$ & $100.00 \%$ \\
\hline & BD Held & 5 & 12 & 10 & \\
\hline & BD Held \% & $18.52 \%$ & $44.44 \%$ & $37.04 \%$ & $100.00 \%$ \\
\hline & All & 6 & 13 & 17 & 36 \\
\hline & All \% & $16.67 \%$ & $36.11 \%$ & $47.22 \%$ & $100.00 \%$ \\
\hline \multirow{6}{*}{$\begin{array}{r}\text { Improved } \\
\text { technological } \\
\text { support or } \\
\text { infrastructure }\end{array}$} & None & 0 & 2 & 7 & \\
\hline & None \% & $0.00 \%$ & $22.22 \%$ & $77.78 \%$ & $100.00 \%$ \\
\hline & BD Held & 2 & 11 & 14 & \\
\hline & BD Held \% & $7.41 \%$ & $40.74 \%$ & $51.85 \%$ & $100.00 \%$ \\
\hline & All & 2 & 13 & 21 & 36 \\
\hline & All \% & $5.56 \%$ & $36.11 \%$ & $58.33 \%$ & $100.00 \%$ \\
\hline \multirow{6}{*}{$\begin{array}{r}\text { Greater clarity } \\
\text { about } \\
\text { responsibilities } \\
\text { for born digital } \\
\text { collection and } \\
\text { preservation }\end{array}$} & None & 2 & 2 & 5 & \\
\hline & None \% & $22.22 \%$ & $22.22 \%$ & $55.56 \%$ & $100.00 \%$ \\
\hline & BD Held & 5 & 10 & 12 & \\
\hline & BD Held \% & $18.52 \%$ & $37.04 \%$ & $44.44 \%$ & $100.00 \%$ \\
\hline & All & 7 & 12 & 17 & 36 \\
\hline & All \% & $19.44 \%$ & $33.33 \%$ & $47.22 \%$ & $100.00 \%$ \\
\hline
\end{tabular}




\begin{tabular}{|r|r|r|r|r|r|}
\hline & & $\begin{array}{r}\text { To little or } \\
\text { no extent }\end{array}$ & $\begin{array}{r}\text { To a } \\
\text { moderate } \\
\text { extent }\end{array}$ & $\begin{array}{r}\text { To a great } \\
\text { extent }\end{array}$ & $\begin{array}{r}\text { Total excl. } \\
\text { don't } \\
\text { knows }\end{array}$ \\
\hline & None & 3 & 2 & 4 & 9 \\
\cline { 2 - 7 } $\begin{array}{r}\text { Mopportunities to } \\
\text { collaborate with } \\
\text { other institutions }\end{array}$ & BD Held \% & $33.33 \%$ & $22.22 \%$ & $44.44 \%$ & $100.00 \%$ \\
\cline { 2 - 7 } & BD Held \% & $15.38 \%$ & $61.54 \%$ & $23.08 \%$ & $100.00 \%$ \\
\cline { 2 - 7 } & All & 4 & 16 & 6 & 26 \\
\cline { 2 - 7 } & All \% & $20.00 \%$ & $51.43 \%$ & $28.57 \%$ & $100.00 \%$ \\
\hline
\end{tabular}


Table 9: Perception of collection of born digital materials as part of the institution/collection's role: breakdown by born digital held/not held

\begin{tabular}{|c|c|c|c|c|c|c|}
\hline & $\begin{array}{l}\text { Strongly } \\
\text { Disagree }\end{array}$ & Disagree & Neutral & Agree & $\begin{array}{r}\text { Strongly } \\
\text { Agree }\end{array}$ & Total \\
\hline $\begin{array}{r}\text { No born } \\
\text { digital held } \\
\text { (n) }\end{array}$ & 0 & 2 & 4 & 1 & 2 & 9 \\
\hline $\begin{array}{r}\text { No born } \\
\text { digital held } \\
(\%)\end{array}$ & $0.00 \%$ & $22.22 \%$ & $44.44 \%$ & $11.11 \%$ & $22.22 \%$ & $100.00 \%$ \\
\hline $\begin{array}{r}\text { Born digital } \\
\text { held (n) }\end{array}$ & 0 & 1 & 5 & 9 & 12 & 27 \\
\hline $\begin{array}{r}\text { Born digital } \\
\text { held (\%) }\end{array}$ & $0.00 \%$ & $3.70 \%$ & $18.52 \%$ & $33.33 \%$ & $44.44 \%$ & $100.00 \%$ \\
\hline $\begin{array}{r}\text { All } \\
\text { respondents } \\
\text { (n) }\end{array}$ & 0 & 3 & 9 & 10 & 14 & 36 \\
\hline $\begin{array}{r}\text { All } \\
\text { respondents } \\
(\%)\end{array}$ & $0.00 \%$ & $8.33 \%$ & $25.00 \%$ & $27.78 \%$ & $38.89 \%$ & $100.00 \%$ \\
\hline
\end{tabular}


Table 10: Perceptions of the preservation of born digital materials as part of the collection/institution's role: breakdown by those holding/not holding born digital materials

\begin{tabular}{|c|c|c|c|c|c|c|}
\hline & $\begin{array}{l}\text { Strongly } \\
\text { Disagree }\end{array}$ & Disagree & Neutral & Agree & $\begin{array}{r}\text { Strongly } \\
\text { Agree }\end{array}$ & Total \\
\hline $\begin{array}{r}\text { No born } \\
\text { digital held } \\
\text { (n) }\end{array}$ & 0 & 2 & 4 & 1 & 2 & 9 \\
\hline $\begin{array}{r}\text { No born } \\
\text { digital held } \\
(\%)\end{array}$ & $0.00 \%$ & $22.22 \%$ & $44.44 \%$ & $11.11 \%$ & $22.22 \%$ & $100.00 \%$ \\
\hline $\begin{array}{r}\text { Born digital } \\
\text { held }(n)\end{array}$ & 0 & 1 & 4 & 9 & 13 & 27 \\
\hline $\begin{array}{r}\text { Born digital } \\
\text { held (\%) }\end{array}$ & $0.00 \%$ & $3.70 \%$ & $14.81 \%$ & $33.33 \%$ & $48.15 \%$ & $100.00 \%$ \\
\hline $\begin{array}{r}\text { All } \\
\text { respondents } \\
\text { (n) }\end{array}$ & 0 & 3 & 8 & 10 & 15 & 36 \\
\hline $\begin{array}{r}\text { All } \\
\text { respondents } \\
(\%)\end{array}$ & $0.00 \%$ & $8.33 \%$ & $22.22 \%$ & $27.78 \%$ & $41.67 \%$ & $100.00 \%$ \\
\hline
\end{tabular}


Table 11: Presence of a written policy governing the acquisition of born digital materials: breakdown by those holding/not holding born digital materials

\begin{tabular}{|c|c|c|c|c|c|c|c|c|c|}
\hline $\begin{array}{r}\text { Written } \\
\text { policy? }\end{array}$ & 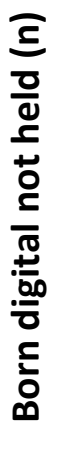 & 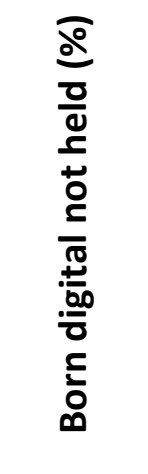 & 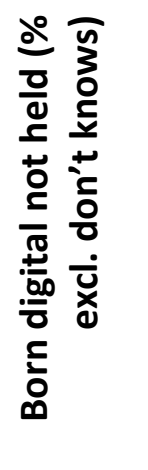 & 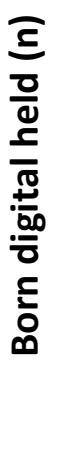 & 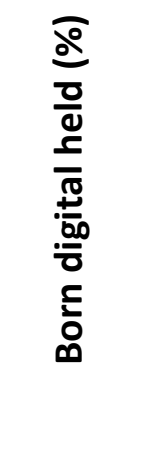 & 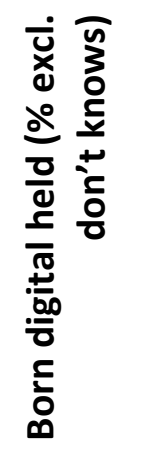 & 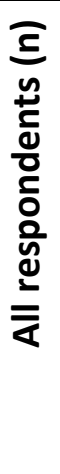 & 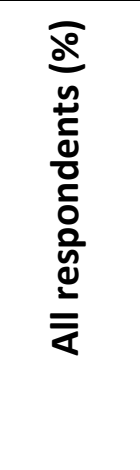 & 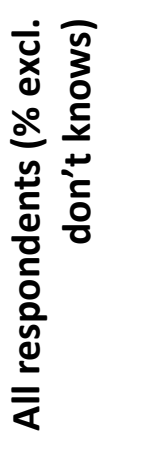 \\
\hline No & 7 & $77.78 \%$ & $87.50 \%$ & 21 & $77.78 \%$ & $77.78 \%$ & 28 & $77.78 \%$ & $80.00 \%$ \\
\hline Yes & 1 & $11.11 \%$ & $12.50 \%$ & 6 & $22.22 \%$ & $22.22 \%$ & 7 & $19.44 \%$ & $20.00 \%$ \\
\hline Don't know & 1 & $11.11 \%$ & & 0 & $0.00 \%$ & & 1 & $2.78 \%$ & \\
\hline Total & 9 & & & 27 & & & 36 & & \\
\hline $\begin{array}{r}\text { Total excl. } \\
\text { don't } \\
\text { knows }\end{array}$ & 8 & & & 27 & & & 35 & & \\
\hline
\end{tabular}


Table 12: Presence of a written policy governing the preservation of born digital materials: broken down by those holding/not holding born digital materials

\begin{tabular}{|c|c|c|c|c|c|c|c|c|c|}
\hline $\begin{array}{r}\text { Written } \\
\text { policy? }\end{array}$ & 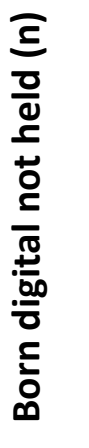 & 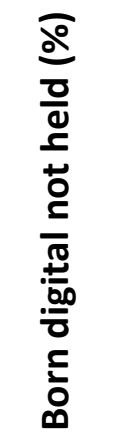 & 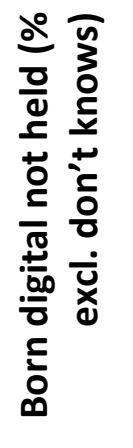 & 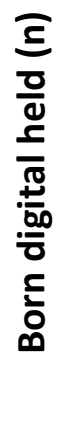 & 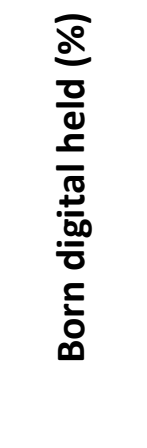 & 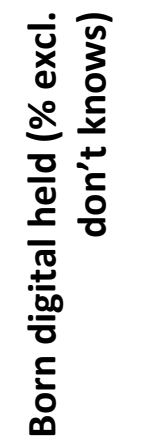 & 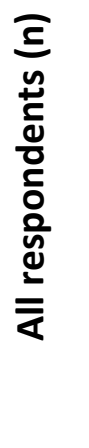 & 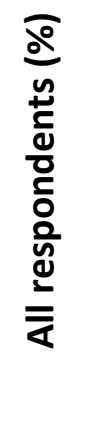 & 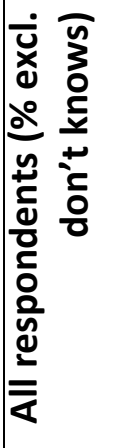 \\
\hline No & 8 & $\begin{array}{r}88.89 \\
\%\end{array}$ & $\begin{array}{r}100.00 \\
\%\end{array}$ & 20 & $74.07 \%$ & $76.92 \%$ & 28 & $\begin{array}{r}77.7 \\
8 \%\end{array}$ & $\begin{array}{r}82.35 \\
\%\end{array}$ \\
\hline Yes & 0 & $0.00 \%$ & $0.00 \%$ & 6 & $22.22 \%$ & $23.08 \%$ & 6 & $\begin{array}{r}16.6 \\
7 \%\end{array}$ & $\begin{array}{r}17.65 \\
\%\end{array}$ \\
\hline Don't know & 1 & $\begin{array}{r}11.11 \\
\%\end{array}$ & & 1 & $3.70 \%$ & & 2 & $\begin{array}{r}5.56 \\
\%\end{array}$ & \\
\hline Total & 9 & & & 27 & & & 36 & & \\
\hline $\begin{array}{r}\text { Total excl. } \\
\text { don't knows }\end{array}$ & 8 & & & 26 & & & 34 & & \\
\hline
\end{tabular}


Table 13: Plans of respondents to create a policy governing the preservation of born digital materials: broken down by those holding/not holding born digital materials

\begin{tabular}{|c|c|c|c|c|c|c|c|c|c|}
\hline & 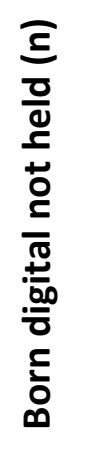 & 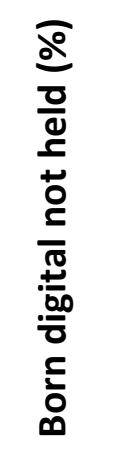 & 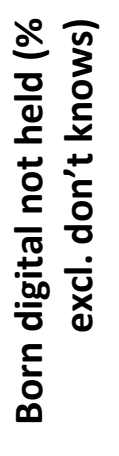 & 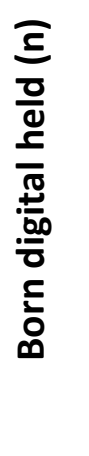 & $\begin{array}{l}\frac{0}{0} \\
\frac{0}{0} \\
\frac{1}{\pi} \\
\frac{0}{00} \\
\frac{0}{0} \\
\frac{5}{0} \\
0\end{array}$ & 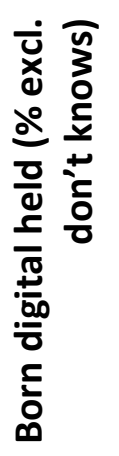 & 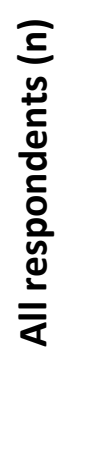 & 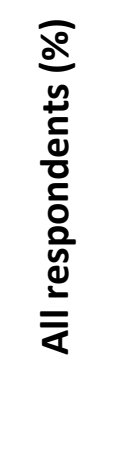 & 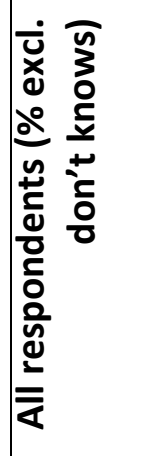 \\
\hline No & 1 & $\begin{array}{r}12.50 \\
\%\end{array}$ & $\begin{array}{r}33.33 \\
\%\end{array}$ & 2 & $\begin{array}{r}10.00 \\
\%\end{array}$ & $\begin{array}{r}18.18 \\
\%\end{array}$ & 3 & $\begin{array}{r}10.71 \\
\%\end{array}$ & $\begin{array}{r}21.43 \\
\%\end{array}$ \\
\hline Yes & 2 & $\begin{array}{r}25.00 \\
\%\end{array}$ & $\begin{array}{r}66.67 \\
\%\end{array}$ & 9 & $\begin{array}{r}45.00 \\
\%\end{array}$ & $\begin{array}{r}81.82 \\
\%\end{array}$ & 11 & $\begin{array}{r}39.29 \\
\%\end{array}$ & $\begin{array}{r}78.57 \\
\%\end{array}$ \\
\hline $\begin{array}{l}\text { Don't } \\
\text { know }\end{array}$ & 5 & $\begin{array}{r}62.50 \\
\%\end{array}$ & $\begin{array}{r}62.50 \\
\%\end{array}$ & 9 & $\begin{array}{r}45.00 \\
\%\end{array}$ & $\begin{array}{r}45.00 \\
\%\end{array}$ & 14 & $\begin{array}{r}50.00 \\
\%\end{array}$ & $\begin{array}{r}50.00 \\
\%\end{array}$ \\
\hline $\begin{array}{r}\text { Total } \\
\text { excl. } \\
\text { don't } \\
\text { know } \\
5\end{array}$ & 3 & & & 11 & & & 14 & & \\
\hline Total & 8 & & & 20 & & & 28 & & \\
\hline
\end{tabular}


Table 14: Presence of procedures for long-term management/preservation of born digital materials: broken down by those holding/not holding born digital materials

\begin{tabular}{|c|c|c|c|c|c|c|c|c|c|}
\hline & 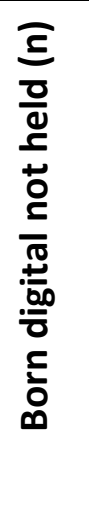 & 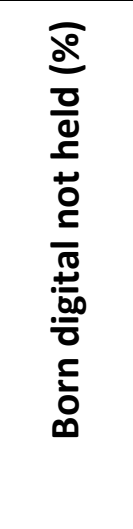 & 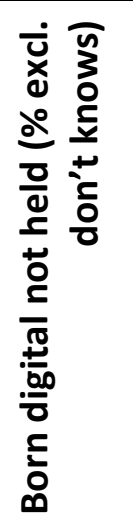 & 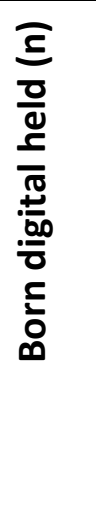 & $\begin{array}{l}\frac{0}{0} \\
\frac{0}{0} \\
\frac{1}{\pi} \\
\frac{\pi}{00} \\
\frac{0}{0} \\
\frac{5}{0} \\
0\end{array}$ & 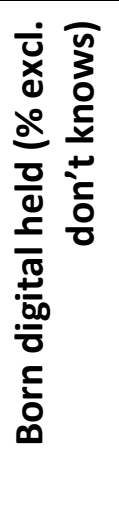 & 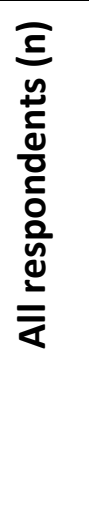 & 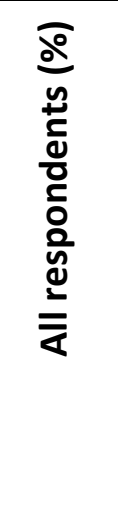 & 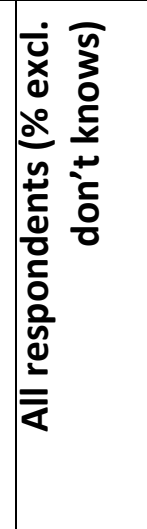 \\
\hline No & 7 & $\begin{array}{r}87.50 \\
\%\end{array}$ & $\begin{array}{r}100.00 \\
\%\end{array}$ & 11 & $\begin{array}{r}40.74 \\
\%\end{array}$ & $\begin{array}{r}55.00 \\
\%\end{array}$ & 18 & $\begin{array}{r}51.43 \\
\%\end{array}$ & $\begin{array}{r}66.67 \\
\%\end{array}$ \\
\hline Yes & 0 & $0.00 \%$ & $0.00 \%$ & 9 & $\begin{array}{r}33.33 \\
\%\end{array}$ & $\begin{array}{r}45.00 \\
\%\end{array}$ & 9 & $\begin{array}{r}25.71 \\
\%\end{array}$ & $\begin{array}{r}33.33 \\
\%\end{array}$ \\
\hline $\begin{array}{l}\text { Don't } \\
\text { know }\end{array}$ & 1 & $\begin{array}{r}12.50 \\
\%\end{array}$ & & 7 & $\begin{array}{r}25.93 \\
\%\end{array}$ & & 8 & $\begin{array}{r}22.86 \\
\%\end{array}$ & \\
\hline $\begin{array}{l}\text { Total } \\
\text { excl. } \\
\text { don't } \\
\text { know }\end{array}$ & 7 & & & 20 & & & 27 & & \\
\hline Total & 8 & & & 27 & & & 35 & & \\
\hline
\end{tabular}




\title{
Appendix 4: Survey and interview invitations
}

\section{Email sent to managers of institutions}

\section{Subject line}

Collecting born digital heritage: Information about research project

\section{Email contents}

\section{Victoria University of Wellington: Research Information Sheet}

\author{
Have we dropped a stitch? Collecting born digital heritage in smaller \\ New Zealand cultural heritage institutions.
}

Researcher: Julia Thompson, School of Information Management, Victoria University of Wellington

\section{Dear XXXX}

This email is to let you know that the above research project is taking place, and that a survey has been sent to XXXXXXXX at your institution. If there is someone else in your institution who you feel should participate in the research, please forward this email to them (in the case of libraries, specifically those involved in local history, heritage or special collections). The survey link is: [survey URL] you would like a summary of the research results (in approximately August 2010) please send me an email at my address below.

I am a student in the Master of Library and Information Studies programme. As part of my degree I am carrying out a research project, exploring the collection of born digital materials for long-term retention by New Zealand cultural heritage institutions below the national level. This includes museums, art galleries and collecting archives; and heritage, local history and special collections in libraries.

The aim of this study is to identify current activities, any barriers to working with born digital materials, and factors that may enable greater engagement. Exploration of these issues will benefit cultural heritage institutions by raising awareness of any needs to be met or issues to be addressed.

Widely available, commercially published digital materials (such as e-books), institutional recordkeeping, and digital materials created through digitisation, are not the focus of this study. 
See below for more detailed information about the study, and contact details of the researcher.

- The first part of the study is an anonymous online survey (no identifying information will be recorded).

- However, if participants elect to participate in a follow-up interview, they will then be asked for contact details. In that case, the survey responses will be confidential.

- Interviews are also confidential, and the researcher will also request access to relevant documents from interview participants.

- Individual participants and institutions will not be identifiable in the final report.

- Written informed consent will be obtained at the beginning of the survey.

- In the case of interviews, participants may withdraw from this study at any time before 30 May 2010 without providing reasons and any interview data provided will be destroyed. Interviewees will have the opportunity to check interview notes.

- Participation is voluntary, and Victoria University of Wellington human ethics approval has been obtained.

- Data will only be available to the researcher and supervisor, and will be stored securely for up to two years from completion of the project and then destroyed.

- Interview recordings will be electronically wiped two years after the end of the project or returned to participants.

- The final report will be deposited in the Victoria University of Wellington library and/or institutional repository, and results may also be submitted for publication in an academic or professional journal, or presented at a professional or academic conference

If you have any questions or would like to receive further information about the project, please contact me at [contact details], or my supervisor, Dr Sydney Shep, at the School of Information Management, Victoria University of Wellington [contact details].

Thank you for your valuable assistance.

Julia Thompson 


\section{Invitation sent to potential participants}

\section{Subject Line}

Collecting born digital heritage: Invitation to participate in research

\section{Email contents}

\section{Victoria University of Wellington: Research Information Sheet}

Have we dropped a stitch? Collecting born digital heritage in smaller

New Zealand cultural heritage institutions.

Researcher: Julia Thompson, School of Information Management, Victoria University of Wellington

Dear XXXX

I am a student in the Master of Library and Information Studies programme. As part of my degree I am carrying out a research project, exploring the collection of born digital materials for long-term retention by New Zealand cultural heritage institutions below the national level. This includes museums, art galleries and collecting archives; and heritage, local history and special collections in libraries.

An increasing proportion of the cultural heritage is "born digital". It is created in, and only exists in digital format. Digital materials are at risk of loss from a number of factors. The aim of this study is to identify current activities, any barriers to working with born digital materials, and factors that may enable greater engagement.

Exploration of these issues will benefit cultural heritage institutions by raising awareness of any needs to be met or issues to be addressed. Widely available, commercially published digital materials (such as e-books), institutional recordkeeping, and digital materials created through digitisation, are not the focus of this study.

- The first part of the study is an anonymous online survey (no identifying information will be recorded).

- However, if participants elect to participate in a follow-up interview, they will then be asked for contact details. In that case, the survey responses will be confidential.

- Interviews are also confidential, and the researcher will also request access to relevant documents from interview participants. 
- Individual participants and institutions will not be identifiable in the final report.

- Written informed consent will be obtained at the beginning of the survey.

- In the case of interviews, participants may withdraw from this study at any time before 30 May 2010 without providing reasons and any interview data provided will be destroyed. Interviewees will have the opportunity to check interview notes.

- Participation is voluntary, and Victoria University of Wellington human ethics approval has been obtained.

- Data will only be available to the researcher and supervisor, and will be stored securely for up to two years from completion of the project and then destroyed.

- Interview recordings will be electronically wiped two years after the end of the project or returned to participants.

- The final report will be deposited in the Victoria University of Wellington library and/or institutional repository, and results may also be submitted for publication in an academic or professional journal, or presented at a professional or academic conference.

If you would like to take part in the survey, please go to: [survey URL]

or forward this to the relevant person in your institution (in the case of libraries, specifically those involved in local history, heritage or special collections).

If you would like a summary of the research results (in approximately August 2010) please send me an email at my address below.

If you have any questions or would like to receive further information about the project, please contact me at [contact details] or my supervisor, Dr Sydney Shep, at the School of Information Management, Victoria University of Wellington [contact details].

Thank you for your valuable assistance.

Julia Thompson 


\title{
3. Survey reminder
}

\section{Subject line}

Survey reminder: Collecting born digital heritage

\section{Email contents}

\section{Victoria University of Wellington}

\author{
Survey Reminder
}

Have we dropped a stitch? Collecting born digital heritage in smaller New Zealand cultural heritage institutions.

Researcher: Julia Thompson, School of Information Management, Victoria University of Wellington

Dear XXXX

If you have already responded to my survey, thank you so much for your contribution.

If you have not yet started, or completed the survey, it is still available, and will only be open until next Friday, 30 April. The survey link is: [survey URL].

This is a study of collecting born digital cultural heritage materials. "Born digital" refers to materials that are created in, and intended to exist only in digital form. This may include things like harvested websites, word processing documents, emails and digital photographs.

Even if your collection does not include any, or many of these digital materials, I would still love to hear from you. In that case, the survey will explore any barriers to, and enablers of, beginning or extending your digital collection activities.

Your institution/collection has been chosen because of the important role you play in collecting and preserving New Zealand's cultural heritage. This survey has been sent to museums, art galleries and archives; and special/heritage collections in public and academic libraries.

A variety of sizes of institutions have been selected, including some that are large in a New Zealand context. "Smaller", in this case, simply refers to institutions that are not operating at a national level, such as the National Library of New Zealand or Te Papa. Even if your institution is one of New Zealand's larger cultural heritage institutions, your contribution would be extremely valuable. 
The study may help cultural heritage institutions by revealing any needs that could be met, or issues that need to be addressed in a wider policy/planning context.

Further information is provided on the first page of the survey, and you can also contact me at [contact details] or my supervisor, Dr Sydney Shep, at the School of Information Management, Victoria University of Wellington [contact details].

Thank you for your participation in this study.

Kind regards,

Julia Thompson 


\section{Interview invitation}

Dear XXXX

Thank you very much for completing my survey on collecting born digital heritage. You indicated that you would be willing to participate in a follow-up interview. I am hoping to conduct some phone interviews next week, May 17-21. If you are still interested, please let me know if there is a time during that week that would be convenient for you. Interviews are expected to take around half an hour.

I am hoping to record the interviews if possible, because this will allow me to listen more closely, without frantically taking notes. Recording is optional, however, so please let me know if you would rather not be recorded. As noted on the consent form at the start of the survey, all recordings will be stored securely, and destroyed two years after the end of the study, or returned to participants. Interviews will be confidential, and neither institutions nor individuals will be identifiable in the final report.

I look forward to hearing from you soon. 


\section{Appendix 5: Survey example, including consent form and letter of introduction}

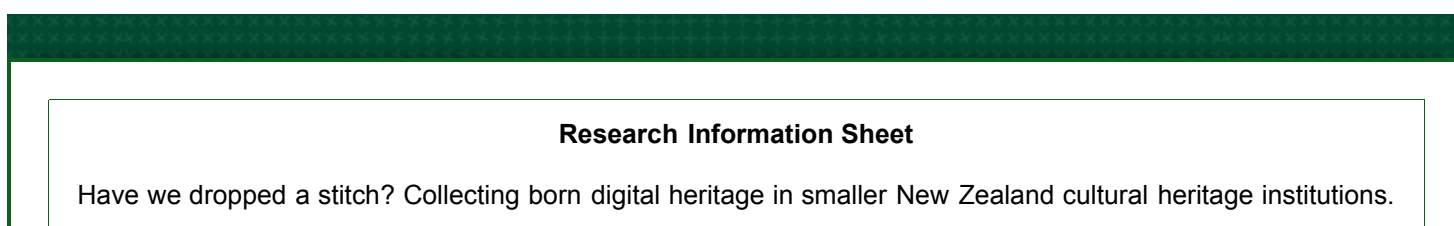

Researcher: Julia Thompson, School of Information Management, Victoria University of Wellington

I am a student in the Master of Library and Information Studies programme. As part of my degree I am carrying out a research project, exploring the collection of born digital materials for long-term retention by New Zealand cultural heritage institutions below the national level. This includes museums, art galleries and collecting archives; and heritage, local history and special collections in libraries. The aim is to identify current activities, any barriers to working with born digital materials, and factors that may enable greater engagement.

Exploration of these issues will benefit cultural heritage institutions by raising awareness of any needs to be met or issues to be addressed. Widely available, commercially published digital materials (such as e-books), institutional recordkeeping, and digital materials created through digitisation, are not the focus of this study.

- This part of the study is an anonymous online survey. No identifying information will be recorded.

- However, if participants elect to participate in a follow-up interview, they will then be asked for contact details. In that case, the survey responses will be confidential.

- Interviews are also confidential, and the researcher will also request access to relevant documents from interview participants.

- Individual participants and institutions will not be identifiable in the final report.

- In the case of interviews, participants may withdraw from this study at any time before 30 May 2010 without providing reasons and any interview data provided will be destroyed. Interviewees will have the opportunity to check interview notes.

- Participation is voluntary and Victoria University of Wellington human ethics approval has been obtained.

- Data will only be available to the researcher and supervisor, and will be stored securely for up to two years from completion of the project and then destroyed.

- Interview recordings will be electronically wiped two years after the end of the project or returned to participants.

- The final report will be deposited in the Victoria University of Wellington library and/or institutional repository, and results may also be submitted for publication in an academic or professional journal, or presented at a professional or academic conference.

- The questions on the next page represent written informed consent to participate in the research.

If you would like a summary of the research results (in approximately August 2010) please send me an email at 


\section{CONSENT TO PARTICIPATION IN RESEARCH}

If you would like to participate in this study, please read the following statements and check the boxes beside them. This represents written informed consent to participate in the research.

$\square$ I have been provided with adequate information relating to the nature and objectives of this research project, I have understood that information and have been given the opportunity to seek further clarification or explanations.

$\square$ I understand that any information or opinions I provide will be kept confidential and reported only in an aggregated/nonattributable form. Individuals and institutions will not be identifiable.

I understand that the information I have provided will be used only for this research project and that any further use will require my written consent.

$\square$ I understand that the information obtained will be stored securely, with access restricted to the researcher and supervisor, retained for up to two years after the research is completed, and then destroyed.

If I participate in a follow-up interview, I understand that I have the right to check interview notes.

If I participate in a follow-up interview, I understand that recordings of my interview will be electronically wiped two years after the end of the project unless I would like them returned to me.

$\square$ In the case of interviews, I understand that I may withdraw from this study at any time before 30 May 2010 without providing reasons.

$\square$ I understand that if I withdraw from the project, any data that I have provided will be destroyed.

$\square$ I understand that the final report will be deposited in the Victoria University of Wellington library and/or institutional repository, and results may also be submitted for publication in an academic or professional journal, or presented at a professional or academic conference.

$\square$ I agree to take part in this research. 


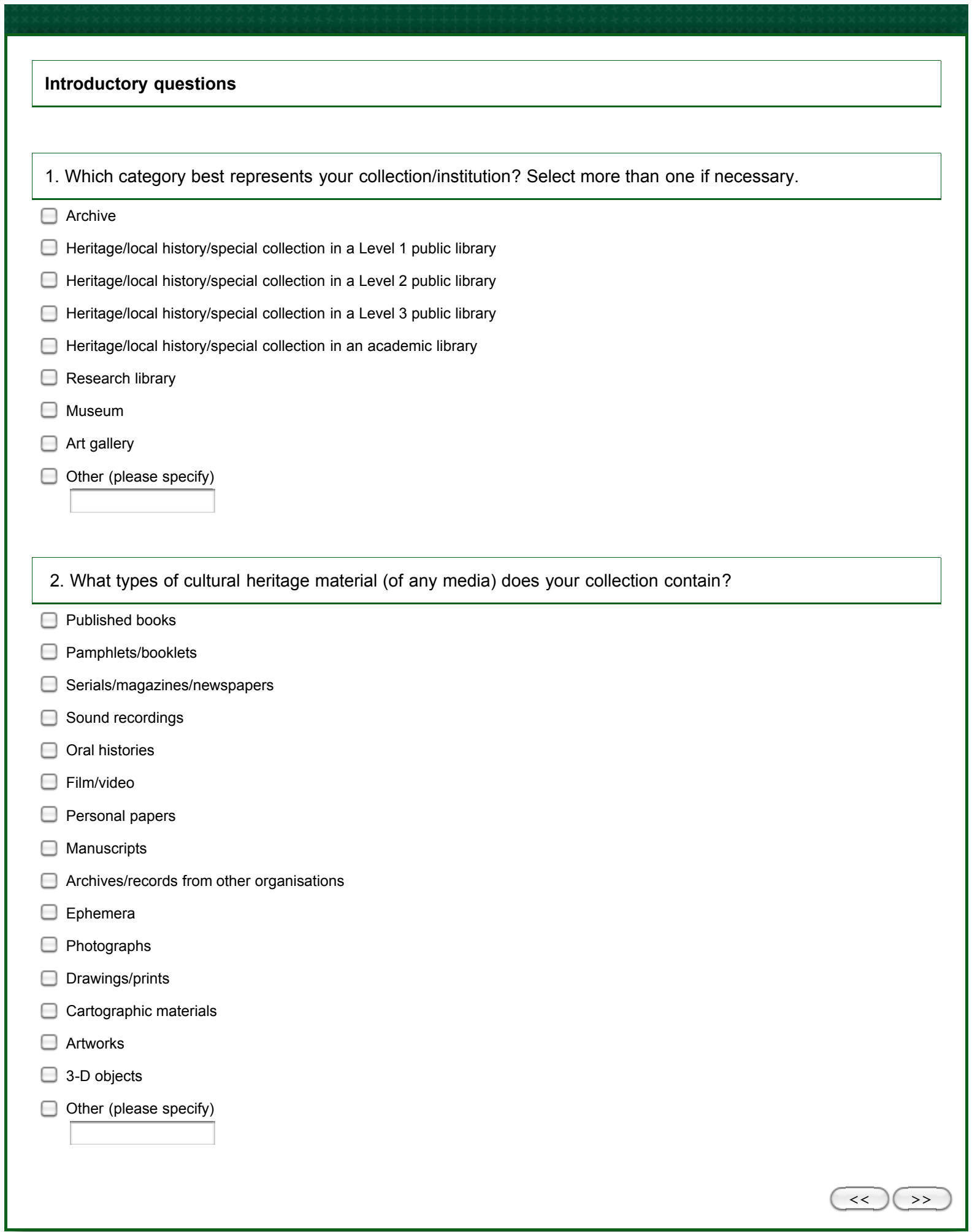


Born digital materials are materials that are created in, and exist only in digital form, and are not intended to have an analogue equivalent.

This study is exploring the collection of born digital cultural heritage materials from outside the institution.

It does not include:

- Digital materials that are created as a result of digitisation activities; or

- Electronic records created by the institution itself as a part of institutional recordkeeping.

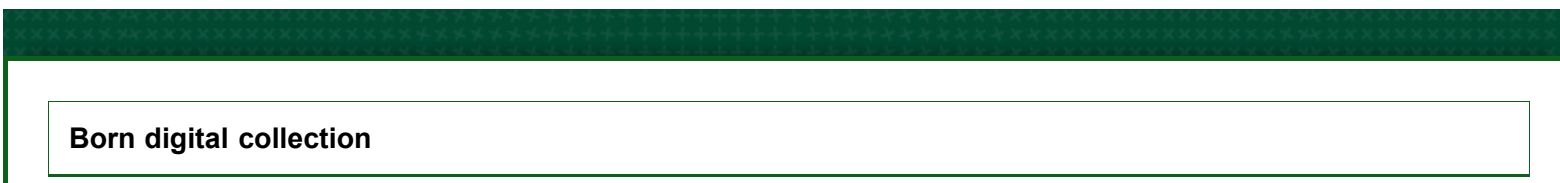

3. Which of the following born digital materials does your collection include? Select as many types as applicable.

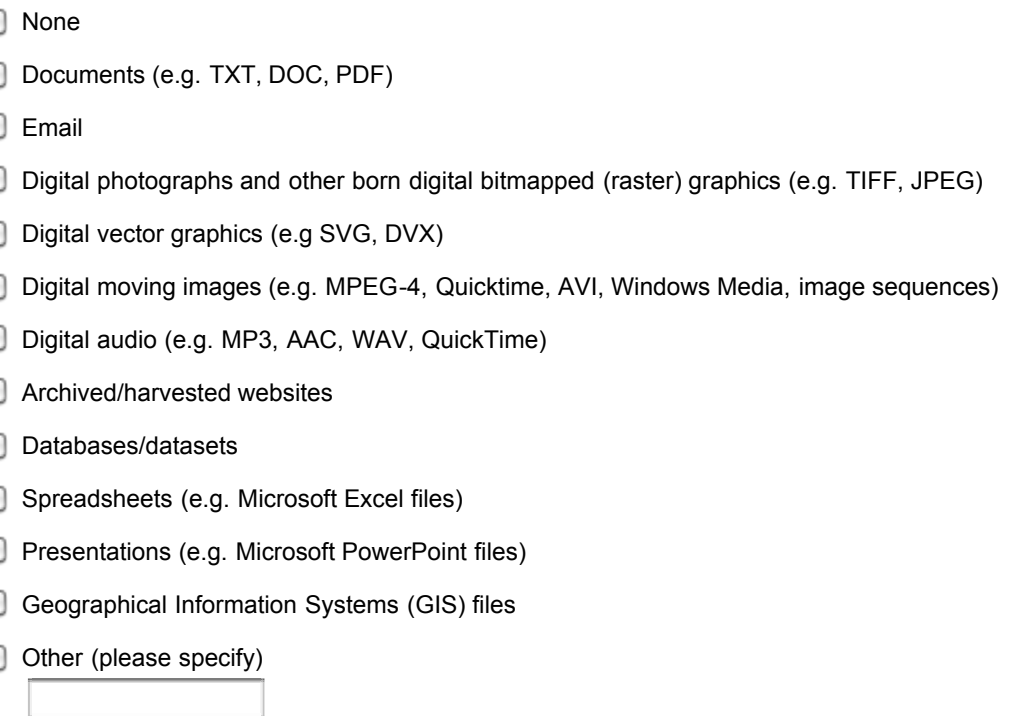


4. Please mark the three types of born digital materials that you hold in the greatest quantity (your best estimate is fine)

Documents (e.g. TXT, DOC, PDF)

Email

Digital photographs and other born digital bitmapped (raster) graphics (e.g. TIFF, JPEG)

Digital vector graphics (e.g SVG, DVX)

Digital moving images (e.g. MPEG-4, Quicktime, AVI, Windows Media, image sequences)

Digital audio (e.g. MP3, AAC, WAV, QuickTime)

Archived/harvested websites

Databases/datasets

Spreadsheets (e.g. Microsoft Excel files)

Presentations (e.g. Microsoft PowerPoint files)

Geographical Information Systems (GIS) files

Other (please specify)

5. Please indicate how important the following factors have been when selecting born digital materials

\begin{tabular}{|c|c|c|c|c|}
\hline & Not important & Of some importance & Very important & Don't know \\
\hline $\begin{array}{l}\text { Fit with the collection policy or } \\
\text { mandate }\end{array}$ & 0 & $\mathrm{O}$ & $\mathrm{O}$ & $\mathrm{O}$ \\
\hline Perceived long term value & 0 & $\mathrm{O}$ & $\mathrm{O}$ & $\mathrm{O}$ \\
\hline $\begin{array}{l}\text { Level of institutional } \\
\text { responsibility for } \\
\text { collection/preservation of the } \\
\text { materials }\end{array}$ & $\mathrm{O}$ & $\mathrm{O}$ & O & $\mathrm{O}$ \\
\hline $\begin{array}{l}\text { Ease of gaining/negotiating } \\
\text { legal rights to acquire/preserve }\end{array}$ & 0 & $\mathrm{O}$ & $\mathrm{O}$ & 0 \\
\hline $\begin{array}{l}\text { Technological aspects (e.g. file } \\
\text { format) and the related } \\
\text { feasibility of acquisition and } \\
\text { preservation }\end{array}$ & $\mathrm{O}$ & O & 0 & $\mathrm{O}$ \\
\hline $\begin{array}{l}\text { Availability of sufficient } \\
\text { documentation (including } \\
\text { metadata) }\end{array}$ & 0 & $\mathrm{O}$ & $\mathrm{O}$ & $\mathrm{O}$ \\
\hline $\begin{array}{l}\text { Whether there is an intention of } \\
\text { long term retention/preservation }\end{array}$ & $\mathrm{O}$ & $\mathrm{O}$ & $\mathrm{O}$ & $\mathrm{O}$ \\
\hline
\end{tabular}

6. Please describe any other selection factors 
7. Please elaborate on how the factors that you identified in the previous two questions have affected selection

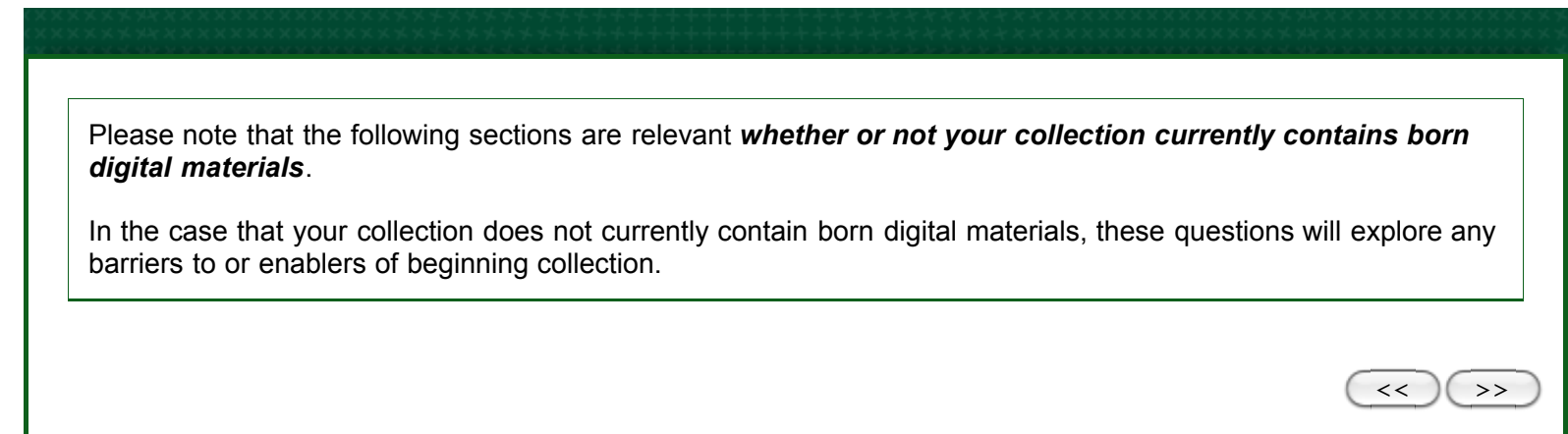




\section{Acquisition challenges and barriers}

8. To what extent have the following factors been a barrier or challenge to the nature or level of collecting born digital materials in your collection/institution?

\begin{tabular}{|c|c|c|c|c|}
\hline & To little or no extent & To a moderate extent & To a great extent & Don't know \\
\hline Lack of adequate funding & $\mathrm{O}$ & $\mathrm{O}$ & $\mathrm{O}$ & $\mathrm{O}$ \\
\hline $\begin{array}{l}\text { Lack of necessary expertise } \\
\text { within the institution }\end{array}$ & 0 & $\mathrm{O}$ & 0 & 0 \\
\hline $\begin{array}{l}\text { Lack of access to guidance or } \\
\text { training }\end{array}$ & $\mathrm{O}$ & $\mathrm{O}$ & $\mathrm{O}$ & $\mathrm{O}$ \\
\hline $\begin{array}{l}\text { Inadequate technological } \\
\text { support or infrastructure }\end{array}$ & 0 & $\mathrm{O}$ & $\mathrm{O}$ & 0 \\
\hline \multirow[t]{2}{*}{ Inadequate staffing levels } & $\mathrm{O}$ & $\mathrm{O}$ & $\mathrm{O}$ & $\mathrm{O}$ \\
\hline & To little or no extent & To a moderate extent & To a great extent & Don't know \\
\hline $\begin{array}{l}\text { Competing institutional } \\
\text { demands/priorities, e.g. of } \\
\text { digitisation }\end{array}$ & $\mathrm{O}$ & 0 & 0 & $\mathrm{O}$ \\
\hline $\begin{array}{l}\text { Lack of clarity about collection } \\
\text { and preservation } \\
\text { responsibilities }\end{array}$ & $\mathrm{O}$ & $\mathrm{O}$ & $\mathrm{O}$ & $\mathrm{O}$ \\
\hline $\begin{array}{l}\text { Lack of opportunities to } \\
\text { collaborate with other } \\
\text { institutions }\end{array}$ & $\mathrm{O}$ & $\mathrm{O}$ & $\mathrm{O}$ & $\mathrm{O}$ \\
\hline $\begin{array}{l}\text { Challenges gaining or } \\
\text { identifying rights to acquire or } \\
\text { preserve }\end{array}$ & $\mathrm{O}$ & $\mathrm{O}$ & $\mathrm{O}$ & $\mathrm{O}$ \\
\hline \multirow[t]{2}{*}{$\begin{array}{l}\text { Difficulty obtaining necessary } \\
\text { documentation (including } \\
\text { metadata) }\end{array}$} & 0 & $\mathrm{O}$ & 0 & 0 \\
\hline & To little or no extent & To a moderate extent & To a great extent & Don't know \\
\hline $\begin{array}{l}\text { Difficulty obtaining materials in } \\
\text { required/preferred } \\
\text { media/formats }\end{array}$ & $\mathrm{O}$ & $\mathrm{O}$ & $\mathrm{O}$ & $\mathrm{O}$ \\
\hline $\begin{array}{l}\text { The future preservation } \\
\text { requirements of the materials }\end{array}$ & $\mathrm{O}$ & $\mathrm{O}$ & $\mathrm{O}$ & 0 \\
\hline $\begin{array}{l}\text { Difficulty determining } \\
\text { authenticity, context or origin }\end{array}$ & $\mathrm{O}$ & $\mathrm{O}$ & 0 & $\mathrm{O}$ \\
\hline $\begin{array}{l}\text { Difficulty determining } \\
\text { uniqueness }\end{array}$ & 0 & 0 & 0 & 0 \\
\hline
\end{tabular}

9. Please describe any other factors that have been a barrier or challenge to born digital collecting 
10. Please elaborate on how the factors that you identified in the previous two questions have affected born digital collection activities 


\section{Acquisition enablers}

11. To what extent would the following factors encourage or enable greater involvement in the collection of born digital materials in your collection/institution?

\begin{tabular}{|c|c|c|c|c|}
\hline & To little or no extent & To a moderate extent & To a great extent & Don't know \\
\hline Increased funding & 0 & 0 & 0 & 0 \\
\hline Increased staffing & 0 & 0 & 0 & 0 \\
\hline $\begin{array}{l}\text { Recruitment/cultivation of staff } \\
\text { with necessary expertise }\end{array}$ & 0 & 0 & 0 & 0 \\
\hline $\begin{array}{l}\text { Increased access to guidance } \\
\text { or training }\end{array}$ & 0 & 0 & 0 & 0 \\
\hline $\begin{array}{l}\text { Improved technological support } \\
\text { or infrastructure }\end{array}$ & 0 & 0 & 0 & 0 \\
\hline $\begin{array}{l}\text { Greater clarity about } \\
\text { responsibilities for born digital } \\
\text { collection and preservation }\end{array}$ & 0 & 0 & 0 & 0 \\
\hline $\begin{array}{l}\text { More opportunities to } \\
\text { collaborate with other } \\
\text { institutions }\end{array}$ & 0 & 0 & 0 & 0 \\
\hline
\end{tabular}

12. Please describe any other factors that would encourage or enable greater involvement in born digital collection

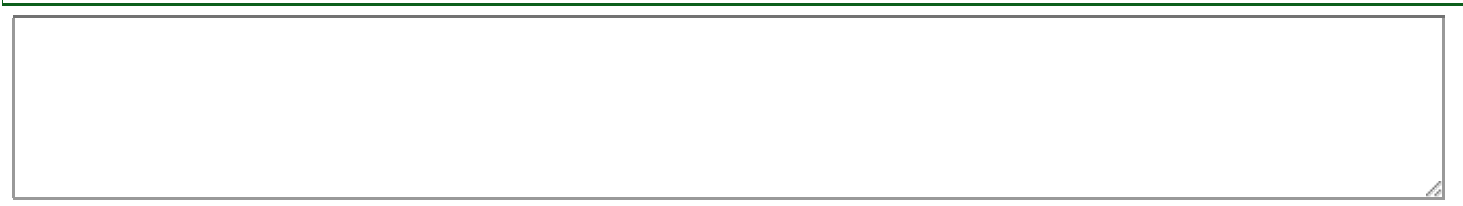

13. Please elaborate on how the factors that you identified in the previous two questions would encourage or enable born digital collection 
Future plans and aspirations: Collection

14. Does your collection/institution currently have a written policy governing the acquisition of born digital materials?
No
Y Yes
Don't know

15. If you answered no, does your collection/institution plan to create a written policy governing the acquisition of born digital materials?
No
Yes (indicate timeframe if possible)

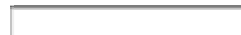
Don't know
Not applicable (my collection has a policy)

16. If your collection does not currently include born digital materials, do you plan to include them in the future?

No

Yes (indicate timeframe if possible)

Don't know

Not applicable (my collection includes born digital materials)

17. If you answered yes to question 16, please describe your collection/institution's future plans or aspirations for collecting born digital materials (including what types of materials you plan to collect) 


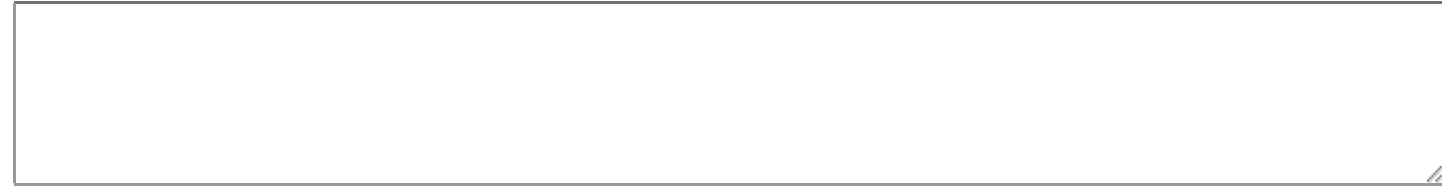

19. If your collection does currently include born digital materials, please describe any future plans or aspirations for collecting born digital materials (including what types of materials you plan to collect in the future) 


\section{Future plans and aspirations: Preservation}

20. Does your collection/institution currently have a written policy governing the preservation of born digital materials?

No

Yes

Don't know

21. If you answered no, does your collection/institution plan to create a digital preservation policy?

No

Yes (indicate timeframe if possible)

Don't know

Not applicable (my collection has a policy)

22. Does your collection/institution have procedures in place for long-term management/preservation of your born digital materials?

No

Yes

Don't know

Not applicable (my collection does not include born digital materials)

23. If you answered yes, please briefly describe your procedures

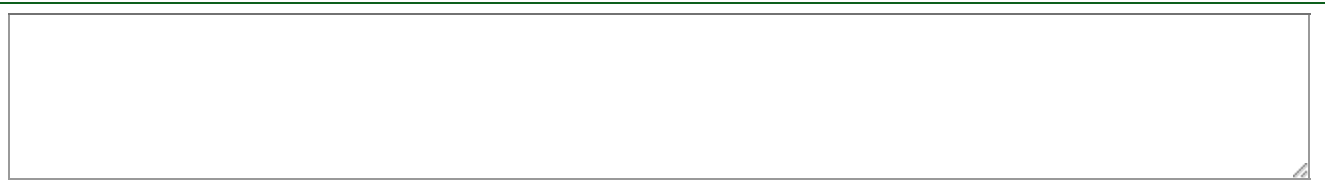

24. Please describe any plans or aspirations for the preservation of born digital materials in your collection/institution 


\section{Roles and responsibilities}

25. Please indicate your level of agreement with the following

\begin{tabular}{|c|c|c|c|c|c|}
\hline & Strongly Disagree & Disagree & Neutral & Agree & Strongly Agree \\
\hline $\begin{array}{l}\text { The collection of born digital } \\
\text { materials is part of my } \\
\text { collection/institution's role }\end{array}$ & 0 & 0 & 0 & 0 & 0 \\
\hline $\begin{array}{l}\text { The preservation of born digital } \\
\text { materials is part of my } \\
\text { collection/institution's role }\end{array}$ & 0 & 0 & 0 & 0 & 0 \\
\hline
\end{tabular}

26. If you answered agree or strongly agree, please describe what you see as your collection/institution's role in collecting and preserving born digital materials

27. If you answered strongly disagree, disagree, or neutral, please elaborate

28. Please feel free to add any additional comments that you have about collecting born digital heritage 


\section{Final questions}

29. Please choose the region your institution is located in from the dropdown box. This will allow for comparison of the activities of institutions in different regions.

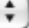

30. Please indicate your job title. This will allow for an exploration of the various job types related to the collection of born digital materials.

31. Would you like to participate in a follow-up interview?

Yes

No

32. If you answered yes, please provide the following contact details. Please note that providing these details means the survey will not be anonymous, however it will be fully confidential.

\section{Name}

Institution

Email

Phone 


\section{Appendix 6: Sample of qualitative analysis approach}

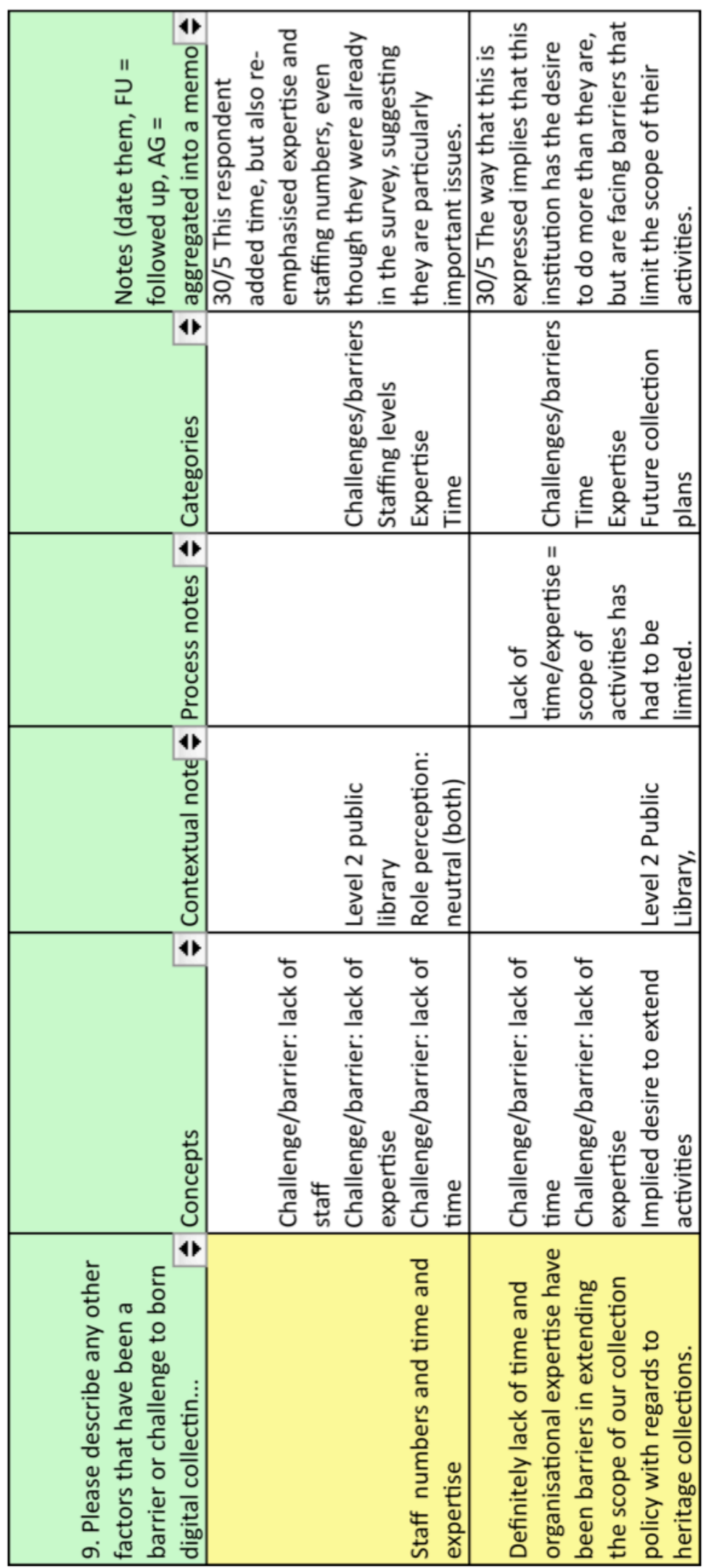

